\title{
OPTIMAL DELEGATION AND DECOUPLING IN THE DESIGN OF LIABILITY RULES
}

\author{
by \\ IAN AYRES* AND PAUL M. GOLDBART**
}

\begin{abstract}
The central allocative decision confronting a judge in a nuisance dispute should not concern the identity of the initial entitlement recipient but rather the identity of the more efficient chooser - the litigant who can more efficiently allocate the entitlement. We show that liability rules can produce four basic allocations which differ centrally in the ways in which courts delegate to litigants the authority to ultimately allocate the entitlement. Two classes concern "single chooser" rules that vest (in the absence of an agreement to the contrary) the allocative decision solely in one of the litigants. The other two classes concern a new type of rule, "dual chooser" rules, that allow either party to veto the transfer of an entitlement. Dualchooser rules are more than a theoretical curiosity both because they exist in our current law and because at times they produce systematically greater allocative efficiency than either type of single-chooser rule. Two heads are sometimes better than one.

A central result of the paper is that in choosing among different liability rules allocative concerns can be decoupled from distributive concerns. There exist an infinite number of liability rules which produce each of the four basic allocations, but every rule within a particular class divides differently between the litigants the expected value of the allocation. To successfully decouple, courts should at times impose "call option," "put option," "Pay or be Paid," and "Pay or Pay" rules.
\end{abstract}

File: E:Zip \goldbart|goldbart.pap.15.wpd

Word Count: 33,365

*William K. Townsend Professor, Yale Law School. ian.ayres@yale.edu.

**Professor, University of Illinois, Department of Physics. goldbart@uiuc.edu.

Bob Ellickson, Peter Siegelman and Fredrick Vars provided helpful comments. 


\section{TABLE OF CONTENTS}

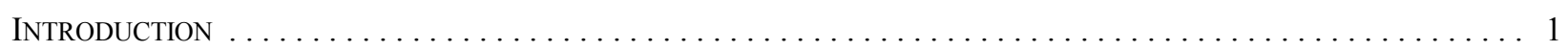

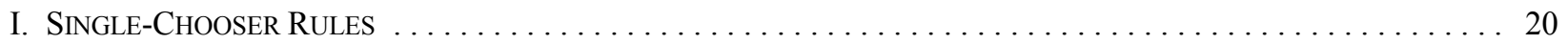

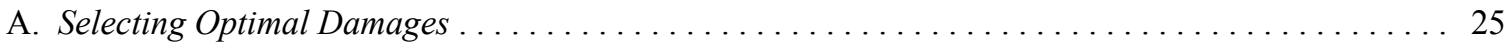

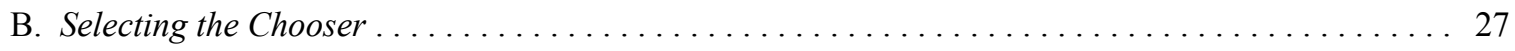

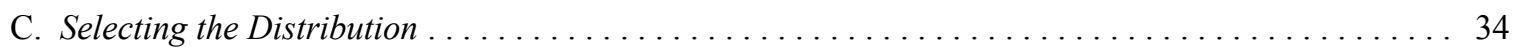

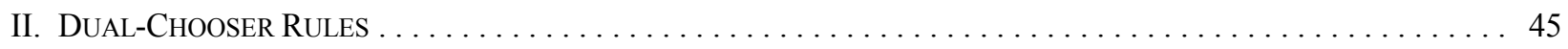

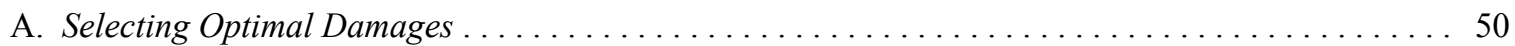

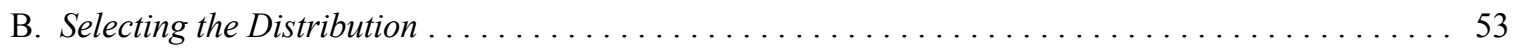

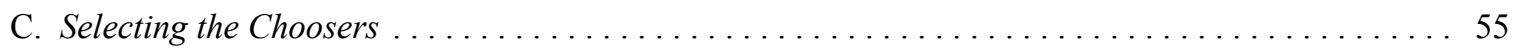

D. Selecting Among the Four Foundational Single-price Allocations . . . . . . . . . . . . . 57

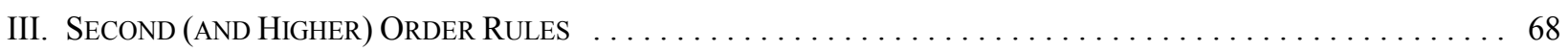

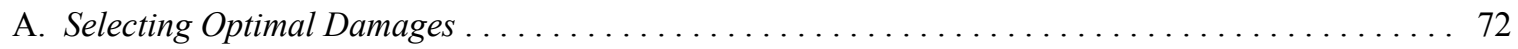

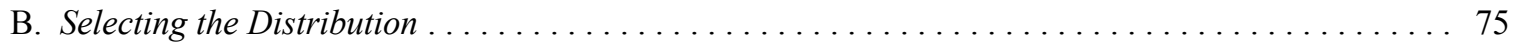

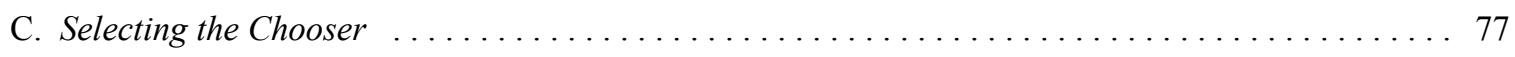

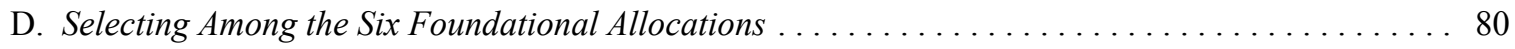

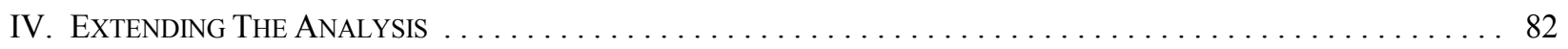

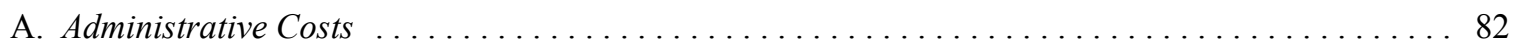

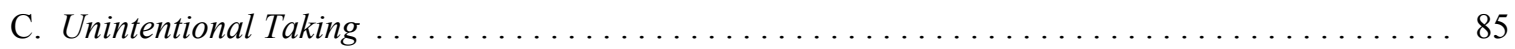

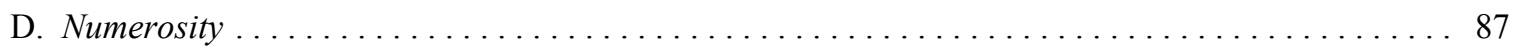

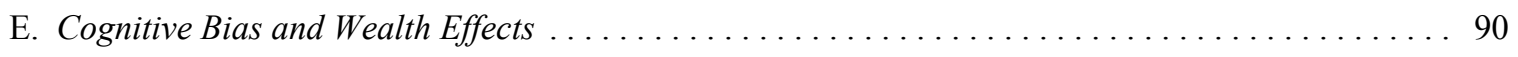

F. Correlated Valuations $\ldots \ldots \ldots \ldots \ldots \ldots \ldots \ldots \ldots \ldots \ldots \ldots \ldots \ldots \ldots \ldots \ldots$

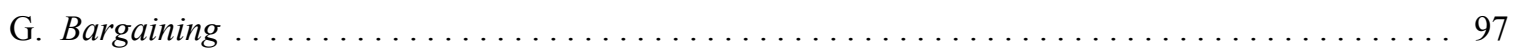

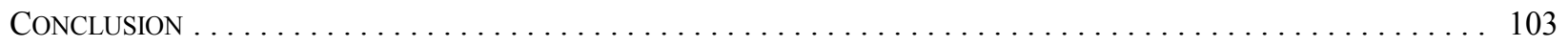

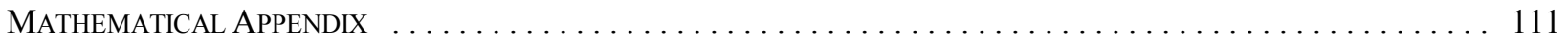




\section{Optimal DELEGATION AND DECOUPLING IN THE DESIGN OF LiABILITY RULES}

\section{INTRODUCTION}

Calabresi and Melamed began a scholarly revolution by seeing that legal entitlements have two readily distinguishable types of protection: property rules and liability rules. ${ }^{1}$ These two archetypal forms protect an entitlement holder's interest in markedly different ways -- via deterrence and compensation. Property rules protect entitlements by trying to deter others from taking. Liability rules protect entitlements not by deterring but by trying to compensate the victims of nonconsensual takings. ${ }^{2}$ Accordingly, the compensatory impetus behind liability rules causes such remedies to focus on the takee's welfare, while the deterrence impetus behind property rules causes such remedies to focus on the potential taker's welfare. Thus, disgorgement and prison terms are traditional property rule remedies, while expectation and other compensatory damages fall squarely in the liability rule camp.

Seeing liability rules as a distinct category of entitlement allowed Calabresi and Melamed to see that there was a missing category in the ways courts resolved nuisance disputes. Consider the classic, if somewhat idealized, nuisance dispute between a single "Polluter" and a single "Resident" who is discomforted by the pollution. Prior to One View of the Cathedral, courts had traditionally chosen among three different judgments:

Rule 1: $\quad$ a court might issue an injunction against a Polluter;

${ }^{1}$ Guido Calabresi \& Douglas Melamed, Property Rules, Liability Rules, and Inalienability: One View of the Cathedral, 85 HARV. L. REV. 1089 (1972).

${ }^{2}$ Entitlements are often protected from intentional takings by property rules, but from negligent takings with liability rules. Hence, it is a criminal offense to intentionally break your neighbor's arm (i.e., her arm is protected by a property rule with regard to your intentional taking), but the neighbor is entitled to compensatory damages if you break her arm through mere negligence (i.e., her arm is protected by a liability rule with regard to your negligent taking). 
Rule 2: $\quad$ a court might find nuisance but permit pollution to continue if the Polluter chose to pay damages; or

Rule 3: a court might find the pollution not to be a nuisance and permit the Polluter to continue without paying damages.

Appreciating the difference between liability and property rules, the authors saw that these three approaches naturally fit into a two-by-two box. In this stylized box (shown in Table 1), the court determines (i) whether the resident or the polluter has the initial entitlement (to control whether or not there will be pollution), ${ }^{3}$ and (ii) whether this entitlement is protected by property or a liability rule. $^{4}$

${ }^{3}$ The term "initial" entitlement is used to convey the idea that because of a subsequent taking the ultimate entitlement to control whether or not pollution will take place may belong to a taker.

${ }^{4}$ Rule 1, for example, represents a decision in which the initial entitlement is granted to the resident and this entitlement is protected by a property rule. The polluter is deterred from a nonconsensual taking by the prospect of being held in contempt. In contrast, Rule 2 represents a decision in which the initial entitlement is granted to the resident, but it is only protected by a lessstringent, compensation-based liability rule. Under Rule 2, the polluter might non-consensually take the resident's entitlement and pay compensatory damages. Rule 2 was famously deployed in Boomer v. Atlantic Cement Co., 257 N.E.2d 870, 875 (N.Y. 1970). Finally, Rule 3, by finding the pollution not to be a nuisance, effectively grants the initial entitlement to the polluter and protects it by a property rule. 
DELEGATION AND DECOUPLING

\section{Table 1: Calabresi and Melamed's Two-By-Two Box with the Missing Category}

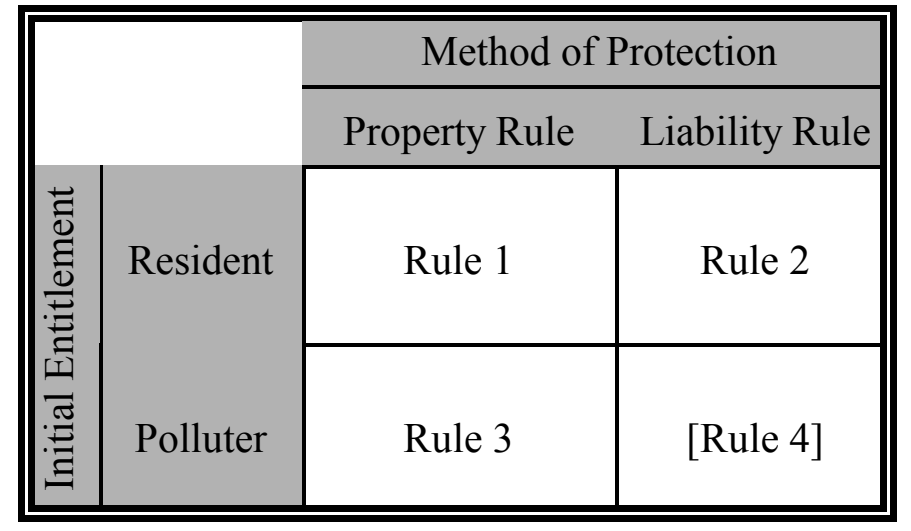

The problem with the traditional tripartite approach to resolving nuisance disputes is that one of the boxes was empty. Calabresi and Melamed's theory suggested a fourth approach:

Rule 4: $\quad$ a court might permit a Polluter to continue unless the Resident chose to pay the Polluter damages in order to enjoin further pollution. ${ }^{5}$

As fate would have it, the fourth box would not long stay empty. In Spur Industries v. Del Webb, Justice James D. Cameron of the Arizona Supreme Court - in what has probably become the most cited "coming to the nuisance" decision - found that pollution could be enjoined, but that a developer representing residents had to "indemnify [the Polluter] for a reasonable amount of the cost of moving or shutting down." Calabresi and Melamed's good fortune in identifying a vacuum that

${ }^{5}$ In a recent symposium honoring the twenty-fifth anniversary of One View of the Cathedral, see 106 YALE L.J. 2083-2213 (1997), Calabresi pointed out that James Atwood had discussed the possibility of a Rule 4-like outcome in a student note that he published in the Stanford Law Review three years before Calabresi and Melamed's analysis. See Guido Calabresi, Remarks: The Simple Virtues of the Cathedral, 106 YALE L.J. 2201, 2204 (1997) (citing James R. Atwood, Note, An Economic Analysis of Land Use Conflicts, 21 STAN. L. REV. 293, 315 (1969)).

${ }^{6}$ Spur Indus., Inc. v. Del E. Webb Dev. Co., 494 P.2d 700, 708 (Ariz. 1972) (Cameron, V.C.J). The court's unconditional order seems different than the definition of Rule 4 in the text which gives the Resident the choice of whether (a) to pay to stop further pollution or (b) not to pay 
DELEGATION AND DECOUPLING

was almost simultaneously filled helped solidify their article's well-deserved fame.

This narrative is well known to the vast majority of tort (and property) professors. ${ }^{7}$ However, the legal academy seems to be much less aware of an analogous phenomenon that has been developing over the last decade. Starting in 1993 with Madeline Morris's article, The Structure of Entitlement, ${ }^{8}$ a group of about a half dozen scholars have started to see "liability rule" protection as a type of call option. ${ }^{9}$ Just as the property/liability rule distinction helped Calabresi and Melamed discover the missing Rule 4, the call option reconceptualization of the two liability rules (Rules 2 and 4) naturally led to consideration of two additional "put option" liability rules.

A call option is an option to buy. The option holder can force a sale at the exercise price

and to allow the Polluter to continue polluting. To harmonize the case with the definition, it is necessary to speculate about what would have happened if Del Webb had petitioned the court to void its order enjoining the pollution as well as its order that Del Webb indemnify Spur. If we believe that the court would have in effect allowed Del Webb to withdraw its initial complaint, it would have in effect been giving Del Webb the Rule 4 choice - that is, the choice of paying to stop pollution or not paying and allowing the pollution to continue. Alternatively, at a minimum, future developers will realize that suing in this jurisdiction may be choosing to pay for an injunction.

${ }^{7}$ Indeed, there are probably a dozen other articles that aver in one way or another to this history. See, e.g., Robert C. Ellickson, Alternatives to Zoning: Covenants, Nuisance Rules and Fines as Land Use Controls, 40 U. CHI. L. ReV. 681 (1973); James E. Krier \& Stewart J. Schwab, Property Rules and Liability Rules: The Cathedral in Another Light, 70 N.Y.U. L. REV. 440, 442 (1995).

${ }^{8}$ Madeline Morris, The Structure of Entitlements, 78 CORNELL L. REV. 822, 854-56 (1993).

${ }^{9}$ Ian Ayres \& Eric Talley, Solomonic Bargaining: Dividing a Legal Entitlement to Facilitate Coasean Trade, 104 Y ALE L.J. 1027 (1995); Krier \& Schwab, supra note 7, at 470-75; Ian Ayres \& J.M. Balkin, Legal Entitlements as Auctions: Property Rules, Liability Rules and Beyond, 106 YALE. L.J. 703, 729-33 (1996); Richard Epstein, A Clear View of the Cathedral: The Dominance of Property Rules, 106 YALE L.J. 2091 (1997); Saul Levmore, Unifying Remedies: Property Rules, Liability Rules and Startling Rules, 106 YALE L.J. 2149 (1997); Carol M. Rose, The Shadow of the Cathedral, 106 YALEL.J. 2175 (1997); Ian Ayres, The 1998 Monsanto Lecture: Protecting Property with Puts, 32 VAL. U. L. REV. 793 (1998). 
DELEGATION AND DECOUPLING

even if the seller does not want to sell. Rules 2 and 4 have just this "call" quality. Under Rule 2, the Polluter has a call option - the choice to pay damages - the choice, in effect, to buy the Resident's right to clean air and, therefore, to be able to continue polluting. The Resident begins with the initial entitlement (to stop pollution), but the Polluter can force the Resident to sell this right for a judicially determined amount. Rule 4 reverses the identity of the Polluter and Resident. Under Rule 4, the Polluter has the initial entitlement, and the Resident has the call option. The Resident can force the Polluter to sell this right to pollute for a judicially determined amount. ${ }^{10}$

Once the traditional liability rules were reconceived as granting a potential taker a call option, it became almost inevitable that scholars would wonder whether "put option" rules might not also be desirable. A put option is an option to sell. While call options give the option holder the choice of whether to pay a non-negotiated amount (the exercise price), put options give the option holder the choice of whether to be paid a non-negotiated amount. Call options when exercised give rise to "forced sales"; put options give rise to "forced purchases."

Rule 2 gives the Polluter the choice of whether to pay; Rule 4 gives the Resident the choice of whether to pay. Scholars thinking about the classic Rule 2 and Rule 4 cases-Boomer ${ }^{11}$ and Spur $^{12}$ - have often focused only on the difference between who pays, but a second dimension exists

${ }^{10}$ Property rules (Rules 1 and 3 ) can also be easily fitted into option framework. From an option perspective, the only difference between protecting an entitlement with a property rule and a liability rule is a difference in the potential taker's exercise price. Property rules set the exercise price so high that no option holder would choose to exercise the option. See Ayres \& Talley, supra note 9 , at 1048 .

\footnotetext{
${ }^{11}$ Boomer v. Atlantic Cement Co., 257 N.E.2d 870, 875 (N.Y. 1970).

${ }^{12}$ Spur Indus., Inc. v. Del E. Webb Dev. Co., 494 P.2d 700, 708 (Ariz. 1972).
} 
of who chooses to force the payment. Rules 2 and 4 concern a choice to pay, while the put options concern the choice to be paid.

Applied to nuisance disputes, the possibility of put options suggests two additional rules. Each rule gives the initial entitlement holder a put option - the option to force a non-consensual purchase by the other side:

Rule 5: a court might allow a Polluter to continue polluting, but also give the Polluter the choice to stop polluting and to receive damages from the Resident; and

Rule 6: a court might allow a Resident to enjoin pollution, but also give the Resident the option of waiving his injunctive rights in return for damages from the Polluter.

These "put option" rules - like their "call option" counterparts - are still "liability rules," the goal of which is to compensate the initial entitlement holder for any non-consensual transfer, rather than to deter such a transfer in the first place. The only difference is that with put options the initial entitlement holder can force the non-consensual transfer, whereas with the more traditional (call option) liability rule the non-entitlement holder can force the transfer.

Table 1 can be expanded as shown in Table 2 to help flesh out the underlying structure of the six rules: 
Table 2: Incorporating the Possibility of "Put Options" Rules

\begin{tabular}{|c|c|c|c|c|}
\hline & \multicolumn{3}{|c|}{ Method of Protection } \\
\hline & & Property Rule & $\begin{array}{l}\text { Liability Rule } \\
\text { (Initial Entitlement } \\
\text { Held Subject To } \\
\text { Other Side's Call } \\
\text { Option to Pay) }\end{array}$ & $\begin{array}{l}\text { "Put Option" or "Force } \\
\text { Purchase" Rule } \\
\text { (Initial Entitlement } \\
\text { Holder Also Has Put } \\
\text { Option to Be Paid) }\end{array}$ \\
\hline 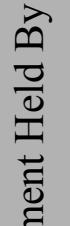 & Resident & Rule 1 & Rule 2 & Rule 6 \\
\hline 焉 & Polluter & Rule 3 & Rule 4 & Rule 5 \\
\hline
\end{tabular}

The two new "put option" rules-Rules 5 and 6 - are similar, except that under Rule 5 the Polluter has the initial entitlement and a put option, whereas under Rule 6 the Resident has the initial entitlement and a put option. ${ }^{13}$ The rules in the three columns of the table differ only as to which party has the option to force a non-consensual transfer of the initial entitlement: under a property rule, neither side has an option to force a transfer; under a traditional liability rule, the nonentitlement holder has an option to force the initial entitlement holder to sell; and under a "put option" rule, the entitlement holder has the option to force the non-entitlement holder to purchase.

While "put option" rules have not been used to resolve nuisance disputes, put option awards

${ }^{13}$ Some authors have reversed the labels of Rules 5 and 6, see, e.g., Levmore, supra note 9, at 2163; Ayres, supra note 9, at $797 \mathrm{n.9}$, but to do so destroys the symmetry of Calabresi and Melamed's original categorization. 


\section{DELEGATION AND DECOUPLING}

are a standard response to intentional taking in other areas of tort law:

Contrary to accepted wisdom, the common law does use "put options" - the right to force a non-consensual purchase - as a mechanism for protecting entitlements: (1) if Calabresi steals Melamed's watch, Melamed has the option of suing to recover the watch (replevin) or suing to receive the watch's value (trover); (2) if Calabresi is a holdover tenant in Melamed's apartment, Melamed has the option of suing to enjoin Calabresi's continuing trespass or (at least in some jurisdictions) suing to force Calabresi to rent for up to an entire additional year; and (3) if Calabresi builds an encroaching wall on Melamed's land, Melamed has the option of suing to force Calabresi to remove the wall or suing to force Calabresi to permanently buy the encroached land. In each of these examples, after Calabresi takes Melamed's entitlement, the common law gives Melamed a put option - the option to choose court-determined damages (for permanently ceding the entitlement to the defendant) or injunctive relief (to reacquire the entitlement). ${ }^{14}$

In the nuisance context, instead of giving an Atlantic Cement the (call option) choice of deciding whether to pay to pollute [Rule 2], a court might give a Boomer the (put option) choice of whether to be paid (and bear continued pollution) or to refuse payment (and win an injunction against continued pollution) [Rule 6].

Scholars have already made some important progress in identifying and analyzing these four liability rules. We now know, for example, that courts should set damages under any of four liability rules $(2,4,5$ or 6$)$ equal to the court's best estimate of the non-option holder's value. ${ }^{15}$ And authors have put forward a series of reasons why "put option" rules might at times dominate "call option" rules. ${ }^{16}$ But to date there has been very little analysis of a very basic question: who should be given

${ }^{14}$ Ayres, supra note 9, at 800 .

${ }^{15}$ See Louis Kaplow \& Steven Shavell, Property Rules Versus Liability Rules: An Economic Analysis, 109 HARV. L. REV. 713 (1996); Ayres, supra note 9.

${ }^{16}$ See Levmore, supra note 9, at 2168-72; Ayres, supra note 9, at 801-13; Krier \& Schwab, supra note 7. 
DELEGATION AND DECOUPLING

the initial entitlement? Most authors — if they address this question at all—suggest that courts should grant the initial entitlement to the litigant it believes to have the higher valuation. This standard is codified in the Restatement (Second) of Torts, which expressly directs courts in deciding whether or not an act constitutes a nuisance to consider whether "the gravity of the harm outweighs the utility of the actor's conduct." ${ }^{17}$ As we will see, ${ }^{18}$ the idea of simply giving the entitlement to the higher valuer-while making eminent sense in terms of maximizing allocative efficiency when choosing between property rule regimes (Rules 1 and 3) —does not make sense when choosing among the four liability rules (Rules 2, 4, 5, and 6).

At its core, this article uses mathematical reasoning in an attempt to provide practical advice on how judges should choose among liability rules. ${ }^{19}$ We both expand and simplify the range of judicial choice. We expand judicial choice by showing that there exist an infinite number of implementations within two foundational classes of liability rules that can produce the same allocative efficiency as those four liability rules. While any rule within a particular class identically allocates the entitlement among the litigants, this proliferation of rules is far from redundant because

${ }^{17}$ RESTATEMENT (SECOND) OF TORTS § 826(a) (1979).

${ }^{18}$ See infra at 33.

${ }^{19}$ The separate and important question of whether and under what conditions liability rules dominate (or are dominated by) property rules has recently been discussed by Ayres \& Talley, supra note 9; Kaplow \& Shavell, supra note 15; Louis Kaplow \& Steven Shavell, Do Liability Rules Facilitate Bargaining? A Reply to Ayres and Talley, 105 YALE L.J. 221 (1995); Ian Ayres \& Eric Talley, Distinguishing Between Concensual and Nonconsensual Advantages of Liability Rules, 105 YALE L.J. 235 (1995); Epstein, supra note 9.

In the conclusion, we return to this issue and show how the analysis of this article also enriches our knowledge of when property rules are likely to be superior to liability rules. See infra at 111 . 


\section{DELEGATION AND DECOUPLING}

the liability rules divide the expected total payoff differently. A central finding of this article is to show how judges can decouple allocative and distributive concerns. A court's decisions about which type of rule will maximize ex post allocative efficiency does not need to affect its decision about which distribution will best promote equity or ex ante investment.

Our analysis also simplifies judicial choice by revealing a deeper structure to liability rules. Maximizing allocative efficiency has nothing to do with a court's decision about who is given an initial entitlement. We will show, for example, that Rule 2-which gives the initial entitlement to the Resident (subject to the Polluter's call option) — produces identical allocations for every possible realization of Polluter and Resident valuations as Rule 5-which gives the initial entitlement to the Polluter (along with a put option). To maximize allocative efficiency, courts should focus instead on delegating the allocation choice to the litigant who is the more efficient chooser.

While from the perspective of the initial entitlement holder, liability rules seem to have compensation as its central aim, from an efficiency perspective liability rules are a means by which an imperfectly informed court can delegate allocative choice to private litigants who potentially have superior allocative information. For example, a traditional liability rule (Rule 2) can be seen as the court delegating the allocative choice to the polluter. The Polluter chooses whether to allocate the entitlement to itself (and to pay damages to the Resident) or to allocate the entitlement to the Resident (and pay nothing). In this article, we provide a theory of how courts might optimally delegate allocative choice.

The four liability rules of Table 2 (Rules 2, 4, 5, and 6) give rise to just two allocative equilibria corresponding to the identity of the chooser. For convenience, we call these "single 
DELEGATION AND DECOUPLING

chooser" rules because a single litigant determines the entitlement's final allocation. Rules 2 and 5 are "defendant choice" rules because they give the polluter the allocative choice, ${ }^{20}$ while Rules 4 and 6 are "plaintiff choice" rules that give the Resident the allocative choice. There is a continuum of defendant-choice rules and a continuum of plaintiff-choice rules, but all the defendant-choice rules (including Rules 2 and 5) allocate the entitlement identically and only differ in the amount of the side payments that are made between the parties. Likewise, there is a continuum of plaintiff-choice rules (including Rules 4 and 6) that identically allocate the entitlement, albeit with different side payments.

But we also show that there are two further foundational classes of liability rules. We dub these "dual chooser" rules in contradistinction to the single-chooser rules, because both the plaintiff and the defendant have a potential impact on how the entitlement is ultimately allocated. ${ }^{21}$ One class of allocation rules gives the entitlement to the plaintiff unless both parties agree to shift it (for a court-determined price) to the defendant-in other words, either party has the power to veto the defendant being allocated the entitlement. We will call this class of rules "defendant-joint-veto" rules. The other class of allocations concern rules that allow either party unilaterally to veto the

\footnotetext{
${ }^{20}$ Under Rule 2, it is the Polluter's (call option) choice either to pollute and pay damages or to refrain from polluting and pay nothing; under Rule 5 it is the Polluter's (put option) choice either to refrain from polluting and receive damages or to pollute and receive nothing. Under either rule, the Resident is powerless to affect the ultimate allocation except by bargaining with the Polluter in the shadow of these Polluter choice laws.

${ }^{21}$ Jack Balkin and Ian Ayres have previously analyzed second-order liability rules which, like dual-chooser liability rules, give both litigants a say in the ultimate allocation. See Ayres \& Balkin, supra note 9. But unlike second (or higher) order rules which require successively higher exercise prices, the dual-chooser rules that are the focus of this article concern judges setting a single exercise price that both litigants react to. The relationship between the dual-chooser rules and second order rules is discussed more fully infra Part III.
} 
plaintiff being allocated the entitlement—which we will analogously label "plaintiff-joint-veto" rules. As with the single-chooser rules, we will give multiple option interpretations of these dualchooser rules and show that there are an infinite number of rules within each of these classes that produce identical entitlement allocations, but which affect how the disputants divide the entitlement's value.

In one sense, these dual-chooser rules represent a kind of centralized planning writ small. Under them, the government (i.e., a judge) sets a price for the entitlement and then asks both litigants whether they want to trade at that price. While this characterization makes the dual-chooser rules seem esoteric and unworldly, we argue that these rules are already being used in some legal contexts. Moreover, we show conditions under which a dual-chooser rule systematically produces greater allocative efficiency than either class of single-chooser rules. ${ }^{22}$

${ }^{22}$ Madeline Morris is the only other person to have considered "dual chooser" regimes. See Morris, supra note 8 , at 854 . She mentions in passing the theoretical possibility of such rules, but she does not identify circumstances when they might be advisable nor does she suggest their arguable existence in current legal practice. 


\section{DELEGATION AND DECOUPLING}

Our four core allocative equilibria are graphically depicted in the stylized panels of Figure

1. The panels show the range of possible plaintiff valuations on the horizontal axis and the range of potential defendant valuations on the vertical axis. If a judge had perfect information about the
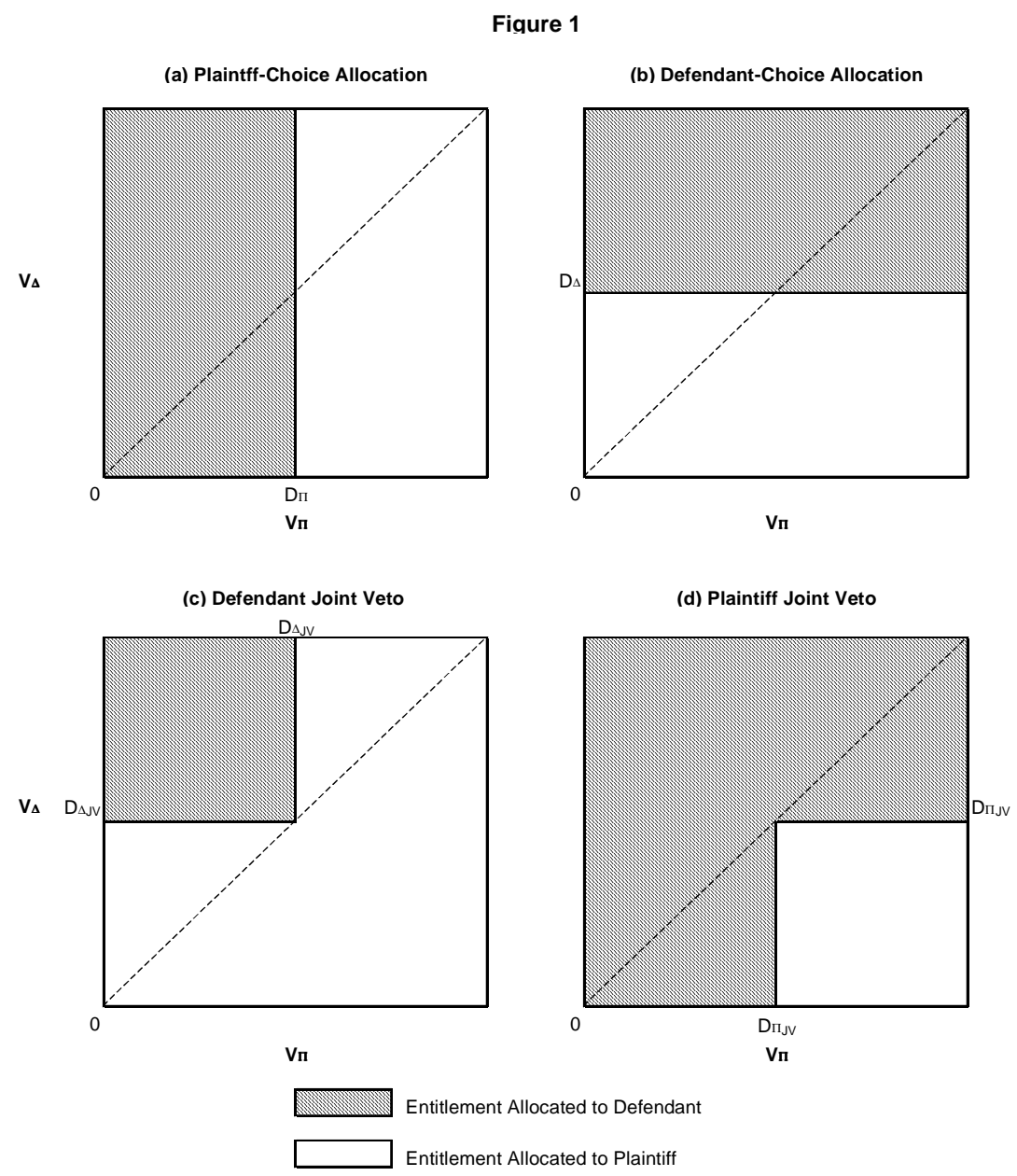

litigants' valuations, she could achieve first-best allocative efficiency by allocating the entitlement to the defendant whenever the defendant's value was higher than the plaintiff's value. A fully informed judge would accordingly use a decision rule corresponding to the dashed diagonal lines in the panels.

But an imperfectly

informed judge instead can resort to liability rules to harness the litigants' superior private information about at least their own values. ${ }^{23}$ As shown in panel (a), the class of plaintiff-choice rules allows the plaintiff to vertically partition the valuation space. Under these rules, when the

\footnotetext{
${ }^{23}$ See Kaplow \& Shavell, supra note 15, at 725.
} 


\section{DELEGATION AND DECOUPLING}

plaintiff values the entitlement more than the damage amount, it will allocate the entitlement to itself; when the plaintiff values the entitlement less than the damage amount, it will allocate the entitlement to the defendant.

The analogous horizontal allocative partition produced by defendant-choice rules is shown in panel (b). For this class of rules, the defendant is vested with the power to allocate the entitlement to itself when its valuation exceeds the damage amount, or to allocate the entitlement to the plaintiff when its valuation falls short of judicially chosen damages. While not achieving first-best (perfect information) allocative efficiency, these single-chooser rules can enhance allocative efficiency by giving the chooser an incentive to make the most efficient allocation given her available information (i.e., that she knows her own valuation precisely but only, like the court, knows the probability distribution of her rival's valuation).

The allocations for the dual-chooser rules are depicted in panels (c) and (d). Panel (c) shows the defendant-joint-veto allocation, in which the entitlement is allocated to the plaintiff unless both parties opt for a defendant allocation. A defendant allocation will only take place if the plaintiff's valuation is less than the damage amount and the defendant valuation is greater than the damage amount. This is because if the plaintiff's valuation is above the damage amount then the plaintiff will choose to allocate the entitlement to itself and forego the payment of damages it would have received if the entitlement were allocated to the defendant. If the defendant's valuation is below the damage amount the defendant will allocate the entitlement to the plaintiff rather than pay the higher damage amount. Panel (d) shows the analogous plaintiff-joint-veto allocation, which allocates the entitlement to the defendant unless the both parties opt for a plaintiff allocation. 
DELEGATION AND DECOUPLING

All four equilibria allocate the upper left quadrant to the defendant and the lower right quadrant to the plaintiff. But there are two crucial differences. First, the optimal damage amounts for the particular classes of rules may differ. We will show that the optimal damages for all the rules within a class are the same, but that optimal damages may differ among the classes. One of our tasks in this article will be to derive the optimal damages for each of the four classes.

Second, a crucial difference between allocative equilibria concern the off-diagonal quadrants (i.e., the lower-left and upper-right quadrants). The dual-chooser rules allocate both of these offdiagonal quadrants to the same litigant, while the single-chooser rules split ownership by quadrant. To determine which of the four basic liability classes maximizes allocative efficiency, a court in effect will need to determine which litigant is likely to be the more efficient entitlement holder within these off-diagonal quadrants. Accordingly, a second task of the article is to provide guidance for judges determining which of the four equilibria depicted in Figure 1 maximizes allocative efficiency (conditional on the judges' imperfect information).

Our finding that there are an infinite number of rules within each class that vary in how the expected total payoffs are divided between the litigants allows courts to decouple the allocative and distributive decisions. ${ }^{24}$ Courts deciding among this expanded set of liability rules should first choose the class of rule that maximizes ex post allocative efficiency and then choose the implementation within the class that best comports with the distributive demands of equity or the need to produce ex ante investment incentives.

\footnotetext{
${ }^{24}$ In this article, we generally distinguish between "allocation" of the entitlement at hand and "distribution" of wealth or value.
} 


\section{DELEGATION AND DECOUPLING}

The core allocative decision is for a judge to decide the optimal number and identity of the choosers. The choice among these four allocative equilibria will turn on judicial beliefs about how much the litigants value the entitlement at issue. But instead of being based simply on which litigant has the higher mean value, we show that the allocation decision should turn more broadly on judicial beliefs as to how these values are distributed. ${ }^{25}$

We will show that dual-chooser allocations will at times dominate single-chooser allocations and at other times be dominated by them. Dual-chooser rules can dominate if neither litigant is well placed to make a "nuanced" decision by herself. When single-chooser rules tend to always allocate the entitlement to the same litigant (what we term a "non-nuanced" decision), there is a greater opportunity for dual-chooser rules to improve allocative efficiency. Even though it may seem from the perspective of an individual litigant, that the plaintiff or the defendant is always likely to be the higher valuer, dual chooser rules may allow the litigants together to identify instances when the other side ends up with a higher value. Under these circumstances, two heads can be better than one.

Single-chooser rules can dominate, however, when the court has relatively good information about one of the litigant's valuation. A court should delegate allocative authority to litigants who have an informational advantage over the imperfectly informed court. Somewhat counter-intuitively, it is the litigant who - from the court's perspective - has a less speculative valuation that is the less

\footnotetext{
${ }^{25}$ Even after the parties have produced evidence of their respective valuations, we imagine that the court will still have residual uncertainty about the true valuations of the entitlement. Some of this uncertainty may relate to inevitable uncertainty about the future (e.g., will the factory's new machine work?), while other uncertainty may simply be the by-product of litigants' strategic incentive to misrepresent their valuations (e.g., "I really value this land because my dog is buried here").
} 
DELEGATION AND DECOUPLING

able to make an allocative choice. A litigant with less-speculative value has a smaller informational advantage vis-à-vis both the court and her rival (who has the more speculative damages). Singlechooser rules can dominate dual-chooser rules when it is inefficient to give a litigant who knows little more than court partial control over who will end up with the entitlement. When a singlechooser rule is optimal, judges should give the choice to the litigant who has from the court's perspective more speculative valuation. We will show that the choice between the two singlechooser rules tends to turn not on which litigant's valuation has a higher mean, but rather on which litigant's valuation has, from the judges' perspective, a higher variance.

Before proceeding, however, it is important to emphasize four qualifications to our option approach concerning numerosity, autarky, intentionality, and value correlation. First, we model disputes between only two litigants. Many nuisance examples concern a single source whose pollution adversely affects multiple residents (à la Boomer or Spur) ${ }^{26}$ Still, there are scores of cases in which the nuisance centrally involves a dispute between only two people. ${ }^{27}$ And even multiple plaintiff cases can be modeled in a bilateral fashion if the plaintiff class is sufficiently unified. More

${ }^{26}$ James Krier and Stewart Schwab have the best modern discussion of how courts should respond to numerosity problems in choosing among liability rules. See Krier \& Schwab, supra note 7.

${ }^{27}$ See, e.g., Copart Indus. v. Consolidated Edison Co., 362 N.E.2d 968 (N.Y. 1977) (pollution from ConEd plant disrupted adjacent new car preparation business); Estancias Dallas Corp v. Shultz, 500 S.W.2d 217 (Tex. App. 1973) (air conditioner noise reduced value of single adjacent residence). The class of cases dealing with visual nuisances is particularly likely to involve a single plaintiff and a single defendant. See, e.g., Fontainebleau Hotel Corp. v. Forty-Five Twenty-Five, Inc. 114 So. 2d 357 (Fla. Dist. Ct. App. 1959) (hotel addition obstructed view of adjacent hotel); Amphitheaters, Inc. v. Portland Meadows, 198 P.2d 847 (Or. 1948) (light from night-time dog track interfered with adjacent drive-in movie). 
DELEGATION AND DECOUPLING

fundamentally, our models assume that the litigants are the only relevant contenders for the role of highest valuer of the entitlement. Our option approach is a powerful way to analyze what economists call "bilateral monopoly," 28 but it is important to remember that in many circumstances there will be third parties who will want to enter the notional bidding to possess the entitlement.

Second, our analysis investigates the allocative efficiency of different liability rules in the absence of bargaining (i.e. under conditions of "autarky"). This is a restrictive assumption because we should expect that in many instances the litigants will bargain in the shadow of the law. Still, our autarky assumption is supported by recent empiricism which suggests that real world nuisance disputants almost never bargain after courts render judgment. ${ }^{29}$ Moreover, as argued by Louis Kaplow and Steve Shavell, there are reasons to expect that the relative efficiency of different liability regimes when bargaining is not allowed will tend to persist even when bargaining is allowed. ${ }^{30}$

Third, the option model is primarily concerned with circumstances of intentional taking. While this often (if not usually) describes nuisance disputes, it is important to remember that liability

${ }^{28}$ Rose characteristically hits the nail on the head when she explains that: "Ayres [is] interested in situations in which two parties are stuck with each other, 'thin' markets instead of 'thick' ones. Neighboring landowners seem to fit that bill.” Rose, supra note 9, at 2183.

${ }^{29}$ See Ward Farnsworth, Do Parties to Nuisance Cases Bargain After Judgment? A Glimpse Inside the Cathedral, 66 U. Chi. L. Rev. 373 (1999).

${ }^{30}$ See Kaplow \& Shavell, supra note 19, at 228-29. The persistence conjecture predicts that a liability rule that has a non-consensual efficiency advantage under conditions of autarky (i.e., high bargaining costs) will continue to be more efficient when the costs of bargaining are lower. According to Kaplow and Shavell, non-consensual headstarts in efficiency will tend to persist when bargaining is possible. $I d$. However, while not denying a persistence effect, we believe that different liability rules themselves can induce different types of information disclosure and thereby affect the relative efficiency of rules independent of the autarkic or non-consensual effect on allocative efficiency. See Ayres \& Talley, supra note 19. 


\section{DELEGATION AND DECOUPLING}

rules are often (if not usually) applied in circumstances of negligent taking. And, finally, we assume that the litigants' valuations are uncorrelated - meaning that an unusually high entitlement valuation for the plaintiff does not entail an unusually high entitlement valuation for the defendant. This is often true in nuisance suits where the economic benefit to the polluter is orthogonal to the noneconomic detriment to the resident. ${ }^{31}$

These restrictive assumptions somewhat limit the applicability of our analysis. But as stressed below, ${ }^{32}$ there are still a rich set of circumstances in which our assumptions fit the stylized facts. While to keep faith with Calabresi and Melamed we highlight nuisance examples, we believe that contractual disputes provide an even larger class where our analysis is relevant. Contractual entitlements are also traditionally protected by liability rules (expectation damages); the decision to breach (i.e. to take the promisee's entitlement) is often intentional; and contractual disputes are often unavoidably bilateral. ${ }^{33}$ For example, once Epstein agrees to cut Rose's hair, Rose is the only one with whom Epstein can bargain if he wants to buy back his promise. ${ }^{34}$ While our article does not provide a view of the entire legal "cathedral," the problem of how imperfectly informed courts

\footnotetext{
${ }^{31}$ However, with regard to visual nuisance, correlated valuations are more likely. For example, new structures often derive much of their value from the good views they obstruct. See, e.g., Fontainebleau Hotel, 114 So. $2 \mathrm{~d}$ at 357.

${ }^{32}$ See infra at 103 .

${ }^{33}$ Carol Rose has acutely observed that Ayres's previous option analysis has a contractual shadow as its paradigmatic example: "The contractual relationship has only a discrete number of parties - paradigmatically two - who . . . are stuck with each other." Rose, supra note 9, at 2187. Rose is clearly right that contractual renegotiations often involve limited numbers and a bilateral monopoly.

${ }^{34}$ See Ayres \& Balkin, supra note 9, at 745. But while contract renegotiations may serve as a paradigm case of bilateral monopoly, they are not the only example.
} 
$\underline{\text { DELEGATION AND DECOUPLING }}$

should resolve bilateral disputes with intentional taking is much more than a theoretical curioso.

The article is divided into four parts. Parts I and II analyze single- and dual-chooser rules, respectively. These parts derive the optimal damages for the four basic classes and analyze the conditions under which a particular allocative equilibrium is most likely to be efficient. Part III then relates the dual-chooser rule to the higher-order rules previously analyzed by Ayres and Balkin. ${ }^{35}$ Finally, Part IV investigates how the preceding results are affected when we relax the most restrictive assumptions of the model. The conclusion shows how our analysis could be applied to improve contract law and also how our analysis illuminates the issue of when liability rules should be used instead of property rules.

\section{Single-Chooser Rules}

The original pair of liability rules analyzed by Calabresi and Melamed provide examples of the two foundational single-chooser rules. Rule 2 represents a defendant-choice rule because the defendant (polluter) chooses who the ultimate entitlement holder will be by deciding whether or not to pay to pollute. And Rule 4 represents a plaintiff-choice rule because the plaintiff (resident) chooses who the ultimate entitlement holder will be by deciding whether or not to pay to stop the pollution.

The option recharacterization not only allows us to see the possibility of two more rules, but also clarifies that liability rules (including "put option" rules) are not merely different ways of protecting an entitlement. They can also be thought of as different ways of dividing the parties' claims to the entitlement. As Carol Rose has written,

\footnotetext{
${ }^{35}$ See Ayres \& Balkin, supra note 9.
} 
[under a property rule regime], the entitlement holder has the whole meatball, so to speak, and the other party has nothing - one has property, the other has zip. Under either of the two [call option] liability rules, on the other hand, the meatball gets split: The factory has an option to pollute (or once exercised, an easement), while the homeowner has a property right subject to an option (or easement). For the sake of simplicity, I will refer to this kind of right as a PRSTO (or PRSTE) for "property right subject to an option (or easement)." ${ }^{, 36}$

Under this view, options merely divide the claims to an entitlement in a different way than, say, a physical or temporal partition.

Table 3: Possible "Derivative" Divisions of an Entitlement

\begin{tabular}{||c|c|c|}
\hline & \multicolumn{2}{|c|}{ How Different Rules Divide Parties' Claims to an Asset } \\
\hline & Resident's Claim & Polluter's Claim \\
\hline Rule 1 & Asset & 0 \\
\hline Rule 2 & Asset - Call & Call \\
\hline Rule 3 & 0 & Asset \\
\hline Rule 4 & Call & Asset - Call \\
\hline Rule 5 & - Put & Asset + Put \\
\hline Rule 6 & Asset + Put & - Put \\
\hline
\end{tabular}

Table 3 shows how each of the six rules represents a different way in which the finite claims to an entitlement might be divided. Each of the rules maintains conservation of "matter," 37 in that

${ }^{36}$ Rose, supra note 9, at 2178-79. See generally Ayres \& Talley, supra note 9, at 1062-65 (discussing dimensions into which an entitlement might be divided, including put and call divisions).

${ }^{37}$ Hohfeld long ago recognized that rights are relational. See Wesley Newcomb Hohfeld, Fundamental Legal Conceptions as Applied in Judicial Reasoning, 26 YALE L.J. 710 (1917); Welsey Newcomb Hohfeld, Some Fundamental Legal Conceptions as Applied in Judicial Reasoning, 23 YALE L.J. 16 (1913). One's right (or asset) can be seen as an obligation (or liability) on someone else's part. The puts and call options in any row of Table 3 sum to zero, reflecting this Hohfeldian 


\section{DELEGATION AND DECOUPLING}

the sum of the Polluter's and Resident's assets and liabilities under each rule nets out to "Asset." As Rose noted, a property rule (such as Rule 1 or 3) gives one party everything and the other person "zip." But other divisions are possible. Rose saw that having a "PRSTO" is the same as owning the asset subject to a liability (depicted by the “- Call”) in that one might be forced to sell against one's will (for a price less than the actual value to one's self) ${ }^{38}$ In contrast, the "put option" rules (Rules 5 and 6) give the initial entitlement holder everything that she would have under a property rule plus a put option. This necessarily implies that the non-entitlement holder has a liability (denoted by “Put") - i.e., she might be forced to purchase against her will (for a price that is more than her true value).

From the perspective of allocative efficiency, the four liability rules collapse into a choice between just two potential allocations. For any given damage amount and for any given litigant valuations, Rule 2 will allocate the entitlement to the same litigant as Rule 5, and Rule 4 will allocate the entitlement to the same litigant as Rule 6.

To see this, consider an entitlement dispute between two litigants -- a plaintiff and a defendant. Let $v_{\Pi}$ be the plaintiff's valuation, and let $v_{\Delta}$ be the defendant's. We assume that each

requirement.

${ }^{38}$ Seeing liability rules as "derivative" divisions that partition the claims to an entitlement into two parts makes explicit the idea that changing the types of "protection" actually changes the content of the entitlement. See Jules L. Coleman \& Jody Kraus, Rethinking the Theory of Legal Rights, 95 YALE L.J. 1335, 1338-39 (1986). Seeing liability rules as merely asset divisions also calls into question Richard Epstein's claim for the dominance of 'property rules.' Because both the PRSTO and the call option are themselves protected by property rules, see Ayres \& Balkin, supra note 9, at 707 , Epstein's claim must not be just a claim about how entitlements should be protected but a claim about what collection of strongly protected claims must be bundled together. 


\section{DELEGATION AND DECOUPLING}

litigant knows her own valuation but—like the court—only knows the probability distribution of her adversary's value. We will refer to the probability density function of the plaintiff and defendant, respectively, as $f_{I I}(v)$ and $f_{\Delta}(v)$, and their means as $\mu_{\Pi I}$ and $\mu_{\Delta}$. Although we will later relax the following assumptions,${ }^{39}$ we also begin by assuming that the litigants' valuations are distributed independently of one another and that the transaction costs (or enmity) are sufficiently high to prevent the litigants from consensually resolving their dispute.

If we let the court awarded damages equal $D$, then it is straightforward to see ${ }^{40}$ that under Rule 2 the defendant will exercise its call option to force the plaintiff's non-consensual sale (in exchange for $D$ damages) if and only if:

$$
v_{\Delta}>D
$$

Similarly, under Rule 5, the defendant will exercise its put option to force the plaintiff's nonconsensual purchase (at a price of $D$ damages) if and only if:

$$
v_{\Delta}<D .{ }^{41}
$$

These inequalities indicate that under either of the defendant-choice rules, the defendant will allocate the entitlement to itself when its value is greater than the damage amount and will allocate the entitlement to the plaintiff when its value is less than the damage amount. Thus, for defendant-

${ }^{39}$ See infra at 82 .

${ }^{40}$ How to arrive such as this will be shown in the Appendix, infra at 111 .

${ }^{41}$ If $v_{\Delta}=D$, the defendant is indifferent as to whether it exercises either its put or its call options. But regardless of how the defendant treats such ties, the expected total payoffs of the litigants is unaffected. The inequalities in the text implicitly assume that the defendant's willingness to pay equals its willingness to accept. See Ayres, supra note 9, and infra at 90 for discussion of why this assumption might not hold. 
DELEGATION AND DECOUPLING

choice rules, the ultimate allocation is independent of the plaintiff's value. And because the defendant-choice rules produce identical allocations, they perforce must produce identical total payoffs. ${ }^{42}$ This means that, given any particular values of $D, v_{I}$, and $v_{\Delta}$, the defendant-choice rules (Rule 2 and 5) produce equal allocative efficiency.

An analogous result obtains for plaintiff-choice rules-Rules 4 and 6 . When the plaintiff's value exceeds the damage amount, the plaintiff will choose to allocate the entitlement to itself; when the plaintiff's value is less than the damage amount, the plaintiff will allocate the entitlement to the defendant. And because the physical allocations are identical for any possible realization of litigants' value, the allocative efficiency of Rules 4 and 6 are equal.

We can now see that the judicial choice of an initial entitlement holder is not a significant determinant of allocative efficiency. Rule 2 is allocatively equivalent to Rule 5, and Rule 4 is allocatively equivalent to Rule 6-even though the two rules within each of these pairs give the initial entitlement to different litigants. Instead, allocative efficiency turns crucially on which litigant gets to decide the ultimate allocation.

But the judicial choice of the initial entitlement holder does importantly affect how the total payoff is distributed between the plaintiff and the defendant. ${ }^{43}$ Looking again at Table 3 , it should

${ }^{42}$ The payoffs of the individual litigant is merely equal to her valuation of the entitlement if she ends up owning it, plus any side payments that she makes to or receives from the other litigants. Since the side payments must sum to zero, the total payoff for the plaintiff and defendant simply equals the value ascribed to the entitlement by the litigant who ultimately owns it.

${ }^{43}$ Note the parallel to the Coase Theorem. In a world without transaction costs, the judicial assignment of entitlements does not affect the allocative equilibrium but does affect the distribution of payoffs. It should not be surprising that an autarkic model (where high transaction costs make bargaining prohibitive) of liability rules can produce a similar result. Ayres and Balkin showed that 


\section{DELEGATION AND DECOUPLING}

be clear that defendants are better off with the defendant-choice rule, which gives them the entitlement plus a put (Rule 5), than with the defendant-choice rule, which gives them merely a call (Rule 2). ${ }^{44}$

The foregoing suggests that judges in choosing among the four liability rules can separate allocative and distributive concerns. Selecting the chooser determines the allocative equilibrium, while selecting the initial entitlement holder determines the distributive equilibrium. To establish a single-chooser regime, judges must (i) select the more allocatively efficient chooser, (ii) select a damage amount, and (iii) select how the expected total payoff will be distributed (for example, choose between Rules 2 and 5). The remainder of this section is organized around these three tasks.

\section{A. Selecting Optimal Damages}

While selecting the optimal chooser seems logically prior to selecting the optimal damages, as is often the case in game-theory, it is more convenient to solve the model backwards -- deriving first the optimal damage amount for a particular chooser and then comparing which chooser is the more efficient. The task of selecting optimal damages is conceptually straightforward. The allocative efficiency of single-chooser rules is maximized when damages are set equal to the nonchooser's expected value. ${ }^{45}$ This means that the (allocatively) optimal damage amount for the

liability rules formed a kind of auction mechanism which would mimic the results of Coasean negotiations. See Ayres \& Balkin, supra note 9, at 727-29.

${ }^{44}$ For example, if the plaintiffs and defendants valuations are independently and uniformly distributed between $\$ 0$ and $\$ 100$, and if damages are set equal to $\$ 50$ (which we later show is the optimal amount), then Rule 5 will yield an expected defendant payoff of $\$ 62.50$, while Rule 2 will yield the defendant only \$12.50. See Ayres, supra note 9, at 806. 2 and 4).

${ }^{45}$ See Kaplow \& Shavell, supra note 15 (deriving this result with regard to call option rules 
defendant-choice rules will be

$$
D_{\Delta}=\mu_{\Pi}
$$

and for the plaintiff-choice rules will be

$$
D_{\Pi}=\mu_{\Delta}
$$

These results are quite general-holding true regardless of the ways in which the valuations of litigants are distributed (so long as the litigants' distributions are independent). ${ }^{46}$ While courts may also have legitimate concerns about equity and other aspects of efficiency (such as inducing adequate ex ante incentives to create the entitlement in question), courts' separate ability to establish almost any desired distributive equilibrium strongly counsels in favor of the courts choosing damages that will maximize the size of the pie to be divided.

Setting damages equal to the non-chooser's expected valuation maximizes the allocative efficiency of a single-chooser rule because it gives the chooser the incentive to allocate the entitlement to herself only when her value is higher than the mean value of the non-chooser (and the incentive to allocate the entitlement to the non-chooser only when the chooser's value is lower than the mean value of the non-chooser). Setting damages at the non-chooser's mean value thus harnesses the private information of the chooser (who is reasonably assumed to know her own value) and induces a choice of ultimate asset allocation that is, on average, correct. ${ }^{47}$ For example, if the

${ }^{46}$ If the distributions are correlated, then the optimal single chooser damages will still be set at the non-choosers mean value -- but because the mean value is now a function of chooser's value optimal damages will find the fixed point at which damages equal the non-chooser's value such that the chooser's value also equal this amount. See infra at 94.

${ }^{47}$ As discussed in the next section, infra at 36, the single-chooser rules give the non-chooser a fixed expected payoff whether or not the chooser exercises her option. For example, under Rule 
DELEGATION AND DECOUPLING

plaintiff's mean valuation is $\$ 50$, then setting damages for either Rule 2 or Rule 5 equal to this amount will induce the defendant only to allocate the entitlement to itself when such an allocation is on average efficient. ${ }^{48}$ Even when the judge does not know as much as the individual litigants, liability rules allow the judge to exploit the private information of one of the litigants.

\section{B. Selecting the Chooser}

The second judicial task that affects allocative efficiency is to choose the chooser. For while the put and call implementations of a given single-chooser rule produce identical allocations, there is no guarantee that a plaintiff-chooser rule will produce the same allocation as a defendant-chooser rule. In this section, we provide some guidance to courts determining which party is the more efficient chooser -- i.e., which chooser will produce the highest total expected payoff.. ${ }^{49}$

The first step to identifying the more efficient chooser is to express the total (that is, combined plaintiff and defendant) expected payoff for a given single chooser rule. These profits can

2, the plaintiff as non-chooser receives an expected value equal to her mean valuation if the defendant does not exercise its call option (because the plaintiff will retain the entitlement) and it will receive its expected value in cash if the defendant does exercise its call option (and pays damages set equal to the expected value). Fixing the expected payoff of the non-chooser makes the chooser the residual claimant of gains from exercising its choice. The non-chooser is like the bondholder in corporate law who is a fixed claimant on the assets of the firm, while the chooser is like the shareholders who is granted the residual claim. Because the chooser internalizes all the marginal effects of her choice, single-chooser rules give the chooser (like the shareholder) an incentive to choose the allocation which - conditional on her knowledge (which is assumed to be superior to that of the judge)-maximizes allocative efficiency.

${ }^{48}$ The defendant under Rule 2 will choose to pollute and pay $\$ 50$, only if its valuation exceeds the plaintiff's mean value; and the defendant under Rule 5 will forego receiving $\$ 50$, only if its valuation exceeds $\$ 50$.

${ }^{49}$ See Krier \& Schwab, supra note 7 (suggesting that more efficient chooser is the side of the litigation that is less numerous). 
be expressed analytically as follows:

$$
E[\text { Total Payoff }]=\mu_{n c}+\int_{\mu_{n c}}^{\infty}\left(q_{c}-\mu_{n c}\right) f_{c}\left(q_{c}\right) d q_{c}
$$

where the subscripts $c$ and $n c$ refer to the chooser and non-chooser, respectively. We derive the foregoing expression in the appendix, but, for now, it can be expressed in more stylized terms as:

$$
\text { Expected Total Payoff= non-chooser's mean }+ \text { chooser's call. }
$$

Intuitively, the chooser has the choice of allocating the entitlement to the non-chooser (in which case the total payoff will equal the non-chooser's mean) or exercising its option of allocating the entitlement to itself (in which case the total payoff will equal the non-chooser's mean plus the expected amount by which chooser's mean exceeds the non-chooser's mean). This option (which we label "chooser's call") of allocating the entitlement to itself when the chooser's privately known value exceeds the non-chooser's mean is the reason that liability rules systematically dominate property rules in the absence of bargaining.

But it turns out that the expected total payoff can be alternatively expressed as:

$$
\text { Expected Total Payoff = chooser's mean }+ \text { chooser's put. }
$$

We can also think of the single-chooser rule as allowing the chooser to keep the entitlement (yielding an allocation the value of which, on average, equals the chooser's mean) or to put the entitlement to the non-chooser when the chooser's privately known value is less than the non-chooser's mean. Finance cognoscenti will recognize the equivalence of these two payoff expressions as an implication of the "put-call parity formula" — which teaches that whenever a value can be expressed in terms of 


\section{DELEGATION AND DECOUPLING}

an implicit call, there must be an equivalent way of expressing the same value in terms of an implicit put. $^{50}$

These two expressions for the expected total payoff when applied to both plaintiff- and defendant-choice rules give rise to 4 equivalent comparisons for determining which litigant is the better chooser. Plaintiff-choice rules (either Rule 4 or 6) will be more efficient than defendantchoice rules (either Rules 2 or 5) if and only if the following equivalent conditions hold:

(i) $\operatorname{call}_{I I}\left(\mu_{\Delta}\right)>\operatorname{put}_{\Delta}\left(\mu_{\Pi}\right)$,

(ii) $\operatorname{put}_{I I}\left(\mu_{\Delta}\right)>\operatorname{call}_{\Delta}\left(\mu_{\Pi}\right)$,

(iii) $\mu_{\Pi}-\mu_{\Delta}>\operatorname{put}_{\Delta}\left(\mu_{\Pi}\right)-\operatorname{put}_{I}\left(\mu_{\Delta}\right)$, and

(iv) $\operatorname{call}_{I I}\left(\mu_{\Delta}\right)-\operatorname{call}_{\Delta}\left(\mu_{\Pi}\right)>\mu_{\Pi}-\mu_{\Delta}$,

where, for example, "call ${ }_{I I}\left(\mu_{\Delta}\right)$ " represents the expected value of a call option for a plaintiff when the exercise price of the call (reported in the parentheses) is set at the defendant's mean valuation. ${ }^{51}$ Two points are immediately worth emphasizing. First, these four inequalities merely restate one

${ }^{50}$ See Richard A. BREAley \& SteWARt C. Myers, Principles of CORPORATE FinANCE 557 (5th ed. 1996) (defining put-call parity); Ayres \& Talley, supra note 9, at 1047 (applying put-call parity to liability rules). The put-call parity formula is often stated in the following form:

$$
\text { Call }+ \text { Exercise Price }=\text { Put }+ \text { Underlying Asset } .
$$

As applied to single-chooser rules, since the exercise price of the options is set equal to the nonchooser's mean value, the left-hand side of this equation equals the first expression (equation A) for the expected total payoff. And since the expected value of the underlying asset to the chooser is its mean, the right-hand side of this equation equals the second expression (equation B) for the expected total payoff.

${ }^{51}$ Analogously, " $\operatorname{put}_{I I}\left(\mu_{4}\right)$ " represents the expected value of a put option for a defendant when the exercise price of the put is set at the plaintiff"s mean valuation 


\section{DELEGATION AND DECOUPLING}

another so that probability distributions which satisfy one of the inequalities must automatically satisfy the others. Second, the exercise price of the options are always set at the mean valuation of non-option holder (i.e. the non-chooser). This latter point is just an implication of the last section's finding that optimal damages should be set at the non-chooser's mean value.

The most important implication of these comparisons - which is particularly evident in the first two inequalities - is that the litigant with the more speculative ${ }^{52}$ valuation will tend to be the more efficient chooser. This again will not surprise finance cognoscenti. A central result of derivative theory is that options tend to be more valuable as the value of the underlying asset becomes more volatile. The litigant which the court perceives to have the more speculative value is the litigant with the greater informational advantage.

Indeed, we show in the Appendix that when the court is choosing between a litigant whose value is commonly known and another litigant whose value is only commonly known to fall within a particular probability distribution, the litigant with the known value is never the efficient chooser. ${ }^{53}$ This makes intuitive sense. The litigant whose non-random value is commonly known has no private information to bring to the allocative table. Given the allocative choice, such a litigant would

\footnotetext{
${ }^{52}$ It should be stressed that we are using the word "speculative" in a special sense. Our model assumes that each litigant places a non-speculative, certain dollar value on its ownership of the entitlement while the court and the adversaries must speculate (via a probability distribution) about how much the entitlement is valued by the litigant. But in many real-world contexts, the litigants themselves may not know their precise valuations. A polluter, for example, may also have to speculate about how profitable a polluting factory would be in the future. We will later relax the assumption that litigants are perfectly informed about their own valuation, see infra at 82 , but for now it is sufficient to say that our core qualitative results go through. The more efficient chooser will continue to be the litigant with the larger informational advantage.

${ }^{53}$ See infra at 111 .
} 
DELEGATION AND DECOUPLING

always allocate the entitlement to herself (i.e., her value were higher than the other litigant's mean) or always allocate the entitlement to her adversary (i.e., her value were lower than the other litigant's mean). A court selecting a litigant with a non-random value and setting the damage amount would effectively be choosing the ultimate entitlement holder. If the actual value placed on the entitlement by the other litigant were different than expected, the entitlement could end up in the wrong hands. In contrast, if the court selected the litigant with the random valuation as the chooser (and set damages equal to the non-random value of the other litigant), first-best allocative efficiency would always be achieved. The random litigant would only allocate the entitlement to herself when she knew that her value was higher than that of the non-random litigant, and she would only allocate the entitlement to the other when her value was lower.

Inspecting the latter two inequalities - (iii) and (iv) —one might at first think that the relative means of the litigants were also relevant in selecting the more efficient chooser. But this turns out not to be true. First, as an algebraic matter, notice that in the third inequality the plaintiff having a higher mean relative to the defendant seems to increase the likelihood that the plaintiff is the efficient chooser, while in the fourth inequality the plaintiff having a higher mean seems to decrease the likelihood that the plaintiff is the more efficient chooser. Both cannot be true because, as we prove in the Appendix, ${ }^{54}$ these inequalities are mathematically equivalent. As it turns out, neither intuition is true because the values of the puts and the calls also change in ways that offset the direct impact of the change in litigants' mean values. For example, if the plaintiff's mean becomes higher relative to the defendant's mean (holding the variance of both litigants' values constant), both the plaintiff's

\footnotetext{
${ }^{54}$ See infra at 111 .
} 


\section{DELEGATION AND DECOUPLING}

call and the defendant's put should become more valuable. This shift in means drives both these options further "in the money." 55

As a general matter, option value is a function of both a "volatility" effect and an "in the money" effect — meaning that options are generally more valuable (a) the more volatile the option holder's value and (b) the further the option holder's expected value exceeds (for call ) or falls short of (for puts) the exercise price. But in working through the four inequalities, one can see that the "in the money" effect on option value equally affects both sides of each inequality. An increase in the plaintiff's mean relative to the defendant's mean, increases both sides of inequality (i) and decreases both sides of inequality (ii). In inequality (i), for example, the "in the money" effect on the plaintiff's call is exactly the same as for defendant's put. ${ }^{56}$ Consequently, a shift in means should not—holding volatility constant— push a court toward either favoring or disfavoring a particular litigant as the more efficient chooser.

Courts in selecting the more efficient chooser should focus on the second moment of the distribution (the variance), not the first moment (the mean) — and select the litigant who from the court's perspective has a higher variance of value. This finding suggests that the Restatement

${ }^{55}$ From a court's perspective, a plaintiff whose mean value is higher than the defendant's mean value is more likely to exercise its call (because more of the probability weight in plaintiff's distribution will exceed the call's exercise price, which is set at the defendant's mean); and the defendant is more likely to exercise its put (because more of the probability weight in the defendant's distribution will fall below the put's exercise price, which is set at the plaintiff's mean).

${ }^{56}$ These effects are at play with inequalities (iii) and (iv) as well. An increase in the plaintiff mean relative to the defendant mean increases both sides of inequalities (iii) and (iv). With regard to (iii), for example, it is easy to directly see that the left-hand side $\left(\mu_{\Pi}-\mu_{\Delta}\right)$ increases, but the righthand side also increases as the shift in mean causes "put $\left(\mu_{\Pi I}\right)$ " to increase and "put ${ }_{I I}\left(\mu_{\Delta}\right)$ " to decreases. 
$\underline{\text { DELEGATION AND DECOUPLING }}$

(Second) of Torts is misguided in suggesting that courts should assign the initial entitlement in nuisance disputes to the party which it perceives to have the higher value. This allocation principle makes eminent sense if the court were merely choosing between the two possible property rules (Rule 1 and 3). But the principle fails to maximize allocative efficiency when the court is contemplating a choice between the call option versions of the liability rules (Rules 2 and 4). Although we demonstrated above that selecting the initial entitlement holder need not affect the ultimate allocation, this is only true in a world in which put-option as well as call-option liability rules are employed - so that the choice of the initial entitlement holder can be decoupled from the choice of the more efficient chooser. But the world contemplated by the Restatement does not decouple these two choices. In the Restatement's world (where the only liability rules that judges award are the call option versions - Rules 2 and 4), a rule that the litigant with the higher perceived value should be the initial entitlement holder is tantamount to a rule that the litigant with the lower perceived value should be the chooser — via the call-option Rule 2 or 4 . Our model does not support the Restatement's position. Rather, we propose that when there are two litigants, the more efficient chooser will tend to be the chooser who from the court's perspective has the greater variance of potential private valuations.

From a pragmatic perspective, our two allocative rules work together to allow the court to avoid calculating speculative damages. We have suggested that courts should select as chooser the litigant with the more speculative value and then set damages equal to the less speculative mean of 
$\underline{\text { DELEGATION AND DECOUPLING }}$

the non-chooser. ${ }^{57}$

In a less reductive model, the court's selection of the more efficient chooser will turn on more than just an assessment of relative volatility of the litigants' values. For example, considerations of the litigants' relative risk aversion might affect a court's choice. The variance of the choosers' expected payoffs will tend to be lower than the non-choosers' because choosers have greater control over their destiny. ${ }^{58}$ Thus, besides selecting the chooser with the more speculative damages, efficiency-minded courts, other things held equal, might also favor selecting as chooser the more risk averse litigant.

At other times, the more efficient chooser will be the litigant that is less numerous. ${ }^{59}$ If a single source of pollution harms multiple residents it may be difficult to implement a plaintiff choice rule for the plaintiff class. We will return to this issue infra when we include a more extended discussion of how numerosity affects our analysis. ${ }^{60}$

\section{Selecting the Distribution}

The first two judicial tasks — selecting the chooser and selecting the damages — are sufficient

${ }^{57}$ We agree with Kaplow and Shavell that the speculative nature of damages is not a reason for excluding them from the court's assessment, see Kaplow \& Shavell, supra note 15, at 728-32, but our approach simplifies the judicial task by only requiring the court to make an assessment of how much the less speculative litigant on average values the entitlement.

${ }^{58}$ See Ayres, supra note 9, at 812-13, $821 \&$ n.81. For example, if the litigants' values are both uniformly distributed between $\$ 0$ and $\$ 100$, then a single-chooser rule will give the chooser a fixed amount $50 \%$ of the time, and a $\$ 50$ range of values the other $50 \%$ of the time, but the rule will give the non-chooser a fixed payoff $50 \%$ of the time and a $\$ 100$ dollar range of values the other $50 \%$ of the time. We derive this more formally in the Appendix, infra, at 111.

${ }^{59}$ See Krier \& Schwab, supra note 7, at 471-72.

${ }^{60}$ See infra at 87. 
DELEGATION AND DECOUPLING

to determine the allocative equilibrium -- that is, who will end up with ultimate entitlement for particular realizations of the litigants' value. For example, we may have determined that a defendant choice rule is efficient, but we would still need to select between Rules 2 and 5 in deciding how the pie should be divided between the litigants. In this section, we show that a court has an unfettered control to divide the expected total payoff as it likes between the two litigants — without affecting the allocative efficiency. In other words, the court can decouple questions of distribution from questions of allocation

It is intuitively obvious that a chooser who is granted the entitlement plus a put option will have a higher payoff than a chooser who merely has a call option to buy the entitlement for a price. Accordingly, the put implementations of the single-chooser rules yield a relatively larger payoff for the chooser (and a relatively smaller payoff for the non-chooser) than the call implementations of the single-chooser rules.

But we can go further in describing the relative payoffs of the litigants. The single-chooser rules have the interesting feature that the non-chooser's expected payoff does not depend on whether the chooser allocates the entitlement to itself or the non-chooser. ${ }^{61}$ The non-chooser's expected

${ }^{61}$ In analyzing the distributive consequences of different rules, it is important to distinguish between two different informational perspectives. The ex ante perspective assesses the litigants' expected payoffs before they acquire information about their own valuation of the entitlement. The interim perspective assesses the litigants' expected payoffs after they learn their own valuations of the entitlement but before learning the other side's valuation. From the ex ante perspective, the possibility of being subject to the other side's put option does not produce a negative expected payoff. Under Rule 6, a Polluter may be forced to purchase the right to pollute, but if the price is set at the Polluter's expected valuation, the Polluter's expected payoff is zero. In contrast, from the interim perspective, the possibility of being subject to the other side's put option can produce a negative expected payoff -- if for example under Rule 6 you are a Polluter who happens to have a lower than average valuation. The ex ante perspective is also the perspective of the court -- in 
payoff is invariant with respect to the chooser's actual choice. More particularly,

(1) in put implementations of the single-chooser rules, the non-chooser's expected payoff is fixed at $\$ 0$ - whether or not the chooser exercises her put option; and,

(2) in call implementations of the single-chooser rules, the non-chooser's expected payoff is fixed at her mean value $\left(\mu_{\mathrm{NC}}\right)$ - whether or not the chooser exercises her call option.

First, consider a put implementation (i.e., where the chooser has both the entitlement and a put option). If the chooser does not exercise the put, the non-chooser's payoff is zero with certainty because she neither receives the entitlement nor makes a payment. Alternatively, if the chooser exercises the put, the non-chooser's expected payoff is zero because she must pay $\mu_{N C}$ for something that she values on average at $\mu_{N C}$. Similar reasoning shows that call implementations fix the nonchooser's expected payoff at $\mu_{N C}{ }^{62}$

Thus, call implementations give the non-chooser an expected payoff that is $\mu_{N C}$ higher than put implementations of single-chooser rules. And since we know that put and call implementations of the single-chooser rules produce the same expected total payoff (equal to $\mu_{N C}+\operatorname{call}_{C}$ ), it must be

deciding how to divide the expected payoffs between sets of observationally equivalent litigants. This perspective may at times also be relevant in creating efficient investment incentives -- if the parties don't know their actualized valuation until after an entitlement has been created. But in other contexts the interim perspective will drive potentially both investment and allocation decisions.

${ }^{62}$ If a chooser exercises her call option, the non-chooser receives $\mu_{N C}$ with certainty. If a chooser does not exercise her call option, the non-chooser simply retains the entitlement which she values on average at $\mu_{N C}$.

Of course, once non-choosers come to know their private value of the entitlement, they will not be indifferent about whether the chooser exercises her option or not. But the court (and other policy makers) will never be privy to this privately held information, so the best that a distributivelyconcerned court can do is to adopt the type of implementation that tends, on average, to produce a preferred distribution. 
DELEGATION AND DECOUPLING

true

(1) that chooser's expected payoff in put implementations equals the total expected payoff $\left(\mu_{N C}+\right.$ call $\left._{\mathrm{C}}\right)$; and

(2) that chooser's expected payoff in call implementations equals the value of a chooser's call $\left(\right.$ call $\left._{\mathrm{C}}\right)$.

The varying distributions of the put and the call implementations give policymakers more flexibility in pursuing non-allocative goals, but, if there were only two implementations, we would still be left with a rather crudely hewn distributive instrument. And distributively-minded lawmakers might at times want to tradeoff ex post allocative efficiency, in favor of more preferred distribution, by selecting an inefficient chooser in order to produce an expected payoff between what would be possible if either the call or put implementations of the efficient single-chooser rule were selected. ${ }^{63}$

Fortunately, it is possible to radically expand the class of single-chooser rules by, in a sense, "convexifying" the payoffs between the call and the put implementations. We refer to this as our convexity result. It turns out that the two single-chooser allocations can be implemented not just by four rules but by a double continuum of rules which give policymakers the option of smoothly distributing the expected joint surplus between the litigants as they see fit. ${ }^{64}$

${ }^{63}$ For example, imagine that the plaintiff is the less efficient chooser. Then the court, in making the defendant the chooser, could give the plaintiff an expected payoff of zero (through a defendant put implementation-Rule 5) or $\mu_{\Pi}$ (through a defendant call implementation-Rule 4). But if the court felt that the plaintiff deserved an expected payoff between zero and $\mu_{\Pi}$, it might decide to make the plaintiff the chooser via a call implementation-so that the plaintiff's expected payoff would fall in this intermediate level $\left(0<\operatorname{call}_{\Pi}<\mu_{\Pi}\right)$.

${ }^{64}$ Other authors have suggested a proliferation of liability rules on different grounds, see, e.g., Levmore, supra note 7, at 2171 (showing how liability rules could require different levels of negligence before taking), but, with our convexity result, we are the first to focus on distributive flexibility. 


\section{DELEGATION AND DECOUPLING}

The key here is to distinguish between the damages that a chooser must pay if it allocates the entitlement to itself (which we will call $D_{C}$ ) from the damages that a chooser must pay if it allocates the entitlement to the non-choosing litigant (which we will call $D_{N C}$ ). As shown in Table 4, a call implementation of a single-chooser rule sets $D_{C}$ equal to the non-chooser's mean $\left(\mu_{N C}\right)$ and sets $\mathrm{D}_{\mathrm{NC}}$ equal to zero, which means that the chooser must pay to nonconsensually take the entitlement, but pays nothing if she leaves the entitlement in the hands of the non-chooser. In contrast, a put implementation sets $D_{C}=0$ and sets $D_{N C}=-\mu_{N C}$, which means that the chooser pays nothing to retain the entitlement, and receives the non-chooser's mean (pays negative $\mu_{N C}$ ) if she puts the entitlement to the non-chooser.

\begin{tabular}{|c|c|c|c|c|}
\hline \multirow{2}{*}{ Table 4: Expanding the Class of Single-chooser Implementations } \\
\hline \multirow{2}{*}{ Implementation } & \multicolumn{2}{|c|}{ Damages } & \multicolumn{2}{c|}{ Expected Payoff } \\
\cline { 2 - 5 } & $D_{C}$ & $D_{N C}$ & call $_{\mathrm{C}}$ & $\mu_{N C}$ \\
\hline Call & $\mu_{N C}$ & 0 & call $_{\mathrm{C}}+\mu_{N C}$ & 0 \\
\hline Put & 0 & $-\mu_{N C}$ & call $_{\mathrm{C}}+\left(\mu_{N C} / 2\right)$ & $\mu_{N C} / 2$ \\
\hline "Pay or Be Paid" & $\mu_{N C} / 2$ & $-\mu_{N C} / 2$ & 0 & call $_{\mathrm{C}}+\mu_{N C}$ \\
\hline "Pay or Pay" & $\mu_{N C}+\mathrm{call}_{\mathrm{C}}$ & $\mathrm{call}_{\mathrm{C}}$ & $\alpha\left(\mu_{N C}+\right.$ call $\left._{\mathrm{C}}\right)$ \\
\hline $\begin{array}{c}\text { Alpha } \\
\text { (for all 0 } \leq \alpha \leq 1)\end{array}$ & $\alpha\left(\mu_{N C}+\right.$ call $\left._{\mathrm{C}}\right)$ & $\alpha\left(\mu_{N C}+\right.$ call $\left._{\mathrm{C}}\right)-\mu_{N C}$ & $(1-\alpha)\left(\mu_{N C}+\mathrm{call}_{\mathrm{C}}\right)$ & $\alpha$ \\
\hline
\end{tabular}

We normally think of an option as requiring a monetary payment only if the option holder exercises the option. But when the puts and calls are described in terms of the amounts paid by the option holder contingent on either choice, it is possible to see a range of new single-chooser rules that induce the chooser to make identical allocations. 
DELEGATION AND DECOUPLING

For example, as shown in Table 4, by merely averaging the damages in the put and the call implementations we can create a new rule - which requires the chooser to pay (to the non-chooser) half the non-chooser's mean value if it allocates the entitlement to itself, but entitles the chooser to a payment (from the non-chooser) of half the non-chooser's mean value if it allocates the entitlement to the non-chooser. We refer to this implementation as a "Pay or be Paid" rule. This rule induces identical allocations as the put and the call rules. For example, instead of asking the plaintiff (under Spur-like application of Rule 4) whether she is willing to pay \$1 million to enjoin defendant's pollution, a "Pay or be Paid" rule might ask the plaintiff to elect whether she prefers to pay half a million dollars to stop pollution or receive half a million dollars from defendant to put up with continued pollution. In either case, the chooser will only allocate the entitlement to herself if its private value is greater than the non-chooser's mean value, because self-allocation requires the chooser to incur a direct cost of half the non-chooser's mean value and an opportunity cost of half the non-chooser's value. ${ }^{65}$ Indeed, any implementation with damages such that:

$$
D_{C}-D_{N C}=\mu_{N C}
$$

will produce an identical allocation.

It is possible to create allocations that produce even more lopsided distributions than either the put or the call implementations without undermining the chooser's incentive to make the efficient choice (i.e., reveal her private information). For example, Table 4 shows that by setting $D_{C}$ equal to $\mu_{N C}+$ call $_{\mathrm{C}}$ and setting $D_{N C}$ equal to call $\mathrm{C}$, a court could grant the chooser a zero expected

${ }^{65}$ Opportunity cost is "the price that you pay for things that you might have done." Ian Ayres, Analyzing Stock Lock-Ups: Do Target Treasury Sales Foreclose or Facilitate Takeover Auctions?, 90 ColuM. L. REV. 682, 688 n.19 (1990) (quoting Billy Joel, Only the Good Die Young (1977)). 


\section{DELEGATION AND DECOUPLING}

payoff - thus giving the entire expected total payoff to the non-chooser. ${ }^{66}$ We call this a "Pay or Pay" rule, because the chooser must pay the non-chooser regardless of whether she allocates the entitlement to herself or to the non-chooser-allocating to the non-chooser merely reduces the amount which the chooser needs to pay. For example, instead of asking a defendant (under Rule 2) whether it is willing to pay $\$ 1$ million for the right to pollute, a "Pay or Pay" rule might ask the polluter to elect between paying $\$ 1.2$ million for the right to pollute and paying $\$ .2$ million if it decides to forego polluting. As with the foregoing "Pay or be Paid" rule, the chooser (absent wealth and framing effects $)^{67}$ will under either rule only allocate the entitlement to itself if its private value is greater than the non-chooser's mean value.

The Put and the "Pay or Pay" implementations are of particular interest because they represent alternatives that would allow judges to retain the allocative efficiency of a single-chooser rule and still allocate all of the expected value to one litigant. The put implementation gives all of the total expected payoff to the chooser, while the "Pay or Pay" gives all of the total expected payoff to the non-chooser. ${ }^{68}$ In the absence of bargaining, the property rules (Rules 1 and 3) also allocate all of the payoffs to one litigant or the other, ${ }^{69}$ but the distributionally extreme liability rules (the Put

${ }^{66}$ To verify this result, just consider the non-chooser's expected payoff. If the chooser allocates the entitlement to itself, the non-chooser receives $\left(\mu_{N C}+c^{2} a l_{C}\right)$ with certainty; and if the

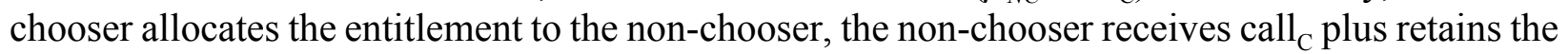
entitlement which on average it values at $\mu_{N C}$.

${ }^{67}$ See infra at 82 .

${ }^{68}$ Even more lopsided distributions are possible, if the court shifted the $D_{C}$ and $D_{N C}$ damages amount up above the "Pay or Pay" or down below the Put amounts.

${ }^{69}$ See Ayres \& Talley, supra note 9, at 1062-65, \& Rose, supra note 9, at 2178-79. 
$\underline{\text { DELEGATION AND DECOUPLING }}$

and "Pay or Pay" implementations) systematically dominate their property rule counterparts because they produce larger expected total payoffs.

By creating convex combinations of these damages under two rules, we can allow a court to adopt any intermediate division of the expected total payoff. As shown in Table 4 (in the row labeled "Alpha"), by setting

$$
\begin{gathered}
D_{C}=\alpha\left(\mu_{N C}+\text { call }_{\mathrm{C}}\right), \text { and } \\
D_{N C}=\alpha\left(\mu_{N C}+\operatorname{call}_{\mathrm{C}}\right)-\mu_{N C},
\end{gathered}
$$

the court effectively distributes a fraction $\alpha$ of the expected total payoff to the non-chooser (and the remaining fraction $(1-\alpha)$ to the chooser). Thus, by choosing the number $\alpha$ between zero and one, this "alpha" implementation gives the court unfettered flexibility in dividing the pie between the litigants without undermining the chooser's incentives to maximize the pie's size. For example, by setting $\alpha$ equal to 0.9 , the court could can effectively distribute $90 \%$ of the expected total payoff to the non-chooser (and only 10\% to the chooser) without affecting the chooser's incentive to allocate the entitlement to the litigant with the higher valuation. This alpha class includes both Pay-or-bePaid rules (when $\alpha$ takes on low values) as well as Pay-or-Pay rules (when $\alpha$ is sufficiently high).

It will have no doubt occurred to the reader that these new-fangled (Pay-or-be-Paid and Payor-Pay) distributive rules are identical to rules in which the court simply implements a traditional call option rule — but in addition requires a lump sum payment between the litigants regardless of what allocation the chooser made. Under this alternative, the court would set two prices -- an allocative price (say, $\mathrm{D}_{\mathrm{A}}$ ) which would determine the amount the chooser would pay if it allocated the entitlement to itself and a distributive price $\left(\right.$ say, $\left.D_{D}\right)$ which would determine the amount the chooser 
DELEGATION AND DECOUPLING

would pay (or be paid if $\mathrm{D}_{\mathrm{D}}$ was negative) regardless of the allocative choice. While these alternative implementations are mathematically equivalent, we conjecture that netting the allocative and distribute prices together into for example a "Pay or be Paid" rule will be less jarring to judges then carving out and naming an explicitly separate distributive lump sum amount. ${ }^{70}$ Indeed, even readers who caught on to this lump sum alternative may not have seen that the put option rules that we discussed in the introduction are mathematically nothing more than call option rules in which $D_{D}$ is set equal to $-\mu_{N C}{ }^{71}$ The very novelty of the put-option implementations suggest that the foregoing distributive analysis has not always been obvious to legal scholars. Indeed, one of the payoffs of this article is to show that put option rules are not esoterica but merely implementations of call option rules with a lump sum side payment.

In the past, courts may have been tempted to accommodate distributive considerations by raising the simple exercise price of the traditional call. This might be accomplished, for example,

\footnotetext{
${ }^{70} \mathrm{Law}$ and economic scholars have analyzed reasons decoupling the amount the defendant pays from the amount that the plaintiff receives. See A. Mitchell Polinsky and Yeon-Koo Che, Decoupling liability: optimal incentives for care and litigation, 22 RAND J Econ 562 (1991). But this type of decoupling analyzed in this article is different because the side payments of the litigants always net to zero.

${ }^{71}$ Rule 6, for example, is a put option rule which gives the plaintiff both the initial entitlement and the option to put the entitlement to the defendant at a price equal to defendant's mean valuation. But the same allocation and distribution could be implemented by a Spur-like Rule 4 (which gives the initial entitlement to the defendant but gives the plaintiff a call option to buy at the defendant's mean valuation) if in addition the court also ordered the defendant to pay her mean valuation to the plaintiff regardless of the plaintiff's choice $\left(\mathrm{D}_{\mathrm{D}}=-\mu_{N C}\right)$. Under the call implementation with the lump-sum mean side payment, the plaintiff would end up with (i) the entitlement and no net dollar transfer if she allocates the entitlement to herself and (ii) a net dollar transfer equaling the defendant's mean value, if she allocates the entitlement to the defendant. This is, of course, the same outcome as under the put implementation.
} 


\section{DELEGATION AND DECOUPLING}

by requiring Atlantic Cement to pay more than the residents' expected value (as a condition for acquiring a pollution right) if for some reason the court felt that the residents deserved a higher expected payoff. ${ }^{72}$ But the foregoing analysis shows that such an award would needlessly sacrifice allocative efficiency (by inducing Atlantic Cement to take too infrequently) on the alter of equity. In this example, a better way to increase the residents' payoff would be to institute a Pay-or-Pay rule - which would simultaneously increase the amount that Atlantic Cement would pay even if it chose not to pollute $\left(D_{N C}\right)$ and increase the price it must pay if it chose to pollute $\left(D_{C}\right)$. More generally, we have shown that it is misguided for courts to deviate from setting damages at the nonchooser's mean valuation as a way to improve distributive equity.

None of these implementations — including the infinity of alpha implementations - affect the variance of expected payoff for either the chooser or the non-chooser. Accordingly, a court's decision to select a chooser on the basis of the litigants' relative risk aversion would not be affected by the adoption of any of the different distribution implementations within a particular class of single-chooser rules. A court's selection of the more efficient chooser-whether it be motivated by considerations of numerosity, variance or risk aversion - is independent of the court's distributive choice.

This convexity result allows lawmakers to decouple distributive concerns from concerns about ex post allocative efficiency, and thus frees courts to divide the expected total payoff in order to further either equity or to generate better ex ante investment incentives. From an equity

${ }^{72}$ At some point, however, an additional increase in the exercise price of the defendant's call would not increase the plaintiff's expected payoff. 


\section{DELEGATION AND DECOUPLING}

perspective, courts might, for example, fine tune the extent to which a plaintiff's coming-to-anuisance claim should be awarded a particular expected payoff. And the option perspective makes clear that the court has more than the mean value of the higher valuing party to distribute. Singlechooser rules produce an expected total payoff that systematically exceeds the expected value of either party - and a court concerned as a matter of equity in how the expected total payoff is distributed can now make a more explicit decision about which litigant has a stronger equitable claim to this option value.

From an efficiency perspective, the way that the court divides the expected total payoff of the single-chooser rules can have important effects on the parties' ex ante investment incentives. If lawmakers think that it is particularly important to give the Resident an incentive to invest in her land, then giving the Resident the initial entitlement plus a put (thereby distributing all of the expected total payoff to her) will give her a much stronger incentive to invest than merely giving her a call. ${ }^{73}$ Thus, expanding the class of plaintiff-chooser and defendant-chooser rules not only allows lawmakers to better accommodate competing equity and efficiency concerns, but can also help lawmakers better accommodate competing efficiency concerns - that is, the concern with ex ante investment efficiency and the concern with ex post allocative efficiency.

While we have shown in our simple model that the courts distributive choice need not affect the chooser's allocative decision making, there is a sense in which the distributive rules may affect the non-chooser's decision making. In some litigation contexts, the non-chooser may take an initial action that triggers the chooser's subsequent (put or call) option. For example, the next section will

\footnotetext{
${ }^{73}$ See Ayres \& Balkin, supra note 9, at 733; Ayres, supra note 9, at 807.
} 


\section{DELEGATION AND DECOUPLING}

show that a common law put rule can be seen as a two-stage process whereby the defendant, by intentionally taking in the first stage, signals its willingness to be subjected to the plaintiff's subsequent put option. Such two-stage liability regimes are examples of what we call dual-chooser rules because both litigants have an impact on the potential ultimate allocation. The goal of the next section is to analyze what damages maximize the allocative efficiency of such rules, and to assess the conditions under which dual-chooser rules dominate (or are dominated by) single-chooser rules.

\section{DuAl-ChOOSER Rules}

As mentioned in the introduction, there are two more foundational allocative equilibria that judges might choose in resolving disputes. We refer to the legal regimes that give rise to these allocations as "dual chooser" rules as opposed to "single chooser" rules because both litigants have a potential impact on how the entitlement is allocated. As with the single-chooser rules, there turn out to be two dual-chooser allocations. In what we call the "defendant-joint-veto" allocation either litigant can veto the allocation of the entitlement to the defendant. If either the plaintiff or the defendant prefers that the entitlement be allocated to the plaintiff (with the associated courtdetermined side-payment), then the plaintiff receives the entitlement. Because both litigants must agree to a defendant allocation, but either litigant is sufficient to ensure a plaintiff allocation, the defendant-joint-veto equilibrium disproportionately allocates the entitlement to the plaintiff. This pro-plaintiff allocation bias can be observed in Panel (c) of earlier Figure 1, where three out of four quadrants are allocated to the plaintiff.

The plaintiff-joint-veto rule conversely allocates the entitlement to the defendant unless both plaintiff and defendant choose to allocate the good to the plaintiff (along with the associated court- 


\section{DELEGATION AND DECOUPLING}

determined side-payment). Because either litigant can veto a plaintiff allocation, this type of rule disproportionately allocates the entitlement to the defendant (see Panel (d) of Figure 1).

All four of these basic allocations - the two single-chooser allocations and the two dualchooser allocations - are the product of what we label "single price" rules. In all the rules that give rise to these allocations, the court sets a single allocative price ${ }^{74}$ and the identity of the chooser or choosers, and then the court sits back and lets the chooser(s) allocate the entitlement.

There are a number of different option interpretations that give rise to these dual-chooser allocations. Here we examine two rules that implement the defendant-joint-veto allocation, but analogous rules that implement the plaintiff-joint-veto allocation can be created by transposing the identity of the plaintiff and defendants in the division of assets and liabilities. Consider the following two divisions of entitlements:
(A)

$$
\Pi: \quad E+\operatorname{put}\left(D_{\Delta J V}\right)-\operatorname{put}\left(D_{\Delta J V}\right)
$$$$
\Delta: \quad-\operatorname{put}\left(D_{\Delta J V}\right)+\operatorname{put}\left(D_{\Delta J V}\right)
$$
(B) $\quad \Pi: \quad \operatorname{call}\left(D_{\Delta J V}\right)-\operatorname{put}\left(D_{\Delta J V}\right)$
$\Delta: \quad E-\operatorname{call}\left(D_{\Delta J V}\right)+\operatorname{put}\left(D_{\Delta J V}\right) \quad$.

In the first ("put-put") regime (A), the plaintiff is given the initial entitlement plus a put option to sell the entitlement to the defendant (and receive a price of $\$ D_{\triangle J V}$ ), but is subject to the defendant's put option, which gives the defendant the option of selling the entitlement back to plaintiff also for $\$ D_{\Delta J V}$. This rules allows either litigant to veto the transfer of the entitlement to the defendant. The plaintiff can veto the transfer of the entitlement by refusing to exercise its initial put,

${ }^{74}$ There is a sense, of course, in which the court in setting both $D_{C}$ and $D_{N C}$ is setting two prices. But from an option perspective there is only one relevant allocative price and that is the difference between these amounts $\left(D_{C}-D_{N C}\right)$. As discussed above, the decoupling of allocative and distributive concerns can alternatively be implemented by the court explicitly seting a single allocative price $\left(D_{A}\right)$ and a single distributive price $\left(D_{D}\right)$. See supra at 41 . 
and even if this put is exercised the defendant can veto the transfer by putting the entitlement back to the plaintiff. The equilibrium choices (strategies) that this rule induces are easy to derive. The plaintiff will only put the entitlement if:

$$
v_{\Pi}<D_{\Delta J V},
$$

and the defendant will only put the entitlement back if:

$$
v_{\Delta}<D_{\Delta J V}
$$

Together this means (as illustrated in panel (c) of Figure 1) that in equilibrium, defendant will be allocated the entitlement if and only if:

$$
v_{\Pi}<D_{\Delta J V}<v_{\Delta \cdot}{ }^{75}
$$

Alternatively, under the second regime (B), the plaintiff is given a call option to buy the entitlement (which is initially allocated to the defendant), but is simultaneously subject to defendant's put option to sell. This rule allows either litigant to force a transfer of the entitlement from the defendant to the plaintiff (in return for a payment of $\$ D_{\Delta J V}$ from plaintiff to defendant). As with regime (A), the defendant will retain the entitlement if and only if:

$$
v_{\Pi}<D_{\Delta J V}<v_{\Delta}
$$

${ }^{75}$ Another option scheme that would allow either party to veto a transfer of the entitlement to the defendant could be implemented by:

$$
\Pi: \quad \mathrm{E}-\operatorname{call}\left(D_{\Delta J V}\right)+\operatorname{call}\left(D_{\Delta J V}\right) \quad \Delta: \quad+\operatorname{call}\left(D_{\Delta J V}\right)-\operatorname{call}\left(D_{\Delta J V}\right) .
$$

In the text's double put rule, the plaintiff in a sense can offer to sell the entitlement for $\$ D_{\Delta J V}$ by initially putting, and the defendant can accept this offer by choosing not to put the entitlement back. In contrast, this footnote's double call rule allows the defendant to figuratively offer to buy the entitlement by exercising its initial call option, and the plaintiff can accept this offer by choosing not to call the entitlement back. 


\section{DELEGATION AND DECOUPLING}

This assures that the allocations of these two rules will be identical for any possible private valuations of the plaintiff and defendant. But as with the single-chooser rules, these different implementations of the defendant-joint-veto allocation produce very different distributions. By inspecting the initial entitlement division, it is apparent that the plaintiff's expected payoff is higher if it is initially allocated its entitlement (and is compensated for its transfer) than if the plaintiff is not initially allocated the entitlement (and can only gain it by paying a court-determined amount). ${ }^{76}$

These dual-chooser rules at first blush seem esoteric and other worldly, but as intimated at the end of the last section, several common law settings provide at least the potential for jointchooser allocations. For example, if Laurel intentionally encroaches on Hardy's land, Hardy traditionally has (in addition to damages for the prior encroachment) the choice of ejectment (an injunction forcing Laurel to remove the encroachment) or permanent damages (forcing Laurel to permanently purchase ${ }^{77}$ the encroaching property at a court-determined amount). ${ }^{78}$ Instead of beginning the analysis with Hardy's allocative choice (of taking back the land or forcing a sale to Laurel), it may be more useful — at least with regard to deliberate encroachment — to think of the law

\footnotetext{
${ }^{76}$ The option interpretation of these dual-chooser rules makes clear that they are constrained versions of what one of us has previously referred to as "second-order rules," see Ayres \& Balkin, supra note 9. The dual-chooser rules constrain the exercise price of the first and second options to be the same (\$D). Part III of this paper analyzes and compares the unconstrained analog to dualchooser rules.

${ }^{77}$ An encroacher may thus be forced to compensate the landowner not just for the temporary (past) encroachment, but to purchase a "permenant" right to encroach on the land (even if the encroacher would prefer to remove the encroachment).

${ }^{78}$ See Pile v. Pedrick, 31 A. 646, 647 (1895) (after finding that defendant's brick wall encroached 1 and 3/8th inches underneath the plaintiff's property, the court granted plaintiff the choice of damages for "permanent tresspass" or an injunction to remove the "offending ends of the stones").
} 


\section{DELEGATION AND DECOUPLING}

as implementing a dual-chooser rule. The encroacher signals his willingness to buy at a courtdetermined price by intentionally encroaching and the plaintiff indicates his willingness to sell at this same price by electing damages instead of ejectment. More generally, in property law, the temporary taking (or impairment) of someone else's right often has the effect of triggering a put option. ${ }^{79}$ When a deliberate taking (with the prospect of paying compensatory damages) is followed by a plaintiff's choice between compensation and restoration of the entitlement, these dual choices of the litigants implement a defendant-joint-veto allocation — in that the entitlement will only be allocated to the defendant if the defendant's private value is higher than the expected court-awarded damages and if the plaintiff's private value is less than expected court-awarded damages.

Indeed, under current law it may be difficult for courts to implement true plaintiff-choice rules-i.e., single-chooser rules that do not effectively include an element of defendant choice. Plaintiffs are traditionally given a put option only after a defendant temporally impairs their initial entitlements. An intentional taking by the defendant converts such single-chooser put options into dual-chooser allocations. Only if the defendant unintentionally takes (as in some encroachment examples) or if the plaintiff comes to a pre-existing nuisance might we have a circumstance in which a true plaintiff-choice allocation is produced. ${ }^{80}$ But our motivation for studying dual-chooser

${ }^{79}$ Accordingly, a similar two-stage analysis might be applied to (i) the tenant's choice to hold over followed by the landlord's choice to force an additional term lease, see JESSE DUKEMINIER \& JAMES E. KRIER, PROPERTY 431 (3d. ed. 1993); RESTATEMENT (SECOND) OF PROPERTy $§ 14.4$ cmt. F (1977), or (ii) the intentional taking of chattel followed by the owner's choice of trover (i.e., compensatory damages) or replevin (i.e., an injunction ordering chattel's return). See DUKEMINIER \& KRIER, supra, at 105.

${ }^{80}$ In contrast, it is usually possible to implement single chooser rules in which the defendant has the sole allocative choice. For example, the defendant's choice both to commence pollution and 
DELEGATION AND DECOUPLING

allocations is not based solely on their current common law existence-rather, we intend to show that dual-chooser rules at times are more allocatively efficient than single-chooser rules and should accordingly be added more consciously to policymakers' toolkits.

\section{A. Selecting Optimal Damages}

In the appendix, we show that the damages that maximize allocative efficiency of a defendant-joint-veto allocation are those $D_{\Delta J V}$ such that:

$$
\mathrm{f}_{\Pi}\left(\mathrm{v}_{\Pi}=D_{\Delta J V}\right) \mathrm{E}\left[\mathrm{v}_{\Delta}-D_{\Delta J V} \mid \mathrm{v}_{\Delta}>D_{\Delta J V}\right]=\mathrm{f}_{\Delta}\left(\mathrm{v}_{\Delta}=D_{\Delta J V}\right) \mathrm{E}\left[D_{\Delta J V}-\mathrm{v}_{\Pi} \mid D_{\Delta J V}>\mathrm{v}_{\Pi}\right],
$$

remembering that $\mathrm{v}_{\Pi}$ and $\mathrm{v}_{\Delta}$ represent the plaintiff's and defendant's respective valuation, $\mathrm{f}_{\Pi}\left(\mathrm{v}_{\Pi}\right)$ and $\mathrm{f}_{\Delta}\left(\mathrm{v}_{\Delta}\right)$ represent the plaintiff's and defendant's respective probability distribution of these valuations and $E$ represents an expectations operator. ${ }^{81}$ While this optimization equation (what economists call a "first-order condition") initially seems forbidding, it has a straightforward intuition. By setting damages, the court is simultaneously determining two allocative margins: the margin on which the plaintiff will veto allocations of the entitlement to the defendant, and the margin on which the

to exercise its call option amount to a unitary decision to take the entitlement and pay damages. Of course, plaintiffs often make deliberate choices about whether to produce the entitlement in the first place -- so the plaintiff's initial investment decision may introduce elements of plaintiff choice into what otherwise would be a defendant chooser rule.

There may, however, also be some limits on the ability of courts to vary how the payoff is distributed. If polluting potentially exposes the polluter to a "Pay or Pay" allocation, then a polluter who will ultimately choose not to allocate the entitlement to itself will prefer not to pollute in the first place. See Levmore, supra note 9, at 2168-70 (discussing impact of expected damages on litigants' initial incentive to pollute or bring suit).

${ }^{81}$ See infra Appendix at 111. Solving an analogous implicit formula for $D$ yields the optimal damages for the plaintiff-joint-veto allocation:

$$
\mathrm{f}_{\Pi}\left(\mathrm{v}_{\Pi}=D_{\Delta J V}\right) \mathrm{E}\left[D_{\Pi J V}-\mathrm{v}_{\Delta} \mid D_{\Pi J V}>\mathrm{v}_{\Delta}\right]=\mathrm{f}_{\Delta}\left(\mathrm{v}_{\Delta}=D_{\Pi J V}\right) \mathrm{E}\left[\mathrm{v}_{\Pi}-D_{J I V} \mid \mathrm{v}_{\Pi}>D_{\Pi J V}\right] .
$$




\section{DELEGATION AND DECOUPLING}

defendant will veto allocations of the entitlement to the defendant. The court's task is to find the single damage amount that optimally trades-off these two veto effects. The damage amount that solves the foregoing equation accomplishes precisely this task.

A small increase in the size of $D_{\Delta J V}-$ say from $D^{\prime}$ to $D^{\prime \prime}$ - has the simultaneous effect of (i) decreasing the plaintiff's willingness to veto defendant allocations, and (ii) increasing the defendant's willingness to veto defendant allocations. ${ }^{82}$ The marginal impact on allocative efficiency of decreasing the plaintiff's willingness to veto is given by the left-hand side of the optimization equation. It represents the changed likelihood that the plaintiff will veto $\left\{\mathrm{f}_{\Pi}\left(D_{\Delta J V}\right)\right\}$ multiplied by the expected change in allocative efficiency affected by the veto change $\left\{\mathrm{E}\left[\mathrm{v}_{\Delta}-D_{\Delta J V} \mid \mathrm{v}_{\Delta}>D_{\Delta J V}\right]\right\}$. The right-hand side of the equation analogously represents the marginal impact on allocative efficiency of increasing the defendant's willingness to veto defendant allocations. Solving the equation for $D_{\Delta J V}$ therefore yields the damage amount that equates the marginal improvements from decreasing the plaintiff's veto (increasing the plaintiff's willingness to allocate to the defendant) with the marginal reduction in allocative efficiency from increasing the defendant's veto (decreasing the defendant's willingness to allocate the entitlement to itself).

In practice, the optimal damage amount will often be a weighted average of the plaintiff's

${ }^{82}$ With higher damage amounts, the plaintiff is less likely to veto a defendant allocation because the plaintiff is willing to allocate the entitlement to the defendant so long as:

$$
v_{\Pi}<D_{\Delta J V}
$$

Higher damage amounts increase defendant's likelihood of vetoing defendant allocations because it makes it less likely that:

$$
D_{\Delta J V}<v_{\Delta}
$$




\section{DELEGATION AND DECOUPLING}

and the defendant's mean values. This makes some intuitive sense. Remember that the litigants' mean values are the optimal amounts when a single litigant can veto the allocation of the entitlement -- so it should not be surprising that the optimal joint veto amount will be some value in between the optimal damages of the two single-chooser rules. And while it outstrips the quality of the evidence (as well as judicial temperament and training) to ask judges to explicitly solve the foregoing equation for an optimal $D$, the idea that optimal defendant-joint-veto damages will often be close to the average of the litigants' mean valuations provides some pragmatic guidance in setting damages. ${ }^{83}$

However, it is possible to construct examples where the optimal dual-chooser damages do not lie between the mean valuations of the litigants. For example, if the court perceives that the plaintiff's valuation is uniformly distributed between $\$ 25$ and $\$ 75$, while the defendant's is uniformly distributed between $\$ 0$ and $\$ 100$, it can be shown that the optimal defendant-joint-veto damages equal $\$ 62.50$ — which is higher than the litigants' mean valuation of $\$ 50 .{ }^{84}$ The reason for this result is that the plaintiff is a systematically poorer chooser than the defendant. Because the variation in the plaintiff's valuation is smaller than in the defendant's valuation, the defendant's informational advantage (vis-à-vis the court) is greater than the plaintiff's. This means — harkening back to the last section - that a defendant single-chooser allocation would dominate a plaintiff

${ }^{83}$ See Ayres, supra note 9, at 827 (discussing possibility of "joint veto" regime with damages that "will approximately split the difference between the Resident's and the Polluter's mean valuations").

${ }^{84}$ Applying our earlier equation for determining optimal dual chooser damages, see supra at 50, to the particular uniform distributions in this example implies that optimal damages will solve the following equation:

$\frac{1}{50} \int_{D}^{100}\left(v_{\Delta}-D\right) \frac{1}{100} d v_{\Delta}=\frac{1}{100} \int_{25}^{D}\left(D-v_{\Pi}\right) \frac{1}{50} d v_{\Pi}$, which when solved yields $\mathrm{D}=\$ 62.50$. 


\section{DELEGATION AND DECOUPLING}

single-chooser allocation. But it also affects how a court will want to distribute the allocative power between the litigants in tailoring a dual-chooser rule. Increasing the damage amount (above both parties' means) when the plaintiff is a relatively poor chooser decreases the likelihood that the plaintiff will exercise its allocative power by vetoing a defendant allocation. It turns out that it is more efficient to cause the more efficient chooser (the defendant) to veto too many defendant allocations because doing so tends to limit the veto power of the less efficient chooser (the plaintiff). We will return to this example again when we compare the four basic allocative equilibria—because, as we will see, the same thing that causes dual-chooser damages to take on extreme, and seemingly counterintuitive, values also causes single-chooser rules to dominate dual-chooser rules.

\section{B. Selecting the Distribution}

Before comparing the relative allocative efficiency of the different rules, we pause here to reiterate that, as with the single-chooser rules, it is possible to proliferate the implementations of dual-chooser rules in ways that leave allocative efficiency unaffected, but which vary the expected relative payoffs of the individual litigants. Just as we distinguished between the price that the chooser would pay if she allocated the entitlement to herself $\left(D_{C}\right)$ and the price that the chooser would pay if she allocated the entitlement to the nonchooser $\left(D_{N C}\right)$, it is possible with regard to defendant-joint-veto allocation to distinguish between:

$D_{\text {No Veto }}=\quad$ the price the defendant pays the plaintiff if neither litigant vetoes the allocation of the entitlement to the defendant; and,

$D_{\text {Veto }}=\quad$ the price the defendant pays the plaintiff if one of the litigants vetoes so that the entitlement is allocated to the plaintiff.

If we label the damage amount that solves the foregoing optimization equation as $D_{\Delta J V}$, then a 


\section{DELEGATION AND DECOUPLING}

continuous variety of allocatively identical defendant-joint-veto rules can be created that take the form:

$$
D_{\text {No Veto }}-D_{\text {Veto }}=D_{\Delta J V} \text {. }
$$

For example, if the allocatively optimal damages equal $\$ 50$, then a dual-chooser rule that required the defendant to pay $\$ 25$ to the plaintiff when the entitlement is allocated to the defendant $\left(D_{\text {No Veto }}\right.$ $=\$ 25)$, and required the plaintiff to pay $\$ 25$ to the defendant when the entitlement is allocated to the plaintiff $\left(D_{\text {Veto }}=-\$ 25\right)$ would produce exactly the same allocative choices by the litigants as a simpler rule that required a payment of $\$ 50$ by the defendant if the parties jointly chose to allocate the entitlement to the defendant. In either case, the plaintiff would only choose to allocate the entitlement to the defendant if the plaintiff's value was less than $\$ 50$, and the defendant would only choose to allocate the entitlement to itself if its value was greater than $\$ 50$.

As before, a lock-step increase (or decrease) in $D_{\text {No Veto }}$ and $D_{\text {Veto }}$ does not affect the litigants' allocative choice and a fortiori the allocative efficiency, but instead has the effect of increasing (or decreasing) the proportion of the expected total payoff that will go on average to the plaintiff. Courts are free to distribute the total expected payoff between the litigants as they see fit. While computationally more difficult, courts could create a dual chooser analog to the earlier "alpha" single chooser rules which would allow them to give a fraction $\alpha$ of the expected joint payoffs to the plaintiff and a fraction $(1-\alpha)$ to the defendant. ${ }^{85}$

${ }^{85}$ For example, assume that $D_{\Delta J V}$ equals the optimal damages for the defendant-joint-veto allocation, see supra 50, and that under the straightforward "put-put" regime (discussed supra at 46, in which $D_{\text {No Veto }}=D_{\Delta J V}$ and $D_{\text {Veto }}=0$ ) the expected payoffs of the plaintiff and the defendant are respectively, $E P_{\Delta}$ and $E P_{\Pi I}$. Then it can be shown that an implementation that sets $D_{\text {NoVeto }}=D_{\Delta J V}$ $E P_{\Pi}$ and $D_{\text {Veto }}=-E P_{\Pi}$ would distribute all of the joint expected payoff to the defendant; and an 


\section{DELEGATION AND DECOUPLING}

\section{Selecting the Choosers}

An initial judicial task in selecting the allocatively efficient chooser is to determine which of the two dual-chooser allocations is the more efficient - the defendant-joint-veto rule or the plaintiff-joint-veto rule. Graphically, this comes down to a determination of whether the offdiagonal quadrants of Figure 2 are better allocated to the plaintiff or to the defendant. Both allocations generate identical allocations of the first quadrant (which is allocated to the defendant)

Figure 2

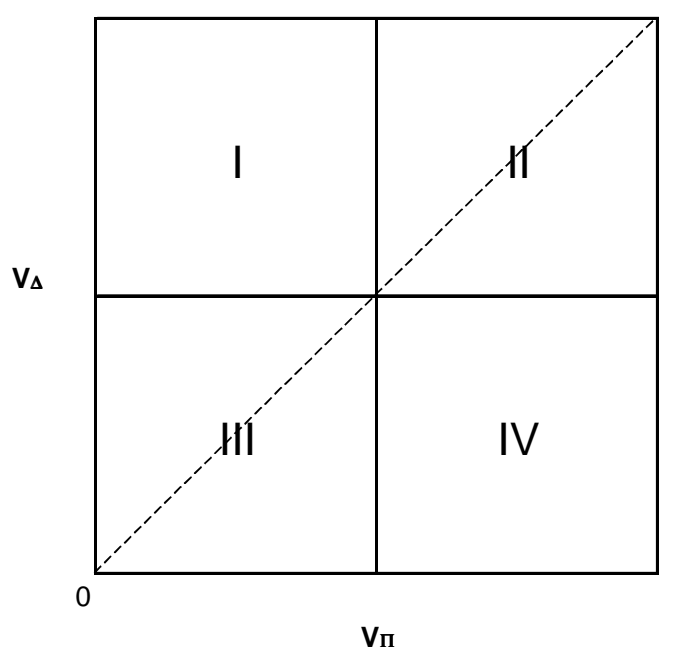

and the fourth quadrant (which is allocated to the plaintiff), but a defendant-joint-veto regime allocates the off-diagonal quadrants (II and III) to the plaintiff, while a plaintiff-joint-veto regime allocates the off-diagonal quadrants to the defendant. ${ }^{86}$

It turns out that the defendant-joint-veto equilibrium will tend to dominate the plaintiff-

joint-veto equilibrium when:

implementation that sets $D_{\text {NoVeto }}=D_{\Delta J V}+E P_{\Delta}$ and $D_{\text {Veto }}=E P_{\Delta}$ would distribute all of the joint expected payoff to the plaintiff. More generally, an implementation that sets $D_{\text {NoVeto }}=D_{\Delta J V}-\alpha E P_{\Pi}$ $+(1-\alpha) E P_{\Delta}$ and $D_{V e t o}=-\alpha E P_{\Pi}+(1-\alpha) E P_{\Delta}$ would distribute a fraction $\alpha$ of the joint expected payoff to the plaintiff and a fraction $(1-\alpha)$ to the defendant.

${ }^{86}$ Besides this "off diagonal" effect, the two types of dual-chooser rules can produce marginally different optimal damages, see supra note 70 and accompanying text, which might affect which equilibrium is more allocatively efficient. 


\section{DELEGATION AND DECOUPLING}

$$
\mu_{\Pi}>\mu_{\Delta \cdot}{ }^{87}
$$

For example, imagine that the defendant's valuation is uniformly distributed between $\$ 0$ and $\$ 100$, and that the plaintiff's valuation is uniformly distributed between $\$ 80$ and $\$ 180$. It can be shown that the optimal damages for either a defendant-joint-veto or a plaintiff-joint-veto rule are equal to $\$ 90$ (the average of the litigants' mean valuations). ${ }^{88}$ But, as shown in Figure 3, a defendant-jointveto rule is much more efficient than a plaintiff-joint-veto rule because the off-diagonal quadrants are more efficiently allocated to the plaintiff. The 45 -degree diagonal line represents the first-best (perfect information) allocation - and it is evident in the figure that much more of the probability mass in the off-diagonal quadrants lies below the first-best allocation line than above it. In other words, there is a greater probability that the plaintiff's valuation will be larger than the defendants' in these off-diagonal quadrants. This simple example gives intuitive support for the claim that the defendant-joint-veto allocation will tend to dominate the plaintiff-joint-veto equilibrium when the

${ }^{87}$ For example, it can be shown that when the litigants' valuations are uniformly distributed, that a higher plaintiff mean implies that defendant-joint-veto equilibrium will produce a higher expected joint payoff than the plaintiff-joint-veto equilibrium.

${ }^{88}$ Applying our earlier equation for determining optimal dual chooser damages, see supra at 50 , to the particular uniform distributions in this example implies that optimal damages will solve the following equation:

$\frac{1}{100} \int_{D}^{100}\left(v_{\Delta}-D\right) \frac{1}{100} d v_{\Delta}=\frac{1}{100} \int_{80}^{D}\left(D-v_{\Pi}\right) \frac{1}{50} d v_{\Pi}$, which when solved yields $\mathrm{D}=\$ 90.00$. 
DELEGATION AND DECOUPLING

Fiqure 3

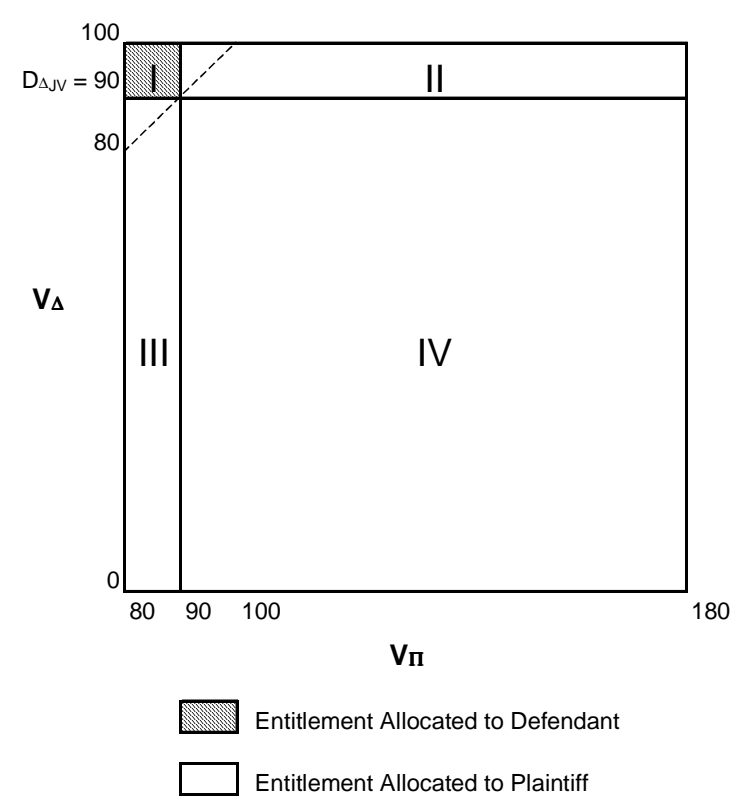

plaintiff's mean is higher than the defendant's. The converse also tends to be true (when the defendant's mean exceeds the plaintiff's).

Appreciating the theoretical and practical possibility of dual-chooser rules in the law resuscitates the Restatement's focus on the parties' relative valuations. Although the relative size of the litigants'

mean valuations is not of primary importance in choosing between the two single-chooser allocations, it is relevant not only to the choice between dual-chooser allocations, but also (as we are about to see) to a choice between dual- and single-chooser allocations themselves.

\section{Selecting Among the Four Foundational Single-price Allocations}

To summarize our results thus far, we have shown that there are four basic allocative equilibria - two single-chooser and two dual-chooser allocations. We have derived the optimal damages for each, and shown that courts can divide the expected total payoff between the litigants as it wishes, without affecting the allocative efficiency of any of the four classes of rules. Finally, as to selecting the optimal chooser or choosers, we have shown that:

(1) as between the two single-chooser rules, the litigant whose valuation has the higher variance will tend to be the better single-chooser, and

(2) as between the two dual-chooser rules, courts should tend to allow either party to veto allocations to the party with the lower mean. 
These last two results can be restated more mathematically as follows:

(1') when $\sigma_{\Pi}>\sigma_{\Delta}, \quad \mathrm{E}[\mathrm{TP}]_{\Pi}>\mathrm{E}[\mathrm{TP}]_{\Delta}$, and

(2') when $\mu_{\Pi}>\mu_{\Delta}, \quad \mathrm{E}[\mathrm{TP}]_{\Delta J V}>\mathrm{E}[\mathrm{TP}]_{\Pi J V}$,

where $\mathrm{E}[\mathrm{TP}]$ represents the expected total payoff, and the subscripts $\Pi, \Delta, \Delta J V$, and $\Pi J V$ refer respectively to the plaintiff-choice, defendant-choice, defendant-joint-veto and plaintiff-joint-veto allocations. In what follows we will refer to the first result as the "different variance" effect, and to the second result as the "different mean" effect.

Our final task is to try to identify which of the four rules is likely (for particular distributions of litigant value) to maximize allocative efficiency. In other words, we need to assess when the better single-chooser rule dominates (or is dominated by) the better dual-chooser rule. As an initial matter, there are many circumstances in which the four basic equilibria will be allocatively equivalent. For example, if the litigants have identical and symmetric probability distributions of valuations, then the four classes of rules will generate identical damages and identical expected total payoffs. Under such circumstances allocating the off-diagonal quadrants to either litigant will be equally efficient — so the four different permutations of quadrant allocations generated by the four basic allocations will be equivalent.

But it turns out for more general probability distributions that the dual-chooser rules are sometimes better than, and at other times inferior to, single-chooser rules. Two heads can be better than one; but sometimes one head — that is, a single allocative chooser - can be better than two.

The optimal allocative rule will turn on the relative size of the "different mean" and "different variance" effects discussed above. When the difference in the litigants' means is large 


\section{DELEGATION AND DECOUPLING}

relative to the difference in the litigants' variances, the dual-chooser rule that allows either party to veto an allocation to the litigant with the lower mean will tend to dominate the other three basic allocations. In contrast, when the difference in the litigants' variances is large relative to the difference in the litigants' means, then the single-chooser rule which allows the higher variance litigant to allocate the entitlement will tend to allocatively dominate the other three basic allocations. $^{89}$

Put more intuitively, two choosers will tend to be better than one when the litigants have relatively different means but relatively similar variances. A sufficiently wide divergence in the litigants' means undermines the importance of a single-chooser rule because no single-chooser has sufficient information to make a nuanced allocation. By a "nuanced allocation," we mean nothing more than an equilibrium in which the chooser makes more refined decisions about who will be allocated the entitlement -- and at times allocates the entitlement to each litigant. As the differentmean effect comes to dominate the different-variance effect, single choosers will tend to make "unnuanced" decisions -- allocating the entitlement $100 \%$ of the time to a particular litigant. Under such conditions, a dual-chooser rule can increase allocative efficiency because the litigants' combined choices can identify circumstances when allocations to the litigant disfavored by single-chooser rules are nonetheless efficient.

${ }^{89}$ For example, for uncorrelated, uniform distributions it can be shown that when there is no mean difference but only a variance difference, the better single-chooser rule dominates the better dual-chooser rule and hence the better single-chooser rule is globally optimal (within the class of single-price liability rules). Conversely, when there is no variance difference, but only a mean difference, it can be shown that the better dual-chooser rule dominates the better single-chooser rule and hence the better dual-chooser rule is globally optimal. 
DELEGATION AND DECOUPLING

For example, consider again a defendant whose value is uniformly distributed between $\$ 0$ and $\$ 100$ and a plaintiff whose value is uniformly distributed between $\$ 80$ and $\$ 180$ (see Figure 3). Notice that the example is intentionally constructed so that the different-mean effect will dominate the different-variance effect — the variances of the litigants' values are equal $\left(\sigma_{I I}^{2}=\sigma_{4}^{2}=\$ 833.33\right)$, but their means are different $\left(\mu_{\Pi}=\$ 130>\mu_{\Delta}=\$ 50\right)$. Our prior analysis shows that the equality of variances will tend to make the plaintiff-choice rule allocatively equivalent to the defendant-choice rule. And the inequality in means tends to favor the defendant-joint-veto rule over the plaintiff-jointveto rule. ${ }^{90}$ But what still needs to be determined is whether the defendant-joint-veto rule dominates either of the equivalent single-chooser rules.

As suggested above, it does, and here's why. Either of the single-chooser rules produces a un-nuanced equilibrium -- allocating the entitlement exclusively to the plaintiff. If the plaintiff is the chooser and damages are set at the defendant's (i.e., the non-chooser's) mean of $\$ 50$, then the plaintiff will always allocate the entitlement to itself. ${ }^{91}$ And if the defendant is the chooser and damages are set at the plaintiff's mean value of $\$ 130$, then the defendant will never allocate the entitlement to itself. ${ }^{92}$ When the difference in means becomes sufficiently large, neither chooser has

${ }^{90}$ The example can also be easily converted to show how a plaintiff-joint-veto rule can dominate any of the other three foundational allocations by simply reversing the identity of the plaintiff and defendant probability distributions - so that the plaintiff's value would be distributed uniformly between $\$ 0$ and $\$ 100$, and the defendant's value between $\$ 80$ and $\$ 180$.

${ }^{91}$ This is because the plaintiff's valuation ranges from $\$ 80$ to $\$ 180$ and thus will always exceed the $\$ 50$ damage amount it would receive if it allocated the entitlement to the defendant.

${ }^{92}$ This is because the defendant's valuation ranges from $\$ 0$ to $\$ 100$ and thus the $\$ 130$ damage amount it would have to pay if it chose to allocate the entitlment to the plaintiff would always exceed the defendant's valuation. 


\section{DELEGATION AND DECOUPLING}

sufficient information to make a nuanced allocation.

But a dual-chooser rule improves allocative efficiency because the joint choice of the litigants allows the entitlement to go to the defendant when this allocation is more efficient. The dualchooser rule allows the low mean litigant (here, the defendant) to end up with the entitlement when she actually has an unusually high value and when the high mean litigant (the plaintiff) has an unusually low value. As discussed above, ${ }^{93}$ the optimal dual-chooser damages for this example equal $\$ 90$. With a single-chooser rule, it would be inefficient to allow either the defendant or the plaintiff as a single chooser to confront a damage amount of $\$ 90$, because such an amount would cause the single chooser to inefficiently allocate the entitlement to the defendant too often. But the defendantjoint-veto rule can effectively use $\$ 90$ damages because under this rule the defendant will only be allocated the entitlement when the defendant's value exceeds $\$ 90$ and when the plaintiff's value falls short of $\$ 90$. This more nuanced equilibrium is depicted in Figure 3. Giving both litigants a say in the ultimate allocation increases the expected total payoff..$^{94}$

The dominance of the dual chooser rules when there is a large difference in the court's estimate of the litigants' mean valuations resolves an embarrassing disconnect between the previous analysis of liability rules and cases like Boomer, where the defendant's value of pollution was

\footnotetext{
${ }^{93}$ See supra note 88 and accompanying text.
}

${ }^{94}$ Expected joint profits under a defendant-joint-veto allocation are equal to $\$ 130.10$ (compared to the single-chooser analog of \$130.00) When the single-chooser rules allocate the entitlement exclusively to one litigant, the dual-chooser rules can never produce a lower expected total payoff, because dual-chooser damages can be set so as to always produce an unnuanced equilibrium. For example, if the defendant-joint-veto damages were set at $\$ 130$, then the defendant would always veto allocating the entitlement to itself. 
DELEGATION AND DECOUPLING

estimated by the court to be much greater than the residents' value of non-pollution. ${ }^{95}$ Simple singlechooser rules of either the call or put varieties (Rules 2, 4, 5 and 6) are allocatively embarrassing, because setting the damages equal to the non-chooser's mean would produce un-nuanced equilibria that are allocatively indistinguishable from simply giving the polluter a property rule interest in the entitlement (Rule 3). A Boomer-like resident confronting an allocative price set equal to the polluter's high mean value would never allocate the entitlement to her self, and an Atlantic Cementlike polluter confronting an allocative price set equal to the resident's low mean value would never fail to allocate the entitlement to itself. When the litigants' means vary greatly, single chooser rules are allocatively a non-event. ${ }^{96}$ In contrast, the dual chooser rules intentionally seek out a damage amount in between the litigant's mean valuations -- where the litigant's probability distributions overlap -- so as to produce more efficient nuanced equilibria. Unlike with single chooser rules, the

${ }^{95}$ See Boomer v. Atlantic Cement Co., 257 N.E.2d 870, 875 (N.Y. 1970). Whalen v. Union Bag \& Paper Co., 101 N.E. 805 (N.Y. 1913), provides an extreme example of some courts' willingness to issue injunctions where the cost to the defendant far exceeds the plaintiff's benefit. In the Union Bag case (discussed later in Boomer, 257 N.E.2d at 872) the plaintiff's harm was assessed at $\$ 100$ per year while the cost of complying with the injunction was the permanent closing of a mill representing an investment of more than $\$ 1,000,000$. See 101 N.E. at 805 . The New York Court of Appeals concluded: "Although the damage to the plaintiff may be slight as compared with the defendant's expense of abating the condition, that is not a good reason for refusing an injunction." Id. at 806. See Ian Ayres \& Kristin Madison, Threatening Inefficient Performance of Injunctions and Contracts, 148 University of PenNsylvania Law Review 45 (1999).

${ }^{96}$ The single chooser rules can also be distributively embarrassing when there is a great disparity in the litigants' mean valuations. Such rules can force the policy makers at times to confront unpalatable divisions. For example, if a court decided that the residents in Boomer were the more efficient choosers, it would have to choose between a call rule which might force resident's to pay a large sum to stop the pollution and a put rule which might force the polluter to disgorge all of its expected profits from polluting. Our foregoing convexity result, however, resolves the distributive embarrassment under either the single- or dual-chooser implementations. 
DELEGATION AND DECOUPLING

court is not forced to set damages at either the plaintiff's or the defendant's divergent mean values. ${ }^{97}$

Dual-chooser rules, however, are not always preferable. When the litigants have relatively different variances but similar means, it will instead be allocatively optimal for the court to implement a single-chooser rule - granting the allocative choice to the chooser with the larger variance. The intuition here is that one head can be better than two when one of the heads is relatively ignorant. When there is a large difference in the litigants' value variances, it may be better to exclude the low variance litigant from having any influence on the ultimate allocation. A litigant with a relatively small variance has very little of an informational advantage over the court or her adversary. When the different variance effect dominates the different mean effect, it is better to have a single chooser than to allow a second litigant with very little private information to muck up the allocation.

Michael Heller in recent writing on the "anti-commons" has persuasively argued that there is an efficient number of vetoers to the deployment of entitlements. ${ }^{98}$ The traditional commons problem is when the number of potential vetoers is too small—no one can veto the deployment of the entitlement. But an analogous anti-commons problem exists when there are too many vetoers who can block the deployment of an entitlement. Heller's favorite examples concern modern Russia, where an entrepreneur may need the approval of dozens of organizations before being able to open

${ }^{97}$ Of course, if the divergence in means is too large (or more particularly, if there is no overlap in the litigants' probability functions), then a more nuanced equilibrium is neither feasible (nor desirable) even under the dual chooser rules.

${ }^{98}$ See Michael A. Heller, The Tragedy of the Anticommons: Property in the Transition from Marx to Markets, 111 HARV. L. REV. 621 (1998). 


\section{DELEGATION AND DECOUPLING}

a business. ${ }^{99}$ Our finding that single-chooser rules can dominate dual-chooser (joint veto) rules suggests that the anti-commons inefficiency can kick-in even when the number of vetoers is just two.

To see this possibility in a concrete example, consider again a defendant whose value is uniformly distributed between $\$ 0$ and $\$ 100$ and a plaintiff whose value is distributed between $\$ 25$ and $\$ 75$. Notice now that this example is intentionally constructed so that the different variance effect will dominate the different mean effect — the means of litigants' value are equal $\left(\mu_{\Pi}=\mu_{\Delta}=\right.$ $\$ 50)$, but that their variances are different $\left(\sigma_{\Delta}^{2}=\$ 833.33>\sigma_{\Pi}^{2}=\$ 208.33\right)$. As our prior analysis showed, the equality of means will tend to make the two dual-chooser rules allocatively equivalent. And the inequality in variances suggests that the defendant-choice rule will dominate the plaintiffchoice rule. ${ }^{100}$ But what still needs to be shown is why the defendant-choice (single-chooser) rule dominates either of the equivalent dual-chooser rules.

The problem with the dual-chooser regime when there is a large difference in the litigant variances is that it allows the poorly informed chooser (the chooser with a low variance) to have too much control over the entitlement's ultimate allocation. For example, as shown in Figure 4's depiction of the defendant-joint-veto rule, even when the plaintiff's value is higher than the nominal damage price, this does not provide very good assurance that the plaintiff's value is higher than the defendant's (higher variance) valuation.

${ }^{99}$ See id. at 633-42.

${ }^{100}$ The example can also be easily converted to show how a plaintiff-joint-veto rule can dominate any of the other three foundational allocations by simply reversing the identity of the plaintiff and defendant probability distributions - so that the plaintiff's value was distributed uniformly between $\$ 0$ and $\$ 100$, and the defendant's value between $\$ 80$ and $\$ 180$. 


\section{DELEGATION AND DECOUPLING}

Indeed, as discussed above, the relative inferiority of the plaintiff as a chooser in this example causes the optimal damages for the defendant-joint-veto rule to exceed the means of both parties $\left(D_{\Delta J V}=\$ 62.50>\mu_{\Pi}=\mu_{\Delta}=\$ 50\right)$. Because the problem with the defendant-joint-veto rule is that it gives the plaintiff too much power to allocate the entitlement to itself, the optimal damages under this rule are raised to reduce the plaintiff's incentives to allocate the entitlement to itself. Because of the litigants' difference in information, it is better to induce the defendant to inefficiently undertake (that is, to allocate the entitlement too often to the plaintiff) in order to restrict the poorly

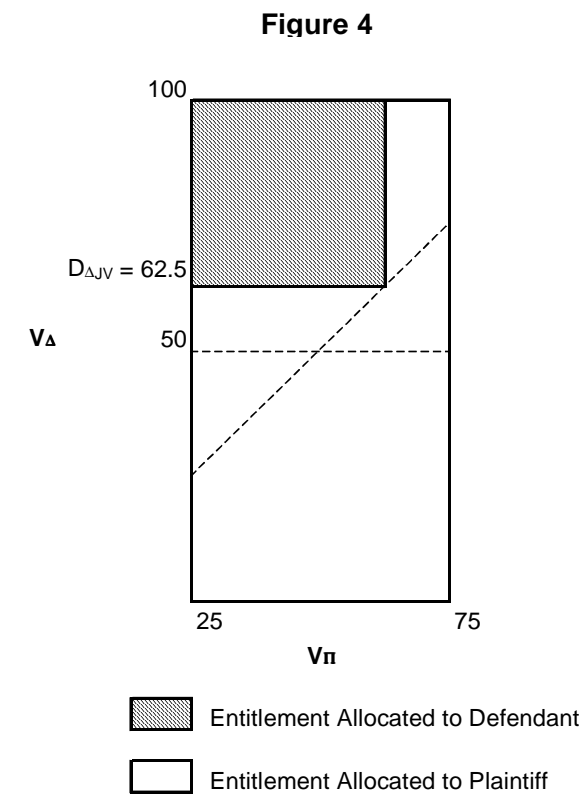
informed plaintiff's incentive to over-take (that is, to allocate the entitlement too often to itself). The fact that optimal joint veto damages are set outside the litigants' mean valuations is evidence that one of the choosers is more inefficient than the other-and therefore evidence that dual-chooser rules will tend to be inefficient relative to single-chooser allocations.

The graphical difference between these rules concerns which litigant will be allocated the entitlement in quadrant II. The defendant-choice rule allocates this quadrant to the defendant, which enhances allocative efficiency. Witness Figure 4, which shows that more of the probability space in this quadrant is filled by situations in which the defendant's valuation exceeds the plaintiff's (as seen from the fact that in this quadrant the area above the 45-degree first-best efficiency line is greater than the area below this line). Divesting the plaintiff of allocative power through the use of the 


\section{DELEGATION AND DECOUPLING}

simpler defendant-choice rule lowers the optimal damages back down to $\$ 50$ and increases the expected joint pay off from $\$ 60.54$ (induced by the defendant-joint-veto rule) to $\$ 62.50$ (induced by the defendant-choice rule). ${ }^{101}$

The foregoing two examples were intentionally constructed to highlight the impacts of the different mean and different variance effects by alternatively assuming one or the other of these differences to be zero. But, more likely, the litigants' distributions will display a mixture of both mean and variance differences. In such cases the choice of the most efficient allocation will turn on which of these difference effects dominates. Figure 5 graphically shows which of the four basic allocations will dominate-holding the difference in variance constant — as we change the relative means of the two litigants. For example, in panel (a), imagine that the plaintiff's valuation is uniformly distributed over a $\$ 100$ range, while the defendant's valuation is uniformly distributed over only a $\$ 50$ range. This assumption of course implies that the variance of the plaintiff's value is greater than the variance of the defendant's value. The relative means of the litigants can then be added to the figure by drawing in a particular 45-degree locus of points in which the litigants' values are equal. Thus, the 45-degree line toward the upper left-hand corner depicts an example in which the plaintiff's mean is greater than the defendant's, while the 45-degree line toward the lower-right

${ }^{101} \mathrm{An}$ analogous argument also shows why in this example a defendant-choice allocation dominates the plaintiff-joint-veto regime. Under a plaintiff-joint-veto rule, the defendant cannot prevent the plaintiff from under-taking - putting the entitlement to the defendant even though the high-mean defendant has a seriously low valuation (as in much of the lower-left quadrant). The optimal damages under a plaintiff-joint-veto rule are lowered below the litigants' mean value in order to increase the poorly informed plaintiff's incentive to unilaterally allocate the entitlement to the defendant, but it turns out to be even better to give all of the allocative power to the defendant - through a single-chooser rule - than to shift the relative allocative decision making through a dual-chooser rule with distorted damages. 
Fiqure 5

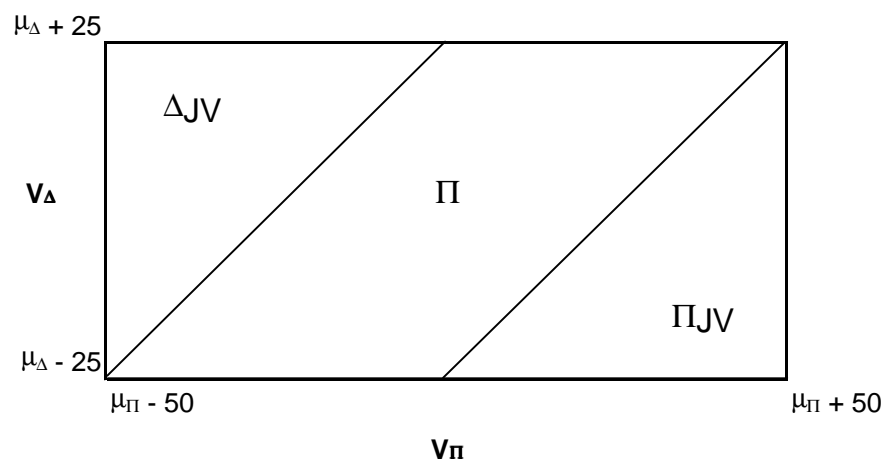

(a) Example where $\sigma_{\Pi}>\sigma_{\Delta}$

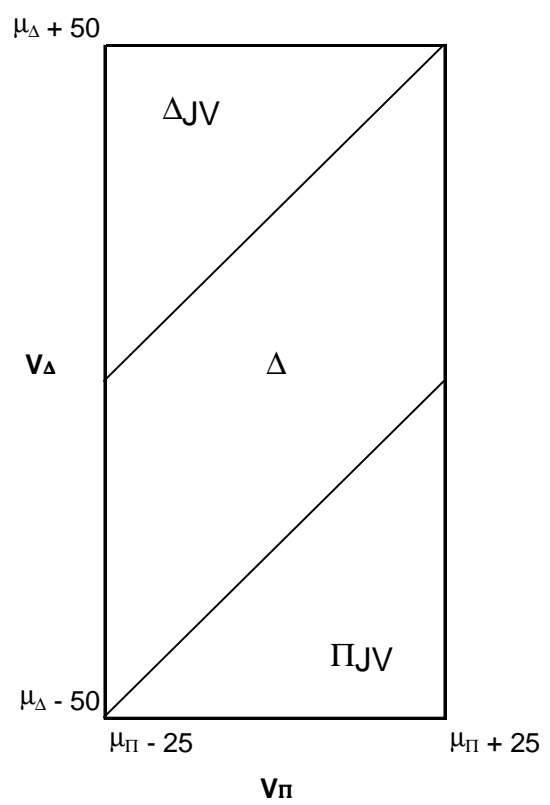

(b) Example where $\sigma_{\Delta}>\sigma_{\Pi}$

$\Pi$ = Plaintiff Choice Rule

hand corner depicts an example in which the defendant's mean is greater than the plaintiff's.

Panel (a) shows that—holding the variance difference constant—as the mean difference varies (from a higher plaintiff mean to a higher defendant mean), three different foundational allocations become alternatively the most efficient. For sufficiently large mean differences in the plaintiff's favor, the different mean effect dominates the variance effect and the defendant-joint-veto allocation is most efficient. ${ }^{102}$ For intermediate differences in the litigant means, the different variance effect dominates, so that the plaintiff-choice rule dominates. And for sufficiently large

${ }^{102}$ If $\mu_{\Pi}-\mu_{\Delta}>\$ 25$, then (given the $\$ 50$ dollar assumed difference in litigants' uniform distribution supports) the defendant-joint-veto allocation produces the highest payoffs. If $-\$ 25<\mu_{\Pi}{ }^{-}$ $\mu_{\Delta}<\$ 25$, then the plaintiff-joint-veto allocation produces the highest payoffs. And if $\mu_{\Pi}-\mu_{\Delta}<-$ $\$ 25$, then the plaintiff joint veto produces the highest payoffs. 
mean differences in the defendant's favor, the different mean effect again dominates the variance effect— this time rendering the plaintiff-joint-veto allocation the most efficient.

Panel (b) works out the optimal allocations for an example in which the variance of the defendant's valuations is greater than the plaintiff's. When the different mean effect dominates, one of the dual-chooser rules is most efficient; when the difference in the litigants' means is not as large, the variance effect dominates and the defendant-choice rule is most efficient.

In sum, we have now provided a complete analysis of the four basic single-price allocations. We have shown what damages optimize allocative efficiency for each type of allocation. We have shown when each type of the four allocations will tend to be allocatively optimal. And we have shown how courts are free to independently distribute the expected payoff between the litigants.

\section{SECOND (AND Higher) ORDER RULES}

In a previous article, Ian Ayres and Jack Balkin analyzed a type of regime that was governed by what they called a "second-order" liability rule. ${ }^{103}$ Second-order rules are types of dual-chooser rules because each litigant makes successive allocative choices. But unlike the dual-chooser rules analyzed above, the second-order rules do not rely on a single judicially-determined allocative price. Instead, second-order rules force one litigant in making an allocative choice to confront one allocative (exercise) price, and force the other litigant to confront a different allocative (exercise) price.

For example, if both of the plaintiff and defendant values are uniformly distributed between $\$ 0$ and $\$ 100$, one type of optimal second-order liability rule would induce the defendant to exercise

\footnotetext{
${ }^{103}$ See Ayres \& Balkin, supra note 9.
} 


\section{DELEGATION AND DECOUPLING}

an option to take when its value is higher than $\$ 33.33$, but would induce the plaintiff to take back the entitlement when its entitlement is greater than $\$ 66.66$. Ayres and Balkin showed that secondorder rules mimicked the allocations of an auction with minimum bid increments. ${ }^{104}$ This allocative equilibrium is graphically displayed in Figure 6. The defendant-joint-veto allocation is a type of

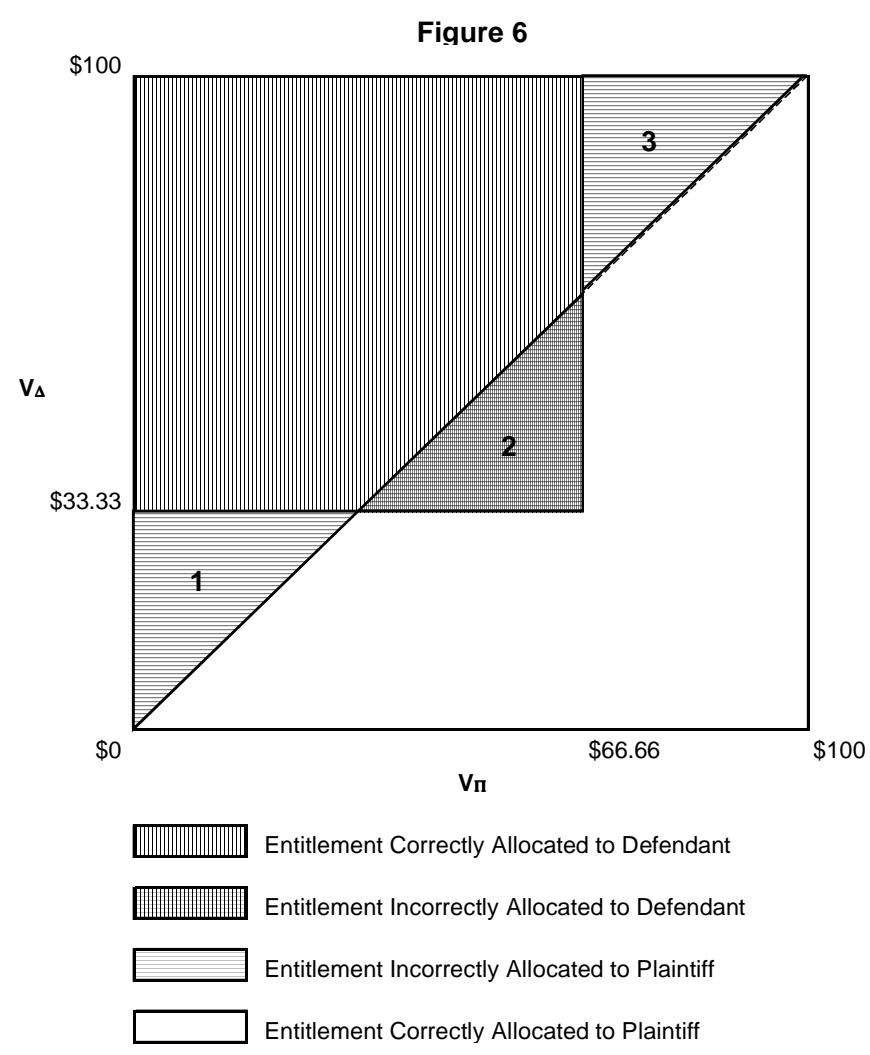
second-order liability rule, but one in which the first- and second-order exercise prices are constrained to be the same.

Ayres and Balkin also showed that allowing the exercise prices to vary induces strategic taking behavior by the initial decision maker. For example, in the foregoing hypothetical, a defendant with a private valuation of only $\$ 33$ would find it advantageous to exercise an initial call option to take an entitlement for $\$ 33.33$ (thus, paying more than her value) because doing so might induce the plaintiff to take back and pay \$66.66. In order to induce the optimal taking strategies (of \$33.33 and \$66.66), the nominal damage amounts would need to be set at $\$ 44.44$ (for the defendant's call option) and $\$ 66.66$ (for the plaintiff's take-back call option). Because of this incentive for strategic exercise, the exercise prices

${ }^{104}$ See id. at 727-28. Unlike traditional auctions, however, in which the proceeds of the auction go to a non-bidder, the internal auction produced by second (and higher-) order rules is one in which the proceeds from the winning bidder are paid to the losing bidder. 


\section{DELEGATION AND DECOUPLING}

of second-order rules do not induce transparently obvious player strategies.

Like the constrained dual-chooser rules, there are multiple option variations that will induce allocatively equivalent second order allocations. For example, what we will call the "defendant unconstrained joint veto" rule might be produced by either:

(1) $\quad \Pi: \quad \mathrm{E}-$ call (Low) + call(High) $\quad \Delta: \quad+$ call(Low) - call(High)

(2) $\quad \Pi: \quad \mathrm{E}+\operatorname{put}($ High $)-\operatorname{put}($ Low $) \quad \Delta: \quad-\operatorname{put}($ High $)+\operatorname{put}($ Low $)$,

where the parenthetical Low's and High's are used merely to indicate the ordinal size of the two exercise prices.

In the first implementation (1), the plaintiff (a) is given the initial entitlement, (b) is subject to a defendant's call option, but (c) also has a call option to take back at a higher price. Like the earlier defendant-joint-veto allocation, this rules allows either litigant to veto the transfer of the entitlement to the defendant. The defendant can veto the transfer of the entitlement to itself by refusing to exercise its initial call option; and even if the defendant's call is exercised, the plaintiff can veto the transfer by exercising its take-back call option. Alternatively, under the second implementation (2), the plaintiff is given (a) the initial entitlement and (b) an option to put at a high exercise price, but (c) the defendant is given an option to put the entitlement back to the plaintiff at a lower exercise price. ${ }^{105}$ An analogous second-order allocation can be implemented by what we call

${ }^{105}$ The same allocation might also be induced by:

(3) $\quad \Pi: \quad-\operatorname{put}($ Low $)+$ call(High)

$\Delta: \quad \mathrm{E}+\operatorname{put}($ Low $)-$ call(High)

Under the third implementation (3), the defendant has the initial entitlement and a put with a low exercise price, while the plaintiff is given a call with a high exercise (which the plaintiff and defendant might be called upon to exercise simultaneously). The entitlement would only end up with 
DELEGATION AND DECOUPLING

"plaintiff unconstrained joint veto" rules simply by reversing the foregoing plaintiff and defendant allocations.

While these second-order rules may seem the most bizarre of an ever expanding universe of "liability" rules, Ayres and Balkin showed that a second-order rule was implicitly implemented in the venerable common law chestnut, Vincent v. Lake Erie Transportation Co. ${ }^{106}$ In that case, the Minnesota Supreme Court held a shipowner liable when his ship damaged a dock while he attempted to moor the ship during a storm—-but the court simultaneously acknowledged that the dock owner would have had to pay damages to the ship owner if the dock owner had subsequently unmoored the defendant's ship, causing it to be damaged. As Ayres and Balkin note:

Vincent [is] a vivid example of how the common law protects an option to take an entitlement (a liability rule) with another liability rule. The dock owner holds the initial entitlement to the physical security of the dock. The shipowner (because of the exigencies of the storm) has a first-stage option to "take" the dock by mooring the ship to it and by paying damages for any injury that results. The dock owner has a second-stage option to unmoor the ship, but at a cost: The dock owner gives up a cause of action against the shipowner for damages and exposes himself to tort liability for any damages to the ship and its crew. ${ }^{107}$

Under Vincent, both the ship and dock owners have a say in the ultimate allocation of the dock, and

the defendant if neither litigant vetoed such an allocation by exercising its option. While these options might be simultaneously exercised, we would still expect non-transparent strategies, as each party would hedge on its decision to exercise hoping that the other litigant would exercise at a more favorable price.

${ }^{106} 124$ N.W. 221 (Minn. 1910).

${ }^{107}$ Ayres \& Balkin, supra note 9, at 716. Jon Hanson and Matt Stowe were the first to see this unusual aspect of Vincent. See Jon Hanson \& Matt Stowe, Lecture Notes, Torts, Harvard Law School (Fall 1996) (on file with The Yale Law Journal). Robert Ellickson long ago also proposed a modification of nuisance rules that would amount to a common law implementation of a secondorder rule. See Robert C. Ellickson, Alternatives to Zoning: Covenants, Nuisance Rules, and Fines as Land Use Controls, 40 U. CHI. L. REV. 681 (1973). 


\section{DELEGATION AND DECOUPLING}

while there was no indication that the court intended to set allocatively optimal rules, the potential damages in the first and second stages were certainly not constrained to be the same number (in contrast with the foregoing single-price, dual-chooser rules).

This section extends Ayres and Balkin's previous analysis by showing more generally how courts should tailor second-order damages, as well as by showing that our convexity result can be applied to second-order rules to again decouple a court's distributive and allocative concerns. Finally, our goal in this section is to compare these unconstrained dual-chooser allocations to the four single-price allocations. Intuitively, it should not be surprising that a less constrained rule should dominate more constrained rules, and indeed we find that, absent transaction costs, secondorder rules dominate.

\section{A. Selecting Optimal Damages}

Calculating optimal damages is computationally difficult —even more so than solving the dual-chooser optimization equation outlined above. We readily admit that it will outstrip the computational capacity and temperament of judges. Still, it is possible to make some progress on the underlying process that would guide a judge inclined to make such an allocation (possibly with the aid of a fairly simple piece of computer software). ${ }^{108}$ First, it is useful to break the task into two parts: (1) identifying the optimal "pivot values" that define when a chooser will optimally allocate the entitlement to itself or the other litigant; and (2) identifying the nominal damages that induce the

${ }^{108}$ The real difficulty will be for a judge to reduce her assessments of valuation to a probability density function. If this is accomplished (and there are interactive software that already help quantiphobes undertake just this task by asking a series of yes/no questions), it is fairly trivial for a piece of software to numerically calculate the optimal damages. We guess that more complicated computational problems are surmounted everytime someone dials a phone number. 


\section{$\underline{\text { DELEGATION AND DECOUPLING }}$}

litigants to adopt particular pivot values as their equilibrium strategies.

The first task, identifying the optimal pivot value, has a surprisingly simple intuition, which we call the "dispositive takings principle." To see how this principle might work, consider again a second-order regime in which the defendant has a first-stage call option to take, and the plaintiff has a second-stage option to take back at a higher price. While it makes superficial sense for a court to want to induce takings when the taker thinks her value is greater than the expected value of the takee, this approach ignores the fact that, in a second-order regime, many of the first-stage takings will not be dispositive. Some of the first-stage takees will have values higher than the expected value of the taker, and they will protect their interests by taking back. The optimal pivot values should focus on the allocations of particular choosers that will be final, or dispositive. Hence, optimal exercise prices for second-order rules should induce the first-stage taker to take whenever the taker's private valuation is greater than the expected valuation of takees who will not take back. ${ }^{109}$ The dispositive takings principle requires that dispositive takings must on average increase welfare.

While the dispositive takings principle has intuitive appeal, implementing it would require a judge to simultaneously solve a system of two equations for the two unknown pivot values:

$$
\begin{aligned}
& \operatorname{Pivot}_{\Delta}=E\left\{v_{\pi} \mid v_{\pi}<\text { Pivot }_{\pi}\right\} \\
& \text { Pivot }_{\pi}=E\left\{v_{\Delta} \mid v_{\Delta}<\text { Pivot }_{\Delta}\right\},
\end{aligned}
$$

${ }^{109}$ Ayres \& Balkin, supra note 9, at 717, proved that the dispositive taking principal maximized allocative efficiency when the litigants's valuations were uniformly distributed and conjectured that the principal would also hold true for more general distributions. In the Appendix, infra at 111 , we prove this to be true. 
where Pivot $_{\Delta}$ and Pivot $_{\Pi}$ represent the pivot values at which defendants and plaintiffs choose to exercise their taking and take-back options respectively. ${ }^{110}$ The first pivot equation asks what is the plaintiff's expected value given that the plaintiff will not take back. It is this class of plaintiffs for whom the defendant's taking will be dispositive. The second pivot equation asks what is the defendant's expected value given that she initially exercised her option to take. It is this class of defendant for whom the plaintiff's taking back will be dispositive.

But even after undertaking the arduous task of calculating the optimal pivot values, a court would then still — because of the first-stage strategic exercise incentive-need to solve a second system of equations to determine what nominal damage amounts will induce the desired pivot strategies. Because second-stage takings are non-strategic, the second-stage damages are identical to the second-stage pivot value:

$D_{\pi}=$ Pivot $_{\pi}$

But the first-stage damages (because of the problem of strategic first-stage taking) are more complicated:

$D_{\Delta}=P\left(v_{\pi}<\right.$ Pivot $\left._{\pi}\right)$ Pivot $_{\Delta}+P\left(v_{\pi}>\right.$ Pivot $\left._{\pi}\right)$ Pivot $_{\pi}$.

Notice that first-stage damages are a weighted average of the two optimal pivot values (with the

${ }^{110}$ The equations can be restated in terms of the explicit integrals and probability density functions as well:

$$
\begin{aligned}
& \text { Pivot }_{\Delta}=\int_{\text {Pivot }_{\pi}}^{\infty} v_{\pi} f_{\pi}\left(v_{\pi}\right) d v_{\pi} \\
& \text { Pivot }_{\pi}=\int_{0}^{\text {Pivot }_{\Delta}} v_{\Delta} f_{\Delta}\left(v_{\Delta}\right) d v_{\Delta} .
\end{aligned}
$$




\section{DELEGATION AND DECOUPLING}

weights concerning the probability of the plaintiff's value being above or below the plaintiff's takeback pivot value).

For example, if plaintiff and defendant have identical probability density functions that take on a quadratic form with zero probability mass at $\$ 0$ and $\$ 100,{ }^{111}$ then it can be shown applying the foregoing dispositive takings equations that the players' joint payoffs are maximized if the defendant to take when its valuation is greater than $\$ 37.80$ and the plaintiff takes back when it's valuation is greater than $\$ 62.20$. And to induce these pivot values, it is necessary for a court to set first stage damages for defendant taking equal to $\$ 45.62$ and second-stage damages for plaintiff taking back equal to $\$ 62.20 .^{112}$

Thus, while optimal damages for second-order liability rules are tractable for any possible value distributions, they are (even) less likely than any of the foregoing variants to be accurately implemented by the present-day judiciary.

\section{B. Selecting the Distribution}

Continuing bravely on, we find that if a court could determine the allocatively optimal damages, it would again be possible to vary the litigants' individual expected payoffs without affecting the litigants' allocative choice. In other words, it is possible to extend our previous convexity result.

Consider, for instance, the familiar example of two litigants whose valuations are uniformly

${ }^{111}$ Formally the density functions would be of the form: $f(v)=6 v(1-v)$.

${ }^{112} \mathrm{An}$ example with the much simpler uniform distribution is derived in Ayres \& Balkin, supra note 15 , at 422 . 


\section{DELEGATION AND DECOUPLING}

distributed between $\$ 0$ and $\$ 100$. As discussed earlier, one example of a second-order rule with optimal damages would give the defendant a first-stage taking (call) option with a $\$ 44.44$ exercise price and the plaintiff a second-stage take-back (call) option with a $\$ 66.66$ exercise price. These nominal damages will induce the optimal pivot strategies in that the defendant will take when its value is greater than $\$ 33.33$ and the plaintiff will take back when its value is greater than $\$ 66.66 .{ }^{113}$

But the same pivot strategies can be induced by a regime that gives the defendant the firststage choice of paying $\$ 24.44$ to the plaintiff to take the entitlement $\left(D_{C}=\$ 24.44\right)$ or receiving $\$ 20$ from the plaintiff if it does not take $\left(D_{N C}=-\$ 20\right)$, and giving the plaintiff the same second-stage choice of paying $\$ 66.66$ to take back the entitlement $\left(D_{C}=\$ 66.66 ; D_{N C}=\$ 0\right)$. Under such a rule, the defendant will still perceive a $\$ 44.44$ cost to taking in the first stage, and thus will continue find it worthwhile to strategically take whenever its value is greater than $\$ 33.33$. But (again) by changing the first-stage option into a "Pay or be Paid" rule, this implementation effectively shifts some of the expected total payoff from the plaintiff and toward the defendant. All that is allocatively important is that the difference between $D_{C}$ and $D_{N C}$ be equal to the nominal damages that would be optimal under a more traditional call (or put) rule. As emphasized above, it is computationally awkward to calculate this initial number, but it is not difficult for a court by moving $D_{C}$ and $D_{N C}$ in lockstep to

\footnotetext{
${ }^{113}$ Notice how this equilibrium is consistent with the dispositive takings principle. The defendant only takes when its value is higher that those plaintiffs who will not take back. The class of plaintiffs who will not take back have valuations ranging from $\$ 0$ to $\$ 66.66$, and the defendant will only take when its value is greater than the mid-point in this range, \$33.33. Similarly, the plaintiff will only take back when its value is higher than those defendants from whom it is taking. The class of defendants from whom a plaintiff might take back has valuations ranging from $\$ 33.33$ to $\$ 100$, and the plaintiff will only take back when its value is greater than the midpoint in this range, $\$ 66.66$.
} 
$\underline{\text { DELEGATION AND DECOUPLING }}$

create "Pay or be Paid" or "Pay or Pay" rules that produce distributively different, but allocatively identical, equilibria. Even when implementing second-order rules, a court's distributive decision can be independent of its allocative decision. So just as there is an infinite class of rules that implement two single-chooser allocations, and an infinite class of rules that implement two dualchooser allocations, there turns out to be an infinite class of rules that implement the two foundational second-order allocations - the defendant-unconstrained-joint-veto allocation and the plaintiff-unconstrained-joint-veto allocation.

\section{Selecting the Chooser}

Which of these two second-order equilibria will be allocatively superior -- the "unconstrained plaintiff-joint-veto" rule or the "unconstrained defendant-joint-veto" rule? The answer parallels our analysis of the constrained dual-chooser rules - it depends on the litigants' relative means. The overarching principle continues to be that as between the two second-order rules, courts should tend to allow either party to veto allocations to the party with the lower mean. This means that the "unconstrained defendant-joint-veto" equilibrium will tend to dominate the "unconstrained plaintiffjoint-veto" equilibrium when

$$
\mu_{\Pi}>\mu_{\Delta}
$$

For example, imagine that the defendant's valuation is uniformly distributed between $\$ 0$ and $\$ 100$, and that the plaintiff's valuation is uniformly distributed between $\$ 80$ and $\$ 180$. It can be shown that the optimal pivot values for a defendant-unconstrained-joint-veto rule are equal to $\$ 86.66$ and 


\section{DELEGATION AND DECOUPLING}

$\$ 93.33$ for the defendant and plaintiff, respectively. ${ }^{114}$ In contrast, the optimal pivot values for a plaintiff-unconstrained-joint-veto rule are equal to $\$ 60$ for the plaintiff and $\$ 120$ for the defendant respectively. ${ }^{115}$ Each of these pivot values are outside the range of the litigant's valuation distribution and as a result the plaintiff-unconstrained-joint veto rule with optimal damages would always allocate the entitlement to the plaintiff. The two allocative equilibria induced by the two rules (with optimal pivot values) are graphically depicted in Figure $7 .{ }^{116}$ As shown in the figure, the "unconstrained defendant-joint-veto" rule is more efficient than an "unconstrained plaintiff-jointveto" rule (as can be seen by the relative difference in misallocatted entitlements). The defendantunconstrained-joint veto rule on net does a better job of allocating the entitlement to the defendant in the unusual circumstances when the defendant has the higher value, whereas the plaintiffunconstrained-joint-veto can do no better than allocating the entitlement solely to the plaintiff.

${ }^{114}$ By the dispositive takings principle, the pivot values must simultaneously satisfy the following two equations:

$$
\text { Pivot }_{\Delta}=\frac{80+\text { Pivot }_{\pi}}{2} \text {, and Pivot }{ }_{\Pi}=\frac{\text { Pivot }_{\Delta}+100}{2} \text {. }
$$

which when solved yield the values in the text. The nominal damages that would induce these pivot taking values are $\$ 92.43$ for the defendant's taking and $\$ 93.33$ for the plaintiff taking back.

${ }^{115}$ By the dispositive takings principle, the pivot value must simultaneously satisfy the following two equations:

$$
\text { Pivot }_{\Delta}=\frac{180+\text { Pivot }_{\pi}}{2} \text {, and Pivot }{ }_{\Pi}=\frac{\text { Pivot }_{\Delta}}{2} \text {. }
$$

which when solved yield the values in the text.

${ }^{116}$ See Ayres \& Balkin, supra note 9, at 727 fig.1. 


\section{Figure 7}

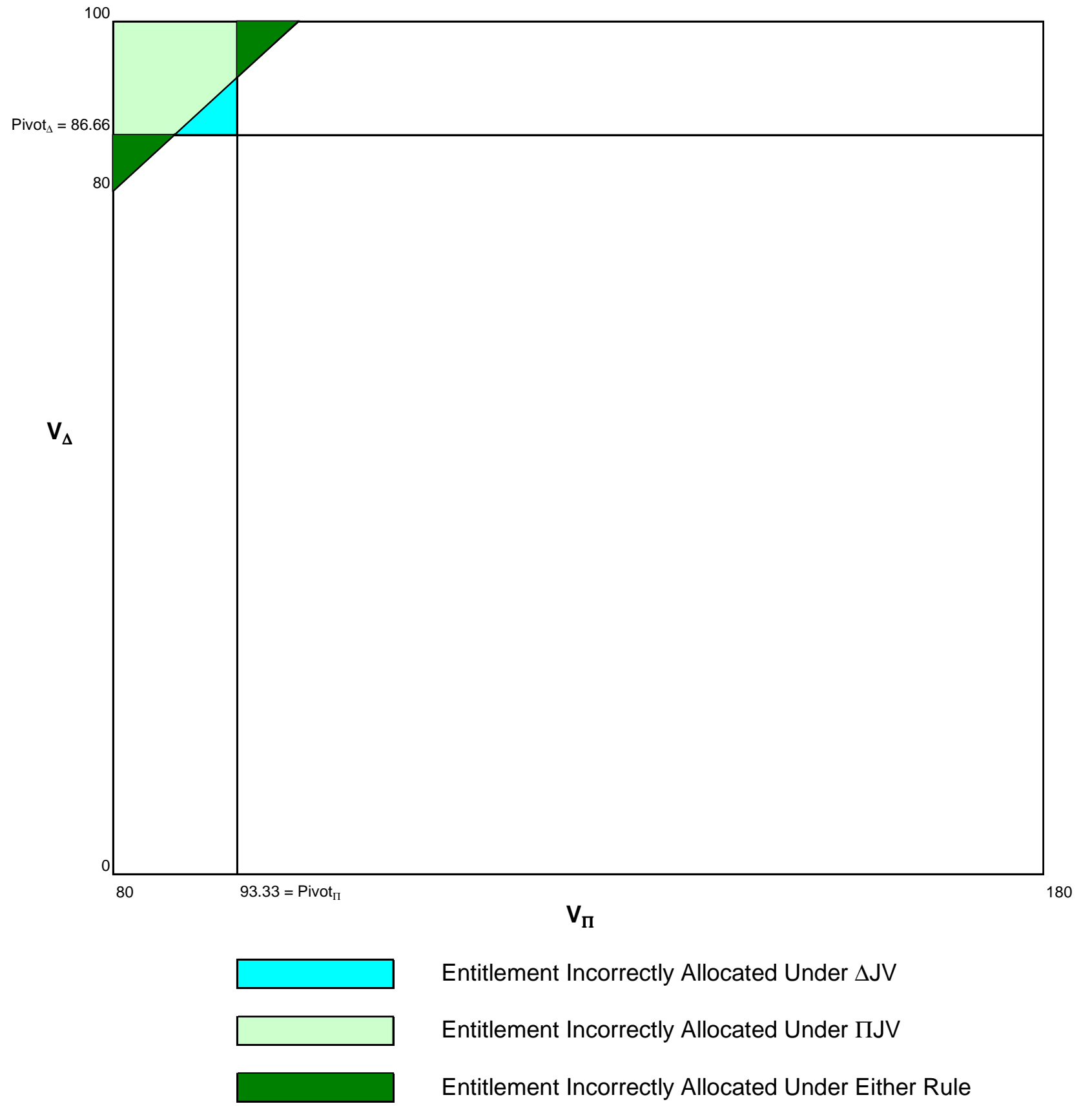




\section{DELEGATION AND DECOUPLING}

\section{Selecting Among the Six Foundational Allocations}

Finally, it is useful to compare the relative efficiency of all six foundational allocations. If courts could accurately calculate optimal damages for second-order rules, the better second-order rule would always dominate all other rules — in the sense of producing at least as high an expected total payoff for the litigants as any of the other five allocations. This is intuitively obvious because the second-order rules are less constrained than either single chooser or dual chooser rules. The court sets not one, but two allocative prices and thus has more freedom to harness the private information of both litigants. Setting two (or more) allocative prices allows a court to implement an internal auction -- where each taking at a sequentially higher (or with puts lower) price effectively allows the individual litigants to credibly signal more information about their private valuation. ${ }^{117}$ Heuristically, these less constrained liability rules allow the court to make more nuanced assignments of allocative authority. Just as the convexity result allows the courts to distribute the expected payoffs as they see fit, the higher-order liability rules allow the court to distribute the allocative power as they see fit -- instead of giving one side or the other the sole allocative authority (as with single chooser rules) or giving the two parties symmetric allocative authority (as with the constrained dual chooser rules).

More prosaically, second order rules can never be dominated because with the appropriate choice of damages these rules can themselves implement the literal equilibria of either the singlechooser or the dual-chooser rules. Second-order rules could be made to implement single-chooser allocations by setting the first-stage exercise price at the non-chooser's value and then setting the

${ }^{117}$ See id, at 729 . 


\section{DELEGATION AND DECOUPLING}

second-stage price at a sufficiently prohibitive amount so that it would not be exercised. And second-order rules could be made to implement dual-chooser allocations by simply setting the firstand second-stage exercise prices equal to one another. ${ }^{118}$

But much as we are attracted to the elegant way in which second-order rules harness the information of both litigants - even when one litigant is relatively poorly informed, we believe that there are many pragmatic drawbacks to implementing second-order rules that rightly refocus our attention on the single-price dual-chooser rules as the best pragmatic alternative that courts will often have for harnessing both litigants' private information to allocate an entitlement. ${ }^{119}$ The rules, by definition, only require the courts to calculate a single allocative price-which in the normal case will be something close to the average of the litigants' mean values. And the single-price dualchooser rules analyzed above induce transparent, dominant strategies that both the court and the litigants can readily understand. If dual-chooser damages are set at $\$ D_{\Delta J V}$ under a defendant-jointveto rule, then the entitlement will be allocated to the defendant only if $v_{\Pi}<D_{\Delta J V}<v_{\Delta}$. The relative simplicity and transparency of such rules suggest that the theoretical dominance of second-order regimes does not undermine our initial efforts to identify how courts should select within an admittedly constrained class of single-price rules.

${ }^{118}$ Indeed, Ayres and Balkin showed that in a world with costless takings successively higher order rules can achieve a higher expected total payoff. See id. at 727-78. Higher-order liability rules implement more refined auctions (with smaller minimum bid increments), and as a theoretical matter these rules in the limit can produce first-best efficiency.

${ }^{119}$ Ayres \& Balkin, supra note 9, at 717 show, for example, that if as the transaction costs of taking or calculating damages increase that single price rules will tend to dominate multiple allocative price rules. 


\section{DELEGATION AND DECOUPLING}

\section{EXTENDING THE ANALYSIS}

In this section, we relax many of the more stringent assumptions of the foregoing analysis and assess the extent to which the assumptions limit the model's applicability or its normative implications.

\section{A. Administrative Costs}

The foregoing analysis ignored costs of administering the liability rules. Taking these costs into account is likely to drive efficiency-minded lawmakers toward simpler rules. Ayres and Balkin have previously shown, for example, that if as the transaction costs of taking or calculating damages increase, single price rules will tend to dominate higher-order liability rules (which entail the calculation of multiple allocative prices). ${ }^{120}$ Indeed, when bargaining is not possible, the costs of administering liability rule regimes militate toward the use of property rules. Property rules tend to deter nonconsensual takings and thus avoid the costs of administering a liability rule regime. But when transaction costs are relatively low, the litigation costs involved in administering a liability rule regime can somewhat counterintuitively facilitate greater allocative efficiency. ${ }^{121}$ Under a liability regime, litigation costs give the parties an additional impetus to negotiate and hence can be a but-for cause of making liability rules more efficient than property rules.

Carol Rose has also stressed that courts may need to incur non-trivial costs in determining which parties should have a potential claim to ultimate ownership of particular entitlements. ${ }^{122}$ Costs

\footnotetext{
${ }^{120}$ Ayres \& Balkin, supra note 9, at 717.

${ }^{121}$ This point is stressed in Ayres \& Talley, supra note 9.

${ }^{122}$ See Rose, supra note 15 , at 2189.
} 
DELEGATION AND DECOUPLING

of determining who owns what entitlements will again militate in favor of property rules, but should not greatly impact the type of liability rules. The foregoing suggests that the optimal tailoring of liability regime will turn on an assessment of how the litigants' valuations are distributed. We will return to these issues again when we consider the associated problems of "numerosity."

\section{B. Alternative Informational Assumptions}

The foregoing analysis made imperfect information assumptions that are standard in the law and economics literature -- namely that the probability distributions of the litigants is (after trial) common knowledge, but that only litigants known their own valuation. ${ }^{123}$ Here, we consider three variations on these assumptions: (a) the litigants are imperfectly informed about their own valuations: (b) the litigants' probability functions are not common knowledge; and (c) courts systematically mis-estimate the probability distributions of the litigants' value.

The possibility that litigants do not precisely know their own valuation is not a major limitation to our analysis. While it is possible that the prospective value of owning an entitlement may not be known by a litigant with precision, the litigant nonetheless may be able to estimate a certain equivalent amount of cash that would leave her indifferent between owning the entitlement or having this additional cash amount. Just as individuals often buy and sell entitlements for discrete cash amounts when they do not precisely know what the future value of ownership to them will be.

As long as the individual litigants are better informed than the court, liability rules -- by privatizing the ultimate allocative authority -- can enhance ex post efficiency. In mathematical

${ }^{123}$ See, e.g., Kalyan Chatterjee \& William Samuelson, Bargaining Under Incomplete Information, 31 Operations Res. 835 (1983); Peter C. Cramton, Strategic Delay in Bargaining with Two-Sided Uncertainty, 59 Rev. Econ. Stud. 205 (1992). 


\section{DELEGATION AND DECOUPLING}

terms, as long as a litigant's beliefs about her valuation probability function are less volatile than the court's belief's about the litigant's valuation, the litigant will have an informational advantage over the court in ultimately allocating the entitlement. ${ }^{124}$

Even if litigants know their own valuation, one might worry that they might not (contrary to our model's assumption) be able to assess the probability distribution of the other party. We believe that this is also not a large concern. Liability rules do not require a chooser to directly assess the probability functions of her adversary -- rather a chooser needs to confront the court-determined damage amount (what we have called the allocative price). Court-appointed choosers do not need to observe non-chooser valuations as long as a court, after discovery and trial can estimate a valuation distribution sufficiently to determine optimal single or dual chooser damages. ${ }^{125}$ And as stressed above, single-chooser rules will tend to simplify the court's decision by only asking the court to estimate the mean of the litigant with the less speculative valuation. Of course, the less speculative valuation may still, from the court's perspective, be quite speculative, but courts only need to be able to make an unbiased estimate in order to harness the litigant's private information in allocating the entitlement.

A more serious informational concern would be if courts' estimates of the litigants' valuation

\footnotetext{
${ }^{124}$ See supra at note 52 .
}

${ }^{125}$ There may be contexts -- especially with regard to dual chooser regimes -- in which the first stage choice is made by a potential litigant before the court has determined damages. For example, a potential defendant may decide to encroach in anticipation that the court will give the plaintiff the put-like choice of injunction or damages for permanent encroachment. In such circumstances, a rational encroacher would want to assess what court-determined damages were likely to be. 
distributions were for some reason systematically biased. For example, if courts in implementing single chooser rules systematically underestimated (overestimated) the non-chooser means, then they would set damages too low (high) and would induce the chooser to inefficiently allocate the entitlement too often (rarely) to itself. If higher branches of government (appellate courts or the legislature) realize that lower branches (trial courts/juries) systematically underestimate the mean value of residents, a standard response is that the higher branch might force the lower branch to eschew liability rules altogether and instead give the residents the pollution entitlement protected by a property rule. But the foregoing analysis suggests that an alternative response may be more efficient and that is for the higher branch to force the lower branch to eschew defendant-choice rules -- which turn on the court's assessment of the residents' mean value -- and instead to use plaintiffchoice rules -- which turn on the trial court's potentially better assessment of the polluter's mean value.

If the valuation assessments of the more authoritative branches of government are also biased, the allocation problem becomes truly intractable. We readily admit that our model will not perform well, but neither will most other allocative regimes.

\section{Unintentional Taking}

Our option model has quintessentially been about intentional takings. One or both litigants makes an intentional choice to exercise a particular option or not. In many contexts, this assumption is reasonable. Potential defendants at times make deliberate decisions to impair plaintiffs' entitlements. And the election of remedies by plaintiffs to seek an injunction or monetary damages is almost always appropriately modeled as deliberate. 


\section{DELEGATION AND DECOUPLING}

However, many (if not most) torts concern unintentional takings. It is reasonable to ask whether our models have anything to say to this large class settings. We believe they do. First, unintentional takings increase the ability of courts to implement single chooser rules -- especially plaintiff choice rules. If Calabresi inadvertently and non-strategically encroaches on Melamed's land, then courts have additional freedom to implement a true plaintiff choice rule -- by giving Melamed the unilateral allocative decision based on a single allocative price. In contrast, with regard to deliberate encroachments, courts may not be able to implement a pure plaintiff choice rule because eventually potential encroachers will take into account the second-stage plaintiff choice when deciding whether or not in the first stage to encroach.

Second, and more speculatively, an options model of deliberate taking may have something to tell us about negligence regimes. Even when a potential defendant does not make a deliberate decision to take a plaintiff's entitlement, the defendant often does make a deliberate choice to take a certain amount of care. Choosing a level of care in some contexts can be thought of as being tantamount to choosing the probability that an accident will occur. Or put more in the argot of finance, by choosing a level of care, potential defendants are choosing the probability that they will exercise their takings option. Setting damages equal to the non-chooser's mean value (i.e., the plaintiff's mean value of impairment) will induce the takings only when the value of probabilistic takings (in saved due care costs) is greater than the plaintiff's average loss. Thus, it is possible to restate the Learned Hand rule in option terms -- but often not much is gained from the translation. Many torts are not amenable to plaintiff choice, because once an entitlement has been destroyed there is no prospect of asking the plaintiff whether she would prefer the thing itself (e.g., her arm) instead 


\section{DELEGATION AND DECOUPLING}

of cash.

But even with regard to negligent taking there may be some circumstances where a secondstage plaintiff election of remedy is possible and the foregoing analysis may be relevant. If Epstein negligently takes Calabresi's galoshes at the theater, common law courts can give (and traditionally have given) Calabresi the option of whether he wants the shoes or the money. ${ }^{126}$ The court in setting the damage amount may be creating a kind of dual chooser rule which will impact both the due care with which Epstein examines galoshes at the theater and Calabresi's decision whether to seek injunctive of damage relief.

D. Numerosity

Our previous discussion has relentlessly concerned bilateral disputes. We have assumed that there is only one plaintiff and one defendant; and we have assumed that there are no third-parties who might contend for being the highest valuer of the entitlement. Both of these assumptions characterize a non-trivial amount of real-world litigation. For example, in Copart Industries $v$. Consolidated Edison, a particular type of pollution from a ConEd plant disrupted the ability of a single plaintiff to continue its new car preparation business. ${ }^{127}$ However, there are many nuisance disputes in which one or both sides of the litigation will involve multiple litigants. In particular, the tendency of a pollution to spread means that multiple plaintiffs may be affected by a single defendant's effluence. ${ }^{128}$ Krier and Schwab have seized on the difference in numerosity to argue that

${ }^{126}$ See Ayres, supra note 15.

${ }^{127} 362$ N.E.2d 968 (N.Y. 1977). See also cases cited supra in note 27.

${ }^{128}$ See Richard L. Revesz, Federalism and Interstate Environmental Externalities, 144 U. Pa. L. Rev. 2341, 2342-44 (1996). 
DELEGATION AND DECOUPLING

defendant's will tend to be the more efficient chooser because they are less numerous. ${ }^{129}$ As applied to our analysis, Krier and Schwab would be arguing that defendant choice rules -- including the Rule 2 call-option implementation and the Rule 5 put-option implementation -- would tend to dominate plaintiff choice rules. We agree that the additional collective action difficulties of a diffuse plaintiff class will -- all else equal -- tend to militate toward the use of defendant choice rules. And our decoupling result improves upon Krier and Schwab by showing that there is a continuum of defendant choice rules that can equally harness the defendant's private information while providing more nuanced distributive possibilities.

But we disagree with Krier and Schwab's seemingly exclusive focus on numerosity as the determinant of the more efficient chooser. Instead, we believe that the more efficient chooser will also turn importantly on which party has a greater informational advantage relative to the court. All else equal, the party who from the court's perspective has the more volatile valuation will be the more efficient chooser.

In many nuisance disputes numerosity and volatility will push the court in different directions. The plaintiffs in nuisance disputes are often more numerous than the defendant/polluter, but these plaintiffs also are likely to have more speculative valuations. It is often easier for courts to measure the economic costs of abating or discontinuing pollution than it is for courts to assess the non-economic damages of pollution to surrounding residents. Even though multiple residents will often have high costs of collective decision-making, they will also often have more relevant private

\footnotetext{
${ }^{129}$ Krier \& Schwab, supra note 7, at 471-72.
} 


\section{DELEGATION AND DECOUPLING}

information available (knowing how much pollution really harms them). ${ }^{130}$

At times, it will be better for courts to give the choice to multiple residents and accept the resultant collective-action problems than to give the polluter the choice and disregard the residents' private information. For example, we believe that the residents in Boomerv. Atlantic Cement might have been the better chooser than the polluter — notwithstanding their relative numerosity — because the court had a more difficult time estimating the value of the entitlement to the residents. While we concede that numerosity will often militate against giving the choice to multiple residents, the variance effect will often militate in favor of giving the residents precisely this choice.

A second way in which our two player models limits the applicability of our analysis concerns the exclusion of potential third party claimants for ultimate ownership of the entitlement in question. In a world in which three or more different parties are potentially the most efficient ultimate owner of the entitlement, it will become more difficult to implement a liability rule regime. Absent bargaining, property rules will, however, also do badly in allocating the entitlement to the most efficient owner -- unless the imperfectly informed court by chance can allocate the entitlement to the highest valuer. When bargaining is feasible, the multiplicity of potential highest valuers militates toward property rules. Liability rules (a) by failing to allocate claims to potentially high valuers or (b) by allocating claims to people who are not high valuers can increase the cost of contracting. For example, when a partial entitlement is given to a person who is not the efficient owner, she will only be a potential seller, and her traditional incentive to seek an inflated price can

${ }^{130}$ In addition, residents often will be more risk averse than the polluter (who may have greater opportunities to diversify loss) and hence will, other things being equal, tend to be the better choosers. 
DELEGATION AND DECOUPLING

impede negotiations among the class of potentially highest valuers. The low entitlement valuers who are mistakenly granted a claim on the entitlement can inefficiently hold up the transaction. ${ }^{131}$ This is another example of what Heller called the anti-commons problem -- where too many people can block the transfer of an entitlement to its highest valuing owner. ${ }^{132}$ As the pool of potentially high valuers increases, liability rules (of both the single chooser and dual chooser varieties) can exacerbate this hold up or anti-commons problem.

\section{E. Cognitive Bias and Wealth Effects}

A central finding of the previous analysis concerned the allocative invariance of all implementations within a particular foundational allocative class. For example, we claimed that any defendant choice rule with a particular allocative price $\left(\mathrm{D}_{\Delta}\right)$ would produce identical allocations for any possible sets of private plaintiff and defendant valuations. This invariance results only holds true, however, in the absence of wealth and cognitive framing effects.

As with the Coase theorem's invariance prediction, ${ }^{133}$ our allocative invariance finding will not hold true if the chooser's willingness to pay is affected by her overall wealth. ${ }^{134}$ Defendant choice rules that allocate larger expected payoffs to the defendant might make the defendant more

${ }^{131}$ See Ayres \& Talley, supra note 9, at 1086.

${ }^{132}$ Heller, supra note 98.

${ }^{133}$ See Schwab, A Coasean Experiment on Contract Presumptions, 17 J. LEGAL STUD. 237 , 242-43 (1988); John J. Donohue, III, Diverting The Coasean River: Incentive Schemes to Reduce Unemployment Spells, 99 Yale L.J. 549 (1989).

${ }^{134}$ See ; A. Mitchell Polinsky, An Introduction to Law and Economics 7-10, 119-27 (2nd ed. 1989); Stewart J. Schwab, Coase Defends Coase: Why Lawyers Listen and Economists Do Not, 87 Mich. L. Rev. 1171, 1195-96 (1989). 
DELEGATION AND DECOUPLING

or less willing to pay a particular allocative price in allocating the entitlement to itself.

More generally, the allocative invariance result will be qualified to the extent that the chooser's willingness to pay is different than the chooser's willingness to accept. For both cognitive and wealth effect reasons, it is often the case that a particular chooser will demand a higher price when selling an entitlement than she would be willing to pay if forced to buy. ${ }^{135}$ As Saul Levmore has noted in discussing put options:

Armed with the legal right to be free of pollution, [a Resident] might have demanded $\$ 1,000,000$, for example before allowing [a Polluter] to send effluents her way, so that [the Resident's] damages from [the Polluter's] operation can fairly be said to amount to $\$ 1,000,000$; but this does not mean that [the Resident] could or would pay this amount to stop [the Polluter], if the law requires [the Resident] to pay in order to [stop pollution]..$^{136}$

This suggests that there will be a range of prices (in Levmore's example, say, between $\$ 700,000$ and $\$ 1,000,000)$ in which the plaintiff-resident would allocate the entitlement to itself under a put-option implementation (Rule 6) but would allocate the entitlement to the defendant under a call-option implementation (Rule 4). For these intermediate damage amounts, the law's determination of an initial entitlement holder will tend to be sticky. This should not be surprising. It has long been known that endowment effects impede trade in the shadow of property rules; this result carries over to option regimes as well.

${ }^{135}$ Mark Kelman, Consumption Theory, Production Theory and Ideology in the Coase Theorem, 52 S. Cal. L. Rev. 669, 673 (1979); Duncan Kennedy, Cost-Benefit Analysis of Entitlement Problems: A Critique, 33 Stan. L. Rev. 387, 401 (1981); Russell Korobkin, Note, Policymaking and the Offer/Asking Price Gap: Toward a Theory of Efficient Entitlement Allocation, 46 Stan. L. Rev. 663 (1994).

${ }^{136}$ Levmore, supra note 15 , at 2166. 


\section{DELEGATION AND DECOUPLING}

What is more controversial is whether lawmakers should privilege endowment effects in cost-benefit calculus. If a Resident values an entitlement (more than a Polluter) merely because she is initially endowed with it, lawmakers might want to set a low call-option price to allow the Polluter to take control of the entitlement and benefit from its own endowment effect. One goal -- to be traded off against other equity goals -- would be to produce a legal regime where the entitlement flowed to the person who would have the highest willingness to accept. ${ }^{137}$ From an efficiency standpoint, this standard would rank people by their value of "having" rather than their value of "not having." Other things being equal, this standard would lead toward giving the initial entitlement to the party with the larger endowment effect.

The proliferation of different single chooser rules -- including the call, put, "Pay or be Paid," and "Pay or Pay" implementations -- is, again, that they can help lawmakers accommodate competing concerns. When cognitive or wealth effect reasons cause these implementations to be allocatively different, policymakers will at least have more flexibility for trading off a variety of efficiency and equity concerns. Efficiency consideration might militate toward giving the initial entitlement to the party with the larger endowment effect. But if this is the party that the court believes is also the more

${ }^{137}$ See Herbert Hovenkamp, Legal Policy and the Endowment Effect, 20 J. Legal Stud. 225, 232-34, 245-47 (1991) (claiming that willingness to accept should always be used rather than willingness to pay). Russell Korobkin, however, has suggested reasons why allocating entitlements on the basis of willingness to accept is inappropriate when there are independent social norms against selling certain types of entitlements:

Narrowly stated, our society teaches us that we should not sell some things, although buying them is socially acceptable. Although an individual might, in a cultural vacuum, prefer a specific quantity of money to a certain entitlement, he might feel that selling the entitlement is improper and therefore, his WTA will exceed his WTP. This explanation has been called the "dignity hypothesis." Korobkin, supra note 135, at 691-92. 


\section{DELEGATION AND DECOUPLING}

efficient chooser, then the court can accommodate both efficiency concerns by giving the party both the initial entitlement and a put option.

But most basically, more work needs to be done to see the extent to which an endowment effect persists under the various implementations of single chooser (and dual chooser) rules. The path-breaking mug experiments of Kahneman, Knetsh and Thaler only tested whether entitlements protected by property rules gave rise to endowment effects. ${ }^{138}$ It is much less clear whether endowments protected by liability rules-i.e., subject to someone else's call option-give rise to the same effect. In the shadow of a call option, the initial entitlement holder has a more transient, less secure claim to the entitlement and, thus, may not establish the cognitive bond that in part may give rise to the effect. In fact, Jeff Rachlinski and Forest Jourden have recently conducted experiments showing that the endowment effect is largely extinguished in the shadow of traditional liability (call option) rules. ${ }^{139}$ However, put options or other intermediate implementations (such as the "Pay or be Paid" rule) may produce different endowment effects. One possibility is that put option rules would heighten the endowment effect. Put-option implementations give the initial entitlement holder even more control over her "endowment" than traditional property rules, and this may enhance the solidity of ownership. ${ }^{140}$ If the endowment effect is seen as a source of real value that we want

${ }^{138}$ Daniel Kahneman et al., Experimental Tests of the Endowment Effect and the Coase Theorem, 98 J. Pol. Econ. 1325 (1990).

${ }^{139}$ Jeffrey J. Rachlinski \& Forest Jourden, Remedies and the Psychology of Ownership, 51 Vand. L. Rev. 1541, 1551 (1998) (arguing that "the endowment effect may only occur among legal entitlements that are protected by injunctive remedies"). This possibility was first suggested in Ayres \& Talley, supra note 9 , at 1102 .

${ }^{140}$ Russell Korobkin, however, has suggested to us that the put option may commodify the entitlement in the owner's mind in ways that reduce the endowment effect. Imagine that after a pure- 


\section{DELEGATION AND DECOUPLING}

to nurture -- as opposed to a "status quo bias" or "framing effect" that we want to overcome ${ }^{141}$ - then put options may be a way to overcome the inefficiencies of the holdup problem in bilateral monopoly settings without destroying the "value of having." More generally, the infinity of single choice rules discovered here gives policymakers more flexibility in testing for and managing the pros and cons of cognitive bias.

\section{F. Correlated Valuations}

Our foregoing analysis has assumed that the litigants' valuations are independently distributed. While this assumption is plausible in some contexts, ${ }^{142}$ Kaplow and Shavell have pointed out that a plaintiff's and defendant's valuation of physical objects may be correlated. ${ }^{143}$ If a plaintiff places a high value on an oilfield or laptop computer, there are good reasons to think that a defendant's value may be positively correlated.

Correlated valuations make it more difficult for courts to use liability rules to harness the parties' private information. For example, Kaplow and Shavell have shown that if the litigants' overall valuation can be decomposed into a "common-value" and an "idiosyncratic-value"

bred dog has puppies that a mother tells her daughter she can keep the puppies or, after they are weaned, can sell them for $\$ 50$ to a neighbor (who has made a firm offer). The daughter's knowledge that she has a put option might stop her from bonding as closely with the puppies during the weaning period and hence mitigate the endowment effect.

${ }^{141}$ See Russell Korobkin, The Status Quo Bias and Contract Default rules, 83 Cornell L. Rev. 608 (1998).

${ }^{142}$ For example, in many nuisance contexts it is plausible to assume that a polluter's value from polluting will be independent to a resident's value of non-pollution.

${ }^{143}$ Kaplow \& Shavell, supra note 15, at 759. 


\section{DELEGATION AND DECOUPLING}

component, ${ }^{144}$ then it will be difficult for courts to set a damage amount that induces takings that tend to increase social welfare. For example, suppose that (i) the litigants' common-value component is uniformly distributed between $\$ 0$ and $\$ 100$; (ii) the plaintiff's idiosyncratic-value component is uniformly and independently distributed between $\$ 0$ and $\$ 100$; and, (iii) the defendant's idiosyncratic-value component is uniformly and independently distributed between $\$ 0$ and $\$ 75$. A traditional liability rule (Rule 2 ) with damages set equal to the plaintiff's mean valuation of $\$ 100$ ( $\$ 50$ mean common value plus $\$ 50$ mean idiosyncratic value) will be less efficient than giving the plaintiff the entitlement protected by a property rule (Rule 1).

When the litigants' valuations are positively correlated it is difficult for the court's allocative price to distinguish between unexpectedly high realizations of the common-value component versus unexpectedly high realizations of the idiosyncratic-value component. Rule 2 with $\$ 100$ damages would induce the defendant in the foregoing example to take too often. For example when the common-value component turned out to be $\$ 80$, a defendant would take if its idiosyncratic value were as low as $\$ 20$ - even though such takings would be inefficient (as the defendant's mean idiosyncratic value is $\$ 50) .{ }^{145}$

Restated in the terms of this article, Kaplow and Shavell have suggested that when the litigants' valuations are substantially correlated the optimal delegation is no delegation. It is better

${ }^{144}$ Kaplow \& Shavell, supra note 15, at 759-60 ("First, suppose that things have a significant common value, that is, a component of value that is the same for both the owner and any taker. . .Second, assume that things also have idiosyncratic value to individuals. Idiosyncratic value derives from characteristics of a thing that different individuals evaluate differently, such as the design of a home.").

\footnotetext{
${ }^{145}$ Kaplow \& Shavell, supra note 15 , at 760.
} 
DELEGATION AND DECOUPLING

for the courts to allocate the entitlement via a property rule rather than to delegate the allocative decision to the litigants via a liability rule.

But while Kaplow and Shavell are correct that correlated valuations make it more difficult to harness private valuations, they are wrong to conclude that property rules dominate liability rules when valuations are positively correlated. In a separate essay, we show that the examples in their original article systematically overstate the advantages of property rules by comparing the more efficient property rule to a liability rule that has non-optimal damages and the less efficient chooser. ${ }^{146}$ But for now, it is useful to see how nicely dual chooser rules can respond to the correlated value problem.

Remember that the problem with a traditional liability rule (Rule 2) is that the defendant may take - not because she has a high idiosyncratic value - but merely because both litigants' have an unexpectedly high common-value realization. The court would like the defendant only to take if its idiosyncratic value is unexpectedly high, but the court can't observe either the common or idiosyncratic-value components. It can only set a single damage figure which might induce a defendant to take either because it has an unexpectedly high idiosyncratic value (efficient takings) or because both it and the plaintiff have an unexpectedly high common value (inefficient taking). But while the court cannot observe whether the defendant is taking because of a high common value, the plaintiff can.

Dual chooser rules are well suited to respond to the problem of correlated valuations because these rules allow the other side to veto takings that are driven by common-value realizations. The

${ }^{146}$ See Ian Ayres \& Paul M. Goldbart, Correlated Values and the Law (working paper 2001). 


\section{DELEGATION AND DECOUPLING}

problem with Rule 2 in the foregoing example was that defendants might take merely because the common-value component was unexpectedly high. But a defendant-joint-veto rule eliminates this problem by allowing the plaintiff to veto takings that are driven by both parties having a high common value. Under a defendant-joint-veto rule, the entitlement will only be allocated to the defendant if the plaintiff's total value (common plus idiosyncratic) is less than the damage amount and if the defendant's total (common plus idiosyncratic) is greater than the damage amount. Indeed, in the foregoing example it can be shown that the optimal dual-chooser rule produces systematically higher expected joint payoffs than the optimal property rule. ${ }^{147}$ Thus, while correlated valuations make optimal delegation a more difficult judicial task, one or two private heads can still be better than none.

\section{G. Bargaining}

Probably the most serious qualification to our foregoing analysis concerns our assumption of autarky. Our formal model assumes that the litigants cannot bargain with each other -- and considers instead the equilibrium allocation and distribution absent negotiations. This assumption can be given two partial defenses, but ultimately much more work needs to be done to understand how liability rules should be strucutred in a world where transaction costs are relatively small. In this section, we sketch these two partial defenses for our autarky assumption and then show how dual chooser rules induce a new type of information forcing that may militate toward their use when transaction costs are relatively low.

\footnotetext{
${ }^{147}$ In the foregoing example, Rule 1 produces an expected payoff of $\$ 100$, while the optimal defendant-joint-veto rule produces an expected payoff of $\$ 101.39$.
} 


\section{DELEGATION AND DECOUPLING}

The first partial defense of an autarky assumption is basically empirical. There are at least some bilateral contexts in which the disputants seem extremely reluctant to even negotiate much less agree to contract. Ward Farnsworth, for example, surveyed the interactions between nuisance disputants after an initial trial decision and found almost without exception that the litigants and their attorneys failed to even consider negotiating in the shadow of the law. ${ }^{148}$ Enmity between the litigants may produce an important barrier to trade -- an thus inhibit private contract as a means of allocation.

Secondly, an understanding of how liability rules perform when trade is not feasible may provide valuable insights into the relative efficiency of these rules when bargaining is possible. The autarkic payoffs that we have analyzed above become the threat points that will deeply influence the litigants' bargaining strategies. Negotiation theorists also at times refer to such autarkic payoffs of the individual litigants as representing their "reservation prices" for trade or their "BATNAs" ("best alternative to negotiated agreement"). ${ }^{149}$ Because litigants can't be forced through consensual trade to accept less than their BATNA, our previous showings of how judges can vary the distribution of payoffs will continue to hold true in a world where bargaining is feasible. For example, by adopting a defendant choice rule that is implemented with a relatively high alpha (a "Pay or be Paid" rule), the court can, even with bargaining, assure the plaintiff a higher expected return and the defendant a lower expected return than a defendant choice rule implemented with a put option (Rule 5).

\footnotetext{
${ }^{148}$ Farnsworth, supra note 29.

${ }^{149}$ See Jennifer Gerarda Brown \& Ian Ayres, Economic Rationales for Mediation, 80 Va. L.
} Rev. 323, 325-26 (1994). 


\section{DELEGATION AND DECOUPLING}

Kaplow and Shavell, however, have gone further to argue that legal regimes that are relatively more efficient in allocating the entitlement when bargaining is not possible are likely to continue to be more efficient as transaction costs subside and bargaining becomes feasible. Of course, the Coase theorem teaches that all contractible legal regimes (property, single chooser, dual chooser, etc.) will be equally efficient in allocating when transaction costs are nil. But Kaplow and Shavell have argued that the relative efficiency of different rules when bargaining is not possible will tend to persist when bargaining is possible (but not perfect). ${ }^{150}$ Under this persistence conjecture, the non-consensual advantage that, say, a defendant choice rule might have (when the litigants' mean valuations are similar and the variance of the defendant's valuation is greater than the plaintiff's) relative to the other three single-price allocations would be likely to persist if the parties could bargain. For Kaplow and Shavell, the non-consensual headstart that a particular rule has over others in promoting allocative efficiency is likely on average to persist as transaction costs recede and trade becomes possible.

If the persistence conjecture is true, then the foregoing analysis would be the end of the story. By knowing how best to tailor rules when bargaining was prohibited, judges would perforce know how best to tailor rules when bargaining was allowed. Unfortunately, we are not convinced that the persistence conjecture is the entire story. While it is surely the case that the most efficient liability rule under autarchy has a headstart when bargaining is permitted, it is at least possible that other, consensual attributes of the rules may come to dominate the non-consensual attributes. We know, for example, that the persistence conjecture is at most a tendency because Ayres and Talley have

\footnotetext{
${ }^{150}$ Kaplow \& Shavell, supra note 15 , at 421.
} 
DELEGATION AND DECOUPLING

provided a numerical counterexample in which the non-consensual advantage of property rules over liability did not persist once bargaining was allowed. ${ }^{151}$ Moreover, these authors showed that liability rules have a much stronger "information-forcing" effect than property rules. This information forcing represents a potential "consensual advantage" of liability rules that may be much more important in determining the relative efficiency of different legal regimes when bargaining costs are low than the non-consensual advantage that Kaplow and Shavell have emphasized.

In terms of the foregoing analysis, single-chooser rules give the non-chooser a robust incentive to reveal through bargaining whether her value is above or below her mean valuation. For example, imagine that a court announces a defendant choice (call option) rule in which the defendant can allocate the entitlement to itself if it pays the plaintiff $\$ 1$ million (the plaintiff's estimated mean valuation). The plaintiff can respond by either trying to (a) sell the entitlement (for less than $\$ 1$ million) or (b) buy the defendant's call option (in essence trying to bribe the defendant not to take non-consensually). The plaintiff as a non-chooser will only offer to pay the defendant money not to take if its valuation is higher than the court's estimate of its valuation, and it will only offer to sell the underlying entitlement if it's valuation is lower than the court's estimate of its mean valuation. By merely expressing an interest in one type of trade or the other, the non-chooser can credibly signal whether her value is higher or lower than the court's estimate of her mean. ${ }^{152}$ Plaintiff-choice rules

${ }^{151}$ Ayres \& Talley, supra note 9 , a1 104.

${ }^{152}$ Under a put implementation of a defendant choice rule, the plaintiff would only offer to pay the defendant not to exercise its put when the plaintiff's value was lower than the court's estimate of her mean valuation, and the plaintiff would only offer to pay the defendant for the underlying entitlement when the plaintiff's value was higher than the court's estimate of her mean valuation. 


\section{DELEGATION AND DECOUPLING}

analogously give the defendant as non-chooser a robust incentive to credibly signal whether its valuation is higher or lower than it's mean by again merely signaling in which type of trade it is interested.

If the parties' imperfect information is the primary barrier to trade, it is at least possible that these information-forcing effects will dominate the non-consensual advantages of different liability rules outlined above. In particular, it is clear that in the absence of bargaining the more efficient chooser will tend to be the litigant with the more speculative valuation. But when bargaining is allowed, it is at least possible that the more efficient chooser will be the party with the less speculative valuation -- as the negotiation will quickly allow the high variance litigant to narrow her distribution by credibly signaling whether she has a relatively high or low valuation. To date, we have not succeeded in producing an example in which, when bargaining was allowed, the litigant with the less speculative valuation became the more efficient chooser. But at a minimum, the information-forcing effect on the non-chooser systematically narrows the allocative efficiency difference between the two single-choice rules.

The question of whether our autarkic results persist with bargaining, becomes all the more interesting when we add to the mix the possibility of dual chooser rules. It turns out that dual chooser rules have arguably an even stronger information-forcing effect than single chooser rules. While single chooser rules give one of the litigants (the non-chooser) an ability to signal whether it has a relatively high or low valuation, dual chooser rules give both litigants an opportunity to credibly signal whether they have a high or a low value by merely signaling their interest in a particular type of trade. 


\section{DELEGATION AND DECOUPLING}

Consider, for example, a defendant-joint-veto situation implemented through a call/call option regime in which the plaintiff receives (a) the initial entitlement plaintiff (b) subject to a defendant's call option (with an exercise price of $D_{\Delta J V}$ ) but (c) also has an option to take back the entitlement (a call option with an exercise price of $D_{\Delta J V}$ ). In the absence of bargaining, the defendant-joint-veto allocation gives rise to two types of inefficiencies. The first type of inefficiency occurs when the defendant has the higher valuation but the plaintiff nonetheless vetoes a defendant allocation by exercising its take back option. This occurs when $\mathrm{v}_{\Delta}>\mathrm{v}_{\Pi}>\mathrm{D}_{\Delta \mathrm{Jv}}$. And the Coasean solution would be for the defendant to buy the plaintiff's take back (call) option. The second type of inefficiency occurs when the defendant has the higher valuation but the defendant nonetheless vetoes a defendant allocation by not exercising its initial call option. This occurs when $\mathrm{D}_{\Delta \mathrm{JV}}>\mathrm{v}_{\Delta}$ $>v_{\Pi}$. And the Coasean solution for this inefficiency would be for the defendant to buy the underlying entitlement (for some price less than $D_{\Delta J V}$ ).

The defendant, when negotiating in the shadow of this legal rule, can credibly signal that it has a relatively high value $\left(\mathrm{v}_{\Delta}>D_{\Delta J V}\right)$ by merely expressing an interest in being willing to pay the plaintiff not to exercise its take back option. ${ }^{153}$ Conversely, the plaintiff could credibly signal that it has a relatively low value $\left(\mathrm{v}_{\Pi}<D_{\Delta J V}\right)$ by merely expressing an interest in selling it's entitlement for a price less than $D_{\Delta J V}$. Low value defendants would never have a strategic reason for expressing an interest in buying - much less actually offering to buy -- the plaintiff's take back option. And high value plaintiffs would never have a strategic reason for expressing an interest in selling - much

${ }^{153}$ The defendant could also credibly signal its high value by exercising its first-stage call option. But the information forcing stressed in the text allows the defendant to signal its high valuation even before it is called upon to exercise its first stage option. 
DELEGATION AND DECOUPLING

less actually offering to sell - their entitlement for a price less than $D_{\triangle J V}$. Thus dual chooser rules create some opportunity for both litigants to credibly communicate their relative valuations through the process of negotiation.

Just as the possibility of correlated litigant valuations expanded the set of circumstances in which dual chooser rules were allocatively dominant, the arguably stronger information-forcing properties of dual chooser rules may further militate toward their use as trade, in the shadow of these rules, becomes more feasible. A full analysis of liability rules when transaction costs (including imperfect information) are low but not zero has eluded scholars. It may be that the particular ranking of rules' efficiency will turn not just on the general characteristics of the litigants' value distributions but on the specifics of the bargaining procedures that are assumed.

In this section, we have tried to argue that autarkic results are of interest because (a) empirically some bilateral disputants face high transaction costs, (b) the non-consensual headstart that we have identified may tend to persist when bargaining is possible, and (c) the autarkic payoffs that we have derived become the threat points that will deeply inform the bargaining behavior of the parties. Our finding that dual chooser rules have different and arguably stronger information-forcing effects than those previously identified for single chooser rules suggests, however, that the autarkic analysis may not be the complete story. On this dimension we are forced to repeat the hackneyed and unsatisfactory conclusion that more research on this issue is warranted.

\section{CONCLUSION}

While we have often motivated our analysis with a nuisance example, this article is really about a deeper and more canonical problem about how courts should allocate rivalrous entitlements 
$\underline{\text { DELEGATION AND DECOUPLING }}$

when the court has poorer information than the litigants about who is the higher-valuing owner. Most basically, we have been envisioning a conflict in which the court -- even after discovery and an adversarial trial -- only has a probabilistic assessment of each litigant's value, whereas each litigant knows (or at least has better information) about how much she values the entitlement. In such a basic bilateral dispute with imperfect judicial information, the court faces a non-trivial problem of how to best allocate claims to the entitlement.

When the private litigants are better informed than the court, it will be useful for the court to adopt an allocative rule that harnesses some of the litigants' private information. This article has shown that there are four basic allocations from which courts may choose. The traditional liability rules -- Rules 2 and 4 -- exemplify two of these equilibria -- the plaintiff choice and defendant choice rules. But we have shown that there are two other dual chooser rules which not only have common law analogs but which, under specific circumstances, can produce greater allocative efficiency than single chooser rules.

Moreover, we have shown there are infinite number of implementations of each type of rule which are allocatively equivalent but which allow the court to distribute the total expected payoff of the litigants as it sees fit. This means that courts, in resolving bilateral disputes, can decouple allocative and distributive concerns. By selecting the more efficient chooser or choosers and by setting the efficient allocative price, a court can maximize ex post allocative efficiency. And independent of these core allocative decisions the court has a free hand to distribute the expected payoffs as it wants. Thus, distributively-concerned courts are free to pursue equity or promote ex ante efficiency without sacrificing the natural desire to see that the entitlement ends up in the hands 


\section{DELEGATION AND DECOUPLING}

of the highest valuing user (the ex post allocative efficiency concern). We take this decoupling result and our analysis of dual chooser rules to be our central findings.

While we have focused on how courts should structure liability rules, our analysis does have implications for the equally important choice of when courts should opt for liability rules over property rules. Legal scholars have generated a number of rationales for why property rules might dominate liability rules. ${ }^{154}$ We focus here on three rationales for property rules that are qualified by the foregoing analysis. One of the oldest rationales was that property rules are better at inducing trade than liability rules when transaction costs were relatively low. Ayres and Talley seriously undermined this rationale by showing that liability rules have a greater information-forcing effect than property rules and providing examples in which liability rules were more effective in inducing trade. And this article has furthered this criticism by showing that dual chooser rules also have new and potentially stronger information-forcing qualities that may give dual chooser rules a consensual advantage over property rules.

As a second rationale, many authors (including Ayres and Talley) ${ }^{155}$ have argued that property rules give individuals better ex ante investment incentives to create the disputed entitlement to begin with. The idea here is that Krier is less likely to build a new house if Schwab has the option to take non-consensually and pay Krier's mean valuation. But this result only makes sense if we limit our attention to the call implementations of liability rules. ${ }^{156}$ The foregoing decoupling result shows that

${ }^{154}$ See Epstein, supra note 7; Rose, supra note 7; Ayres \& Talley, supra note 7.

${ }^{155}$ Ayres \& Talley, supra note 7, at 1743.

${ }^{156}$ Even under the call implementation, its not clear why this argument makes sense. If Krier at the time of investment does not yet know what his valuation will be, then promising him his mean 


\section{DELEGATION AND DECOUPLING}

there are both single chooser and dual chooser implementations that can allocate even greater expected payoffs to either litigant than can be allocated in the absence of bargaining under a property rule regime. The decoupling result seriously qualifies the investment rationale for using property rules because it suggests that courts both retain the ex post (information-harnessing) benefits of liability rules without undermining ex ante investment incentives.

Finally, and most recently, Kaplow and Shavell have argued that property rules will tend to dominate liability rules when the litigants' valuations are correlated. They argue that liability rules will tend to be less efficient because chooser will allocate the entitlement to themselves not because their idiosyncratic value for the entitlement is high, but because the common-value element of the entitlement's value takes on an unexpectedly high value which exceeds the court's allocative price. ${ }^{157}$ Their analysis makes eminent sense in comparing the relative efficiency of property rules to single chooser rules, ${ }^{158}$ but as we showed above, there analysis was limited because it did not consider the possibility of dual choice rules. Dual choice rules, by giving both litigants a veto over certain allocations, can better select for circumstances when the idiosyncratic and not common value is

valuation should not deter his investment - indeed, if he is risk averse it may decrease the variance in his payoffs and make him more willing to invest. However, if Krier at the time of investing knows what his future valuation will be, then promising him his mean valuation (should Schwab take) may deter him from some valuable types of investment when his actual value will turn out to be higher than the court's perceived mean value.

${ }^{157}$ Conversely, choosers may allocate the entitlement to the non-chooser, not because their idiosyncratic value for the entitlement is low, but because the common-value element of the entitlement's value takes on an unexpectedly low value which falls short of the court's allocative price.

${ }^{158}$ Even though, as we note above, supra at 94, Kaplow and Shavell fail to compare the property rule to the most efficient single chooser rule -- because their example uses the less efficient chooser and non-optimal damages. 


\section{DELEGATION AND DECOUPLING}

driving the allocative choice.

In sum, the option analysis of liability rules tends to increasingly tilt as a theoretical matter toward the use of liability rules. In some sense this is a natural byproduct of entering more liability rule horses in the race to compete against the two property rule stalwarts (Rules 1 and 3). Still, there are strong reasons why property rules will at times dominate, ${ }^{159}$ but this article and other recent efforts have made progress on identifying narrower but firmer grounds on which property rules can stake their dominance. But when liability rules dominate, lawmakers would be well advised to consider the fuller panoply of implementations than merely the call option rules of Calabresi and Melamed.

To get a fuller sense of why other implementations of the four basic allocations might be useful, it is useful in closing to speculate on how the foregoing analysis might be applied to breach of contract. ${ }^{160}$ Contractual entitlements are normally protected by a single type of liability rule. The promisor has a call option on the promisee's entitlement to performance. The promisor by breaching can take the promisee's entitlement to performance and merely pay compensatory damages set at the court's best estimate of the promisee's value of performance. Thus, unless the extraordinary damage

${ }^{159}$ Ayres \& Talley, supra note 9, at 214; Epstein, supra note 9, at 2195; and Rose, supra note 9 , at 2180 .

${ }^{160}$ To begin, the absence of contract law from Calabresi and Melamed's view of the cathedral is striking. The subject might have been omitted because contracts didn't fit their theory well. Calabresi and Melamed have been understood by subsequent scholars to have argued that liability rules tend to dominate when transaction costs are high, but that property rules dominate when transaction costs are low. Contractual entitlements don't fit because they are protected by liability rules even though transaction costs were sufficiently low for the parties to enter into an initial contract. 
$\underline{\text { DELEGATION AND DECOUPLING }}$

of specific performance is due, the standard remedy implements (in nuisance terminology) a kind of Rule 2. Recharacterized in this way, we can see that contract law lags behind the state of nuisance law because while at least one court (in Spur) has implemented Calabresi and Melamed's Rule 4, contract courts do not give promisees the choice of whether they prefer performance or to receive damages.

Contract remedies are infirm for placing the allocative authority solely in the hands of the promisor. True expectations damages, as an implementation of a defendant choice rule, can induce the defendant to breach efficiently - given her private information about the costs of breach. But the foregoing analysis suggests that, at times, the plaintiff will be the better chooser to decide whether performance should take place, or at still other times both the plaintiff and the defendant will make better allocative decisions (than either one or the other could do by herself). The traditional expectation damage rule does a good job of harnessing the defendant/promisor's private information, but does not harness the information of the plaintiff/promisee. At times (particularly when the litigants have similar variances but different means) the court would do better to implement a dual chooser rule by announcing an allocative price and then giving each party the opportunity to veto the defendant's breach.

Or, as an alternative, it might be useful to give the promisee the option of increasing the damages she would receive for the promisor's breach by making a firm offer to pay more for performance. ${ }^{161}$ Thus, after a seller anticipatorilly repudiated a contract, a court might give the buyer the option of offering the seller an additional amount to perform. The seller could either accept this

${ }^{161}$ Ayres \& Balkin, supra note 15 , at 746. 
DELEGATION AND DECOUPLING

amount and perform, or breach the contract and pay ordinary damages plus the additional amount that the buyer offered to pay. ${ }^{162}$ Judges could implement this scheme by instructing a jury to determine ordinary expectation damages (without knowledge of the attempted modification), and then simply adding the enhancement to the jury's award. This mechanism would allow the plaintiff/buyer to credibly signal when her value of performance was higher than the provable mean valuation. ${ }^{163}$ The defendant/seller would then face a truer allocative price in deciding whether to breach.

Both contract and nuisance law provide rich settings in which to apply our analysis, but there are others as well. For example, many countries use "compulsory licensing" schemes to mitigate the bilateral monopoly problems of "blocking patents." ${ }^{\text {"164 }}$ Compulsory licenses of course amount to a call-option implementation of a single choice rule. But by now it should be obvious that giving the allocative choice to the other side or to two both sides in a block patent dispute might be superior

${ }^{162}$ Buyer's ability to enhance the seller's potential damages should be limited to circumstances in which performance was feasible. Otherwise, buyers might make an inflated offer (i.e., an offer that exceeds their private values for performance) if they know that changed circumstances have rendered the seller's performance impossible. See id, at 747 n. 137.

${ }^{163}$ Buyers deciding how much to offer to induce performance would have a powerful incentive not to offer too much. If the offer were too generous, the seller would simply accept it and perform.

${ }^{164}$ See Gianna Julian-Arnold, International Compulsory Licensing: The Rationales and the Reality, 33 Idea 349 (1987) (noting that blocking patents are one of the three most common conditions for compulsory licensing abroad). Countries that have compulsory licenses for blocking patents include Australia, China, France, Japan, the Netherlands, New Zealand and Switzerland. See Robert Merges, Intellectual Property Rights and Bargaining Breakdown: The Case of Improvement Inventions and Blocking Patents 30-31 (1994). U.S. patent law also mandates compulsory licenses with regard to nuclear power and environmental engineering technologies. See Ayres \& Talley, supra note 15, at 1093 . 
(and that it might be useful to consider "Pay or be Paid" implementations to adjust the expected distribution). At the end of the day, bilateral disputes over rivalrous entitlements do not come close to describing the "cathedral" of allocative dilemmas facing courts, but they represent a substantial enough proportion of the world to justify our inquiry. 


\section{Appendix: Exploring the derivation of some of the results considered in the main text}

\section{INTRODUCTION}

The purpose of this appendix is to explain how to derive a selection of the results used in the main text. Examples of these results include formulas for (or at least obeyed by) optimal damages under various liability rules. We shall, for the sake of completeness, adopt formulations that allow for probability distributions for plaintiff and defendant valuations that are correlated in the most general way. However, we shall quickly proceed to important special cases, such as those in which the valuations are uncorrelated from one another or may be decomposed into one common and two idiosyncratic components, these three components being uncorrelated from one another.

Our aim is to be pedagogical and illustrative rather than exhaustive, and we hope that readers will find our derivations digestible. Along the way we shall introduce some technical devices, such as the Dirac delta functions and the Heaviside theta, which we find rather useful in the present context.

\section{A. Basic ingredients}

We shall denote by $\mathcal{A}$ the asset whose ultimate ownership is being established. We shall denote by $\Pi$ both the plaintiff and quantities associated with the plaintiff; similarly we denote by $\Delta$ both the defendant and quantities associated with the defendant. We shall denote the value that $\Pi$ ascribes to the asset $\mathcal{A}$ by $V_{\Pi}$; similarly, we shall denote the value that $\Delta$ ascribes $\mathcal{A}$ by $V_{\Delta}$. The quantities $V_{\Pi}$ and $V_{\Delta}$ vary randomly from instance to instance. In any specific instance, the value of $V_{\Pi}$ is known only to $\Pi$ and the value of $V_{\Delta}$ is known only to $\Delta$. All parties, however, know the joint probability distribution $P_{\Pi \Delta}\left(V_{\Pi}, V_{\Delta}\right)$ governing the values $V_{\Pi}$ and $V_{\Delta}$ of $\mathcal{A}$ ascribed by $\Pi$ and $\Delta$. The joint probability distribution $P_{\Pi \Delta}\left(V_{\Pi}, V_{\Delta}\right)$ is defined so that, for vanishingly small ranges $\delta V_{\Pi}$ and $\delta V_{\Delta}$, the probability that $\mathcal{A}$ will have a value to $\Pi$ in the range $V_{\Pi}$ to $V_{\Pi} \delta V_{\Pi}$ and a value to $\Delta$ in the range $V_{\Delta}$ to $V_{\Delta} \delta V_{\Delta}$ is given by $P_{\Pi \Delta}\left(V_{\Pi}, V_{\Delta}\right) \delta V_{\Pi} \delta V_{\Delta}$.

\section{B. Some notation and mathematical devices}

\section{Expectation values}

It is convenient to introduce the notational device of representing expectation values of quantities that depend on random variables such as $V_{\Pi}$ and $V_{\Delta}$ by enclosing those quantities in angle brackets $\langle\ldots\rangle$. Such objects have the meaning of the value of the enclosed quantity averaged over random variables on which it depends, this average being weighted by the appropriate joint probability distribution. We shall find it useful to indicate the random variables that are being averaged over via subscripts on the angle brackets. For example, $\left\langle V_{\Pi} V_{\Delta}\right\rangle_{\Pi \Delta}$ denotes the expectation value of the product $V_{\Pi} V_{\Delta}$ with respect to $P_{\Pi \Delta}\left(V_{\Pi}, V_{\Delta}\right)$; and $\left\langle V_{\Pi}^{2}\right\rangle_{\Pi}$ denotes the expectation value of $V_{\Pi}^{2}$ with respect to $\tilde{P}\left(V_{\Pi}\right)$

\section{Heaviside step function}

It is also convenient to introduce the Heaviside step function $\theta(x)$, which is defined via

$$
\theta(x)= \begin{cases}0 & \text { for } x<0 \\ 1 & \text { for } 0 \leq x\end{cases}
$$

This function makes it straightforward to restrict the range of values over which a random variable (e.g. $\left.V_{\Pi}\right)$ runs. One often needs to make such restrictions when there is extra information known (and hence conditions obeyed) by random variables, e.g., that the variable exceeds some specificed value. In most circumstances the precise value of $\theta$ at $x=0$ is not significant, although it is often convenient to take it to be one half. Note the elementary and useful property: $\theta(x)+\theta(-x)=1$.

\section{Dirac delta function}

We also introduce the Dirac delta function $\delta(x)$, which one may define

$$
\delta(x)=\frac{d}{d x} \theta(x) .
$$

Strictly speaking, this is a distribution rather than a function and, as such, it needs to be handled with some care. Despite this, like the Heaviside step function, the Dirac delta function is a very useful mathematical device. It makes it straightforward to impose the condition that a random variable takes on a certain value.

For readers who are unfamiliar with the Dirac delta function $\delta(x)$ we mention that one (of many) useful ways to think about it is as a normalized Gaussian probability distribution for the random variable $x$, taken in the limit that the width (i.e. the standard deviation) of the distribution is vanishingly small (i.e. is much smaller than any characteristic value of the variable in question).

With this thought in mind, readers might wish to try sketching $\theta(x)$ versus $x$ and then its slope $d \theta(x) / d x$. This exercise should show that it is at least plausible (and can 
in fact be shown) that for suitably well-behaved functions $f(x)$ we then have

$$
\int d x \delta(x) f(x)=f(0) \int d x \delta(x)=f(0),
$$

where the lower and upper limits of integration respectively lie below and above the origin (i.e. $x=0$ ). From this result one can readily show, e.g., that

$$
\int d x \delta(x-y) f(x)=f(y)
$$

provided that the range of integration encloses the point $x=y$ and that $f(x)$ is suitably well-behaved.

More information concerning the Heavisde step function and the Dirac delta function can be found in many sources, including, e.g.: a nonrigorous account in K. F. Riley, M. P. Hobson and S. J. Bence, Mathematical Methods for Physics and Engineering (Cambridge University Press, 1997), Sec. 11.1.3; and more rigorous accounts in M. J. Lighthill, Fourier Analysis and Generalised Functions (Cambridge University Press, 1962) and A. H. Zemanian, Distribution Theory and Transform Analysis (Dover, 1987).

\section{Model distributions}

We collect here some ideas concerning various model probability distributions governing the valuations that the plaintiff $\Pi$ and the defendant $\Delta$ ascribe the the asset $\mathcal{A}$.

\section{Generally correlated asset valuations}

In the most general case, the random values ascribed to $\mathcal{A}$ (viz. $V_{\Pi}$ and $V_{\Delta}$ ) are correlated. This means that the probability density for a specific value of $V_{\Pi}$ to occur, given a value of $V_{\Delta}$, depends on the value of $V_{\Delta}$ (and vice versa). In such cases, the joint probability distribution $P_{\Pi \Delta}\left(V_{\Pi}, V_{\Delta}\right)$ does not factorize into two factors, and neither do expectation values of products of factors, one depending on $V_{\Pi}$ and one depending on $V_{\Delta}$.

\section{Uncorrelated asset valuations}

Considerable simplifications arise, as we shall see, if we adopt a special model in which the random values $V_{\Pi}$ and $V_{\Delta}$ are uncorrelated. In this case, the joint probability distribution $P_{\Pi \Delta}\left(V_{\Pi}, V_{\Delta}\right)$ factorizes into two factors:

$$
P_{\Pi \Delta}\left(V_{\Pi}, V_{\Delta}\right)=\tilde{P}_{\Pi}\left(V_{\Pi}\right) \tilde{P}_{\Delta}\left(V_{\Delta}\right),
$$

in which one factor, $\tilde{P}_{\Pi}\left(V_{\Pi}\right)$, governs the distribution of $V_{\Pi}$, and the other, $\tilde{P}_{\Delta}\left(V_{\Pi}\right)$, governs the distribution of $V_{\Pi}$. Under such circumstances, expectation values of products of terms, one depending solely on $V_{\Pi}$ and the other solely on $V_{\Delta}$, factorize into independent expectation values:

$$
\left\langle F_{\Pi}\left(V_{\Pi}\right) F_{\Delta}\left(V_{\Delta}\right)\right\rangle_{\Pi \Delta}=\left\langle F_{\Pi}\left(V_{\Pi}\right)\right\rangle_{\Pi}\left\langle F_{\Delta}\left(V_{\Delta}\right)\right\rangle_{\Delta},
$$

where $F_{\Pi}$ and $F_{\Delta}$ are arbitrary functions of their arguments, and $\langle\cdots\rangle_{\Pi}$ and $\langle\cdots\rangle_{\Delta}$ denote expectation values with respect to the respective distributions $\tilde{P}$ and $\hat{P}$. An important diagnostic of correlations is provided by the fluctuation correlator

$$
\left\langle\left(V_{\Pi}-\left\langle V_{\Pi}\right\rangle_{\Pi \Delta}\right)\left(V_{\Delta}-\left\langle V_{\Delta}\right\rangle_{\Pi \Delta}\right)\right\rangle_{\Pi \Delta},
$$

which characterizes the extent to which departures of $V_{\Pi}$ from its expectation value $\left\langle V_{\Pi}\right\rangle_{\Pi \Delta}$ are correlated with (i.e. occur in the same sense as) departures of $V_{\Delta}$ from its expectation value $\left\langle V_{\Delta}\right\rangle_{\Pi \Delta}$.

\section{Decomposable correlated asset valuations}

As our second special case, let us suppose that the random values $V_{\Pi}$ and $V_{\Delta}$ are correlated, but not arbitrarily so. Instead, we shall take the correlations to have a special, relatively simple, form. Specifically, let us regard $V_{\Pi}$ and $V_{\Delta}$ as being composed from the underlying random variables $W_{B}, W_{\Pi}$ and $W_{\Delta}$ via

$$
\begin{aligned}
& V_{\Pi}=W_{B}+W_{\Pi}, \\
& V_{\Delta}=W_{B}+W_{\Delta},
\end{aligned}
$$

the variables $W_{B}, W_{\Pi}$ and $W_{\Delta}$ being governed by the factorized, and hence uncorrelated, joint probability distribution

$$
P\left(W_{B}, W_{\Pi}, W_{\Delta}\right)=\hat{P}_{B}\left(W_{B}\right) \hat{P}_{\Pi}\left(W_{\Pi}\right) \hat{P}_{\Delta}\left(W_{\Delta}\right) .
$$

This distribution has the following interpretation: $V_{\Pi}$ and $V_{\Delta}$ have a common random component $W_{B}$ and are respectively supplemented by the random components $W_{\Pi}$ and $W_{\Delta}$, with all three ingredients $\left(W_{B}, W_{\Pi}\right.$ and $W_{\Delta}$ ) being statistically independent of one another. To acquire some feeling for this distribution, consider the fluctuation correlator quantity

$$
\left\langle\left(V_{\Pi}-\left\langle V_{\Pi}\right\rangle\right)\left(V_{\Delta}-\left\langle V_{\Delta}\right\rangle\right)\right\rangle_{\Pi \Delta} .
$$

In terms of the component variables, this becomes

$$
\begin{aligned}
\left\langle\left( W_{B}+\right.\right. & \left.W_{\Pi}-\left\langle W_{B}\right\rangle-\left\langle W_{\Pi}\right\rangle\right) \\
& \left.\times\left(W_{B}+W_{\Delta}-\left\langle W_{B}\right\rangle-\left\langle W_{\Delta}\right\rangle\right)\right\rangle_{B \Pi \Delta},
\end{aligned}
$$

which reduces (given the statistical independence of $W_{B}$, $W_{\Pi}$ and $\left.W_{\Delta}\right)$ to

$$
\left\langle\left(W_{B}-\left\langle W_{B}\right\rangle\right)^{2}\right\rangle_{B}
$$

i.e., simply to the mean-square fluctuations in the common component $W_{B}$ away from its expectation value $\left\langle W_{B}\right\rangle$. This result exemplifies the fact that it is the common component that induces correlations between $V_{\Pi}$ and $V_{\Delta}$. 


\section{SINGLE-CHOOSER RULES}

We now explore an example of the single-chooser rules, specifically the scenario presented by Single-Chooser Rule 2. Under this rule, the plaintiff $\Pi$ begins with the entitlement to the asset $\mathcal{A}$ and the defendant $\Delta$ begins with a call option (which we shall denote by $\mathcal{C}$ ). This furnishes $\Delta$ with option to buy $\mathcal{A}$ from $\Pi$ upon payment of certain damages, which we shall denote by $D$. We may indicate this scenario schematically by

$$
\begin{array}{rr}
\text { П }: & \mathcal{A}-\mathcal{C}, \\
\Delta: & +\mathcal{C} .
\end{array}
$$

\section{A. Optimal damages}

We now set about determining the value of the damages $D$ that impose the least constraint on "the economy". This value of $D$ has the property that imposing it would ensure that the expectation value of the total profit [i.e. the sum of the profits made by $\Pi$ and $\Delta$, averaged with respect to $\left.P_{\Pi \Delta}\left(V_{\Pi}, V_{\Delta}\right)\right]$, which is denoted by $\langle T\rangle_{\Pi \Delta}$, be as large as possible. As we shall see, the computation of $D$ and the corresponding calue of $\langle T\rangle_{\Pi \Delta}$ does not require any knowledge of the values of the assets in any specific instances, being determined by only the scenario being applied and $P_{\Pi \Delta}\left(V_{\Pi}, V_{\Delta}\right)$. Thus, it is, at least in principle, computable by any party, including a third party, such as a judge, who has knowledge of $P_{\Pi \Delta}\left(V_{\Pi}, V_{\Delta}\right)$. In the absence of information beyond $P_{\Pi \Delta}\left(V_{\Pi}, V_{\Delta}\right)$, the value of $D$ that maximizes $\langle T\rangle_{\Pi \Delta}$ is the choice that sets the least constraint on $\langle T\rangle_{\Pi \Delta}$.

\section{Generally correlated asset valuations}

To determine the optimal value of $D$, observe that $\Delta$ will exercise the call option in all instances in which it is profitable for her to do so (i.e. in all instances in which her valuation of the asset $V_{\Delta}$ exceeds a certain value $Q$, which we shall refer to as the pivot value and shall discuss in detail, below). Let us now set about determining the pivot value $Q$ and contructing a scheme for determining the value of $D$

Let us indicate by the pair $\left(T_{\Pi}, T_{\Delta}\right)$ the profit made, respectively, by $\Pi$ and $\Delta$ in a specific instance (i.e. for specific valuations $V_{\Pi}$ and $V_{\Delta}$ of the asset respectively to $\Pi$ and $\Delta$ ). According to the scenario outlined above, we have

$$
\left(T_{\Pi}, T_{\Delta}\right)= \begin{cases}\left(V_{\Pi}, 0\right) & \text { for } V_{\Delta} \leq Q \\ \left(D, V_{\Delta}-D\right) & \text { for } V_{\Delta}>Q\end{cases}
$$

In particular, for the total profit $T$ we then have

$$
T \equiv T_{\Pi}+T_{\Delta}= \begin{cases}V_{\Pi} & \text { for } V_{\Delta} \leq Q \\ V_{\Delta} & \text { for } V_{\Delta}>Q\end{cases}
$$

Said more informally, if $V_{\Delta} \leq Q$ then $\Delta$ does not exercise the option to buy the asset, so $\Pi$ retains the asset (which has value $V_{\Pi}$ to her) and $\Delta$ has nothing. By contrast, if $V_{\Delta}>Q$ then $\Delta$ does exercise the option to buy the asset, so $\Pi$ no longer has the asset but instead has the damages $D$, and $\Delta$ has the asset (which has value $V_{\Delta}$ to her) but has had to pay $D$ to exercise this option.

Now, by averaging the total profit $T$ over $V_{\Pi}$ and $V_{\Delta}$ with respect to $P_{\Pi \Delta}\left(V_{\Pi}, V_{\Delta}\right)$ we arrive at an expression for the expectation value of $T$, viz.,

$$
\begin{aligned}
\int_{V_{\Delta} \leq Q} d V_{\Pi} d V_{\Delta} P_{\Pi \Delta}\left(V_{\Pi}, V_{\Delta}\right) V_{\Pi} \\
\quad+\int_{V_{\Delta}>Q} d V_{\Pi} d V_{\Delta} P_{\Pi \Delta}\left(V_{\Pi}, V_{\Delta}\right) V_{\Delta} .
\end{aligned}
$$

In terms of the Heaviside step function $\theta$ discussed in Sec. 0.B 2 we may rewrite this expectation value as

$$
\begin{aligned}
& \int d V_{\Pi} d V_{\Delta} P_{\Pi \Delta}\left(V_{\Pi}, V_{\Delta}\right) V_{\Pi} \theta\left(Q-V_{\Delta}\right) \\
& \quad+\int d V_{\Pi} d V_{\Delta} P_{\Pi \Delta}\left(V_{\Pi}, V_{\Delta}\right) V_{\Delta} \theta\left(V_{\Delta}-Q\right) .
\end{aligned}
$$

In terms of the angle-bracket notation for expectation values we have the convenient and compact expression

$$
\begin{aligned}
\langle T\rangle_{\Pi \Delta} & =\left\langle T_{\Pi}+T_{\Delta}\right\rangle_{\Pi \Delta} \\
& =\left\langle V_{\Pi} \theta\left(Q-V_{\Delta}\right)\right\rangle_{\Pi \Delta}+\left\langle V_{\Delta} \theta\left(V_{\Delta}-Q\right)\right\rangle_{\Pi \Delta} .
\end{aligned}
$$

The first term on the right hand side can be thought of as the product of two factors:

$\left\langle V_{\Pi} \theta\left(Q-V_{\Delta}\right)\right\rangle_{\Pi \Delta} /\left\langle\theta\left(Q-V_{\Delta}\right)\right\rangle_{\Pi \Delta}$ and $\left\langle\theta\left(Q-V_{\Delta}\right)\right\rangle_{\Pi \Delta}$. The former is the expectation value of $V_{\Pi}$ subject to the condition that $V_{\Delta}\langle Q\rangle$; the latter is the probability that $V_{\Delta}<Q$. Similarly, the second term on the right hand side can be thought of as a product of two factors: $\left\langle V_{\Delta} \theta\left(V_{\Delta}-Q\right)\right\rangle_{\Pi \Delta} /\left\langle\theta\left(V_{\Delta}-Q\right)\right\rangle_{\Pi \Delta}$ and $\left\langle\theta\left(V_{\Delta}-Q\right)\right\rangle_{\Pi \Delta}$. The former is the expectation value of $V_{\Pi}$ subject to the condition that $V_{\Delta} \geq Q$; the latter is the probability that $V_{\Delta} \geq Q$.

Our next task is to relate the pivot value $Q$ to the damages $D$. To do this, we note that, in any specific instance, in exercising her option $\Delta$ would make a profit of $\left(V_{\Delta}-D\right)$ whereas in not exercising her option she would make a profit of 0 . Thus, in the context of this single-chooser rule, $\Delta$ will elect to exercise her option whenenver $V_{\Delta}>D$ and, hence, the pivot value and the damages are equal: $Q=D$.

Now that we have established that the pivot value of $V_{\Delta}$ is in fact the damages $D$, what remains is to determine the value of the damages $D$ that maximises the expectation value of the total profit $\langle T\rangle_{\Pi \Delta}$. To do this, we examine the condition that $\langle T\rangle_{\Pi \Delta}$ be stationary with respect to variations of $D$ : 


$$
\begin{aligned}
0 & =\frac{\partial}{\partial D}\langle T\rangle_{\Pi \Delta} \\
& =\frac{\partial}{\partial D}\left(\left\langle V_{\Pi} \theta\left(D-V_{\Delta}\right)\right\rangle_{\Pi \Delta}+\left\langle V_{\Delta} \theta\left(V_{\Delta}-D\right)\right\rangle_{\Pi \Delta}\right) .
\end{aligned}
$$

By using the properties of $\theta(x)$ and $\delta(x)$ in the computation of the derivative with respect to $D$ in Eq. (1.6) we arrive at the condition

$$
\left\langle V_{\Delta} \delta\left(V_{\Delta}-D\right)\right\rangle_{\Pi \Delta}=\left\langle V_{\Pi} \delta\left(D-V_{\Delta}\right)\right\rangle_{\Pi \Delta}
$$

Next, by observing that the entity being averaged on the right hand side is nonzero only when $V_{\Delta}=D$ we can extract a factor of $D$ and rearrange to obtain a formula for the value (or possible values) of $D$ that make $\langle T\rangle_{\Pi \Delta}$ stationary:

$$
D=\frac{\left\langle V_{\Pi} \delta\left(V_{\Delta}-D\right)\right\rangle_{\Pi \Delta}}{\left\langle\delta\left(V_{\Delta}-D\right)\right\rangle_{\Pi \Delta}}
$$

which determines $D$ implicitly in terms of the joint probability distribution $P_{\Pi \Delta}$. Let us pause to interpret this formula. It says that that for $D$ to make $\langle T\rangle_{\Pi \Delta}$ stationary it must equal the expectation value of $V_{\Pi}$ subject to the condition that $V_{\Delta}$ takes the value $D$. Now let us explore some special cases of Eq. (1.8).

\section{Uncorrelated asset valuations}

The least complicated setting holds if $P_{\Pi \Delta}$ is an uncorrelated probability distribution. Then the expectation value in the numerator of the right-hand side of Eq. (1.8) factorizes into $V_{\Pi}$-dependentand $V_{\Delta}$-dependent factors, the latter then cancelling with a similar factor in the denominator to yield the simple result

$$
D=\left\langle V_{\Pi}\right\rangle_{\Pi}
$$

i.e., the optimal damages should be set to the mean of $\Pi$ 's valuation (i.e. the non-chooser's mean).

To ascertain the nature of the optimal value of $\langle T\rangle_{\Pi \Delta}$ with respect to variations of $D$ at the stationary point determined by Eq. (1.9) we consider the second derivative:

$$
\begin{aligned}
\frac{\partial^{2}\langle T\rangle_{\Pi \Delta}}{\partial D^{2}}= & \frac{\partial^{2}}{\partial D^{2}}\left(\left\langle V_{\Pi}\right\rangle_{\Pi}\left\langle\theta\left(D-V_{\Delta}\right)\right\rangle_{\Delta}\right. \\
& \left.+\left\langle V_{\Delta} \theta\left(V_{\Delta}-D\right)\right\rangle_{\Delta}\right) \\
= & \left(\left\langle V_{\Pi}\right\rangle_{\Pi}-D\right) \frac{\partial}{\partial D} \tilde{P}_{\Delta}(D)-\tilde{P}_{\Delta}(D)
\end{aligned}
$$

At the stationary point in question, $D$ is given by Eq. (1.9) and, hence, the second derivative takes on the value $-\tilde{P}_{\Delta}(D)$ which, by virtue of $\tilde{P}_{\Delta}$ being a probability distribution, is negative. Thus we ascertain that the stationary point in question is indeed a maximum of $\langle T\rangle_{\Pi \Delta}$, so that the damages are indeed optimal.
We are also able to give an explicit formula for the total mean profit in terms of $D$ :

$$
\langle T\rangle_{\Pi \Delta}=\left\langle V_{\Pi}\right\rangle_{\Pi}\left\langle\theta\left(D-V_{\Delta}\right)\right\rangle_{\Delta}+\left\langle V_{\Delta} \theta\left(V_{\Delta}-D\right)\right\rangle_{\Delta} .
$$

The meaning of this formula is as follows: the first contribution is the expectation value of $\Pi$ 's valuation, multiplied by the probability that $\Delta$ 's valuation is less than $D$; the second contribution is the expectation value of $\Delta$ 's valuation subject to the condition that this valuation exceeds $D$, multiplied by the probability that $\Delta$ 's valuation exceeds $D$. As we shall soon see, Eq. (1.11) can be rewritten in several equivalent ways by invoking the property if the Heavisde step function mentioned Sec. 0 B 2 as well as Eq. (1.9).

It is straightforward to apply this technology to the other three of the four single-chooser rules (i.e. Rules 4,5 and 6 ). In doing so one finds, just as we we have for Rule 2, that the pivot value is given by the damages, and that under each rule the optimal value of the damages is given by the non-chooser's mean valuation of the asset. One can also establish, for each rule, formulas for the expected total profit analogous to that given for Rule 2 in Eq. (1.11). In fact, it is useful to rewrite these formulas in two equivalent ways by invoking the property if the Heavisde step function mentioned Sec. 0 B 2. In doing so one finds the following expressions for the total mean profit, appropriate for each of the four single-chooser rules (which rule being indicated by the pre-superscript):

$$
\begin{aligned}
{ }^{2}\langle T\rangle_{\Pi \Delta} & =\left\langle V_{\Pi}\right\rangle_{\Pi}+\left\langle\left(V_{\Delta}-\left\langle V_{\Pi}\right\rangle_{\Pi}\right) \theta\left(V_{\Delta}-\left\langle V_{\Pi}\right\rangle_{\Pi}\right)\right\rangle_{\Delta} \\
& =\left\langle V_{\Delta}\right\rangle_{\Delta}+\left\langle\left(\left\langle V_{\Pi}\right\rangle_{\Pi}-V_{\Delta}\right) \theta\left(\left\langle V_{\Pi}\right\rangle_{\Pi}-V_{\Delta}\right)\right\rangle_{\Delta}, \\
{ }^{4}\langle T\rangle_{\Pi \Delta} & =\left\langle V_{\Delta}\right\rangle_{\Delta}+\left\langle\left(V_{\Pi}-\left\langle V_{\Delta}\right\rangle_{\Delta}\right) \theta\left(V_{\Pi}-\left\langle V_{\Delta}\right\rangle_{\Delta}\right)\right\rangle_{\Pi} \\
& =\left\langle V_{\Pi}\right\rangle_{\Pi}+\left\langle\left(\left\langle V_{\Delta}\right\rangle_{\Delta}-V_{\Pi}\right) \theta\left(\left\langle V_{\Delta}\right\rangle_{\Delta}-V_{\Pi}\right)\right\rangle_{\Pi}, \\
{ }^{5}\langle T\rangle_{\Pi \Delta} & =\left\langle V_{\Pi}\right\rangle_{\Pi}+\left\langle\left(V_{\Delta}-\left\langle V_{\Pi}\right\rangle_{\Pi}\right) \theta\left(V_{\Delta}-\left\langle V_{\Pi}\right\rangle_{\Pi}\right)\right\rangle_{\Delta} \\
& =\left\langle V_{\Delta}\right\rangle_{\Delta}+\left\langle\left(\left\langle V_{\Pi}\right\rangle_{\Pi}-V_{\Delta}\right) \theta\left(\left\langle V_{\Pi}\right\rangle_{\Pi}-V_{\Delta}\right)\right\rangle_{\Delta}, \\
{ }^{6}\langle T\rangle_{\Pi \Delta} & =\left\langle V_{\Delta}\right\rangle_{\Delta}+\left\langle\left(V_{\Pi}-\left\langle V_{\Delta}\right\rangle_{\Delta}\right) \theta\left(V_{\Pi}-\left\langle V_{\Delta}\right\rangle_{\Delta}\right)\right\rangle_{\Pi} \\
& =\left\langle V_{\Pi}\right\rangle_{\Pi}+\left\langle\left(\left\langle V_{\Delta}\right\rangle_{\Delta}-V_{\Pi}\right) \theta\left(\left\langle V_{\Delta}\right\rangle_{\Delta}-V_{\Pi}\right)\right\rangle_{\Pi} .
\end{aligned}
$$

For each rule the former of the equivalent versions has the structure: non-chooser's expected valuation plus the chooser's expected call option valuation (including a factor or the probability that this option be exercised). The latter has the structure: chooser's expected valuation plus the chooser's expected put option valuation (including a factor or the probability that this option be exercised). The are, respectively, the forms (A) and (B) given in Sec. IB of the main text.

Notice that the plaintiff choice rules (Rules 4 and 6) yield identical damages (i.e. $\left\langle V_{\Delta}\right\rangle_{\Delta}$ ) and thus identical total expected profits. Similarly, the defendant choice rules (Rules 2 and 5) yield identical damages (i.e. $\left\langle V_{\Pi}\right\rangle_{\Pi}$ ) and thus identical total expected profits. Thus, as far as the 
total expected profit and damages are concerned, under single-chooser rules all that matters is who is the chooser. Thus we may denote ${ }^{4}\langle T\rangle_{\Pi \Delta}$ and ${ }^{6}\langle T\rangle_{\Pi \Delta}$ by ${ }^{\Pi}\langle T\rangle_{\Pi \Delta}$; and we may denote ${ }^{2}\langle T\rangle_{\Pi \Delta}$ and ${ }^{5}\langle T\rangle_{\Pi \Delta}$ by ${ }^{\Delta}\langle T\rangle_{\Pi \Delta}$.

We now examine the issue of which single-chooser rules dominate (i.e. yield greater total expected profits and are, therefore, more efficient), the plaintiff choice rules (Rules 4 and 6) or the defendant choice rules (Rules 2 and 5). This amounts to ascertaining the conditions under which $\left.{ }^{\Pi}\langle T\rangle_{\Pi \Delta}\right\rangle^{\Delta}\langle T\rangle_{\Pi \Delta}$, and from the equivalent formulas for the total expected profits, given above, one arrives at the following four equivalent versions of these conditions:

$$
\begin{array}{cc}
\left\langle\left(V_{\Pi}-\left\langle V_{\Delta}\right\rangle_{\Delta}\right) \theta\left(V_{\Pi}-\left\langle V_{\Delta}\right\rangle_{\Delta}\right)\right\rangle_{\Pi} & (1.13 \mathrm{a}) \\
>\left\langle\left(\left\langle V_{\Pi}\right\rangle_{\Pi}-V_{\Delta}\right) \theta\left(\left\langle V_{\Pi}\right\rangle_{\Pi}-V_{\Delta}\right)\right\rangle_{\Delta}, & (1.13 \mathrm{~b}) \\
\left\langle\left(\left\langle V_{\Delta}\right\rangle_{\Delta}-V_{\Pi}\right) \theta\left(\left\langle V_{\Delta}\right\rangle_{\Delta}-V_{\Pi}\right)\right\rangle_{\Pi} & (1.13 \mathrm{c}) \\
>\left\langle\left(V_{\Delta}-\left\langle V_{\Pi}\right\rangle_{\Pi}\right) \theta\left(V_{\Delta}-\left\langle V_{\Pi}\right\rangle_{\Pi}\right)\right\rangle_{\Delta}, \\
\left\langle V_{\Pi}\right\rangle_{\Pi}-\left\langle V_{\Delta}\right\rangle_{\Delta}>\left\langle\left(\left\langle V_{\Pi}\right\rangle_{\Pi}-V_{\Delta}\right) \theta\left(\left\langle V_{\Pi}\right\rangle_{\Pi}-V_{\Delta}\right)\right\rangle_{\Delta} \\
-\left\langle\left(\left\langle V_{\Delta}\right\rangle_{\Delta}-V_{\Pi}\right) \theta\left(\left\langle V_{\Delta}\right\rangle_{\Delta}-V_{\Pi}\right)\right\rangle_{\Pi}, & (1.13 \mathrm{~d}) \\
\left\langle\left(V_{\Pi}-\left\langle V_{\Delta}\right\rangle_{\Delta}\right) \theta\left(V_{\Pi}-\left\langle V_{\Delta}\right\rangle_{\Delta}\right)\right\rangle_{\Pi} & \\
-\left\langle\left(V_{\Delta}-\left\langle V_{\Pi}\right\rangle_{\Pi}\right) \theta\left(V_{\Delta}-\left\langle V_{\Pi}\right\rangle_{\Pi}\right)\right\rangle_{\Delta}>\left\langle V_{\Pi}\right\rangle_{\Pi}-\left\langle V_{\Delta}\right\rangle_{\Delta} .
\end{array}
$$

These are the inequalities discussed in Sec. IIB of the main text. Inspecting the expessions for $\Pi_{\langle T\rangle_{\Pi \Delta} \text { and }}$ ${ }^{\Delta}\langle T\rangle_{\Pi \Delta}$, it is also easy to see that the expected joint profits for a single chooser rule will be greater than the expected joint profits under either property rule (i.e. $\left\langle V_{\Pi}\right\rangle_{\Pi}$ and $\left.\left\langle V_{\Delta}\right\rangle_{\Delta}\right)$ so long as non-chooser's mean lies within the support of the chooser's probability distribution.

To shed a little more light on the issue of which singlechooser rulese dominate, let us consider the situation in which the distribution of plaintiff valuations is sharp, i.e., $\tilde{P}_{\Pi}\left(V_{\Pi}\right)=\delta\left(V_{\Pi}-\bar{V}_{\Pi}\right)$. In this case one finds the nonnegative result

$$
\begin{aligned}
& { }^{\Delta}\langle T\rangle_{\Pi \Delta}-{ }^{\Pi}\langle T\rangle_{\Pi \Delta}= \\
& \quad \theta\left(\bar{V}_{\Pi}-\left\langle V_{\Delta}\right\rangle_{\Delta}\right)\left\langle\left(V_{\Delta}-\bar{V}_{\Pi}\right) \theta\left(V_{\Delta}-\bar{V}_{\Pi}\right)\right\rangle_{\Delta} \\
& +\theta\left(\left\langle V_{\Delta}\right\rangle_{\Delta}-\bar{V}_{\Pi}\right)\left\langle\left(\bar{V}_{\Pi}-V_{\Delta}\right) \theta\left(\bar{V}_{\Pi}-V_{\Delta}\right)\right\rangle_{\Delta},
\end{aligned}
$$

which indicates that it is preferable for the uncertain valuer (in this case $\Delta$ ) to be the chooser.

\section{Decomposable correlated asset valuations}

For this correlated distribution (whose form and meaning were discussed in Sec. 0. C 3), the stationarity condition (1.8) takes the form

$$
\begin{aligned}
D & =\left\langle W_{\Pi}\right\rangle_{\Pi}+\frac{\left\langle W_{B} \delta\left(W_{B}+W_{\Delta}-D\right)\right\rangle_{\Pi \Delta}}{\left\langle\delta\left(W_{B}+W_{\Delta}-D\right)\right\rangle_{\Pi \Delta}}, \\
& =\left\langle W_{\Pi}\right\rangle_{\Pi}+\frac{\left\langle W_{B} \hat{P}_{B}\left(D-W_{B}\right)\right\rangle_{B}}{\left\langle\hat{P}_{B}\left(D-W_{B}\right)\right\rangle_{B}},
\end{aligned}
$$

i.e., an implicit equation for $D$.

Even within the context of this special choice of correlated distribution it is not possible to progress towards more explicit results without making more explicit assumptions concerning the form of the probability distributions.

\section{DUAL-CHOOSER RULES}

Let us now explore some properties of dual-chooser rules. For the sake of concreteness we focus on the calloption implementation of the Defendant-Joint-Veto Rule. We can envisage this rule in terms of a sequence of options: $\Pi$ begins with the asset $\mathcal{A} ; \Delta$ has a call option $\mathcal{C}$ to obtain $\mathcal{A}$ upon payment of damages $D$; and $\Pi$ has a callback option $\widetilde{\mathcal{C}}$ to obtain $\mathcal{A}$ upon repayment of damages $D$. Thus, unless both $\Pi$ and $\Delta$ agree, the asset remains with the original entitlement holder, viz., П. Said equivalently, either $\Pi$ of $\Delta$ can veto the transfer of $\mathcal{A}$ to $\Delta$; hence the name: Defendant-Joint-Veto. We may indicate this scenario schematically by

$$
\begin{array}{cr}
\Pi: & \mathcal{A}-\mathcal{C}+\tilde{\mathcal{C}}, \\
\Delta: & +\mathcal{C}-\tilde{\mathcal{C}} .
\end{array}
$$

It is depicted schematically in panel (c) of Fig. 1.

\section{A. Optimal damages}

We now set about determining the optimal value of the damages $D$ under this Defendant-Joint-Veto Rule. To do this, we must first ascertain the pivot values $Q$ and $\tilde{Q}$. These are, repectively, the value of $V_{\Delta}$ at which $\Delta$ will exercise option $\mathcal{C}$ and the value of $V_{\Pi}$ at which $\Pi$ will exercise option $\tilde{\mathcal{C}}$. As, when exercising option $\mathcal{C}$, $\Delta$ is acquiring the asset at the cost $D$, it will only be profitable for $\Delta$ to exercise this option in instances for which $V_{\Delta}>D$; hence $Q=D$. Similarly, as, when exercising option $\tilde{\mathcal{C}}, \Pi$ is acquiring the asset at the cost $D$, it will only be profitable for $\Pi$ to exercise this option in instances for which $V_{\Pi}>D$; hence $\tilde{Q}=D$. Knowledge of the pivot values allows us to determine the total mean profit, as we now do.

\section{Generally correlated asset valuations}

Again indicating by the pair $\left(T_{\Pi}, T_{\Delta}\right)$ the profit made, respectively, by $\Pi$ and $\Delta$ in a specific instance, the scenario outlined at the begining of Sec. II amounts to the following specification of profits for various valuations:

$$
\begin{aligned}
& \left(T_{\Pi}, T_{\Delta}\right)= \\
& \begin{cases}\left(D, V_{\Delta}-D\right) & \text { for } V_{\Delta}>D \text { and } V_{\Pi}<D ; \\
\left(V_{\Pi}, 0\right) & \text { otherwise. }\end{cases}
\end{aligned}
$$


In particular, for the dependence of the total profit $T$ on $D$ we have

$$
T=T_{\Pi}+T_{\Delta}= \begin{cases}V_{\Delta} & \text { for } V_{\Delta}>D \text { and } V_{\Pi}<D ; \\ V_{\Pi} & \text { otherwise }\end{cases}
$$

What remains is for us to establish the condition obeyed by the value of the damages that maximizes the expectation value of the total profit $\langle T\rangle_{\Pi \Delta}$. To do this, observe that $\langle T\rangle_{\Pi \Delta}$ may be expressed as

$$
\begin{aligned}
\langle T\rangle_{\Pi \Delta}= & \left\langle T_{\Pi}+T_{\Delta}\right\rangle_{\Pi \Delta} \\
= & \left\langle V_{\Pi} \theta\left(D-V_{\Delta}\right)\right\rangle_{\Pi \Delta} \\
+ & \left\langle V_{\Delta} \theta\left(V_{\Delta}-D\right) \theta\left(D-V_{\Pi}\right)\right\rangle_{\Pi \Delta} \\
+ & \left\langle V_{\Pi} \theta\left(V_{\Delta}-D\right) \theta\left(V_{\Pi}-D\right)\right\rangle_{\Pi \Delta} \\
= & \left\langle V_{\Pi}\right\rangle_{\Pi \Delta} \\
+ & \left\langle\left(V_{\Delta}-V_{\Pi}\right) \theta\left(V_{\Delta}-D\right) \theta\left(D-V_{\Pi}\right)\right\rangle_{\Pi \Delta} .
\end{aligned}
$$

Now examine the condition that $\langle T\rangle_{\Pi \Delta}$ be stationary with respect to variations of $D$ :

$$
\begin{aligned}
0= & \frac{\partial}{\partial D}\langle T\rangle_{\Pi \Delta} \\
= & \frac{\partial}{\partial D}\left(\left\langle V_{\Pi}\right\rangle_{\Pi \Delta}\right. \\
& \left.\quad+\left\langle\left(V_{\Delta}-V_{\Pi}\right) \theta\left(V_{\Delta}-D\right) \theta\left(D-V_{\Pi}\right)\right\rangle_{\Pi \Delta}\right) .
\end{aligned}
$$

By using Eq. (0.2) and observing that quantities involving Dirac delta functions are only nonzero when the argument of the delta function is nonzero we obtain the following formula for the value(s) of $D$ that makes $\langle T\rangle_{\Pi \Delta}$ stationary:

$$
\begin{aligned}
& \left\langle\left(V_{\Delta}-D\right) \theta\left(V_{\Delta}-D\right) \delta\left(V_{\Pi}-D\right)\right\rangle_{\Pi \Delta} \\
& =\left\langle\left(D-V_{\Pi}\right) \theta\left(D-V_{\Pi}\right) \delta\left(V_{\Delta}-D\right)\right\rangle_{\Pi \Delta} .
\end{aligned}
$$

This determines $D$ implicitly in terms of the joint probability distribution $P_{\Pi \Delta}$. Let us pause to interpret this formula. It says that that by selecting the the optimal value of $D$, the expectation value of $D-V_{\Pi}$ subject to the conditions that $V_{\Pi}<D$ and $V_{\Pi}=D$, multiplied by the probability that $V_{\Pi}<D$ and $V_{\Pi}=D$, is equal to the expectation value of $V_{\Delta}-D$ subject to the conditions that $V_{\Delta}>D$ and $V_{\Pi}=D$, multiplied by the probability that $V_{\Delta}>D$ and $V_{\Pi}=D$. Now let us explore some special cases of Eq. (2.7).

\section{Uncorrelated asset valuations}

For uncorrelated joint probability distributions $P_{\Pi \Delta}\left(V_{\Pi}, V_{\Delta}\right)$ the total mean profit $\langle T\rangle_{\Pi \Delta}$ under the Defendant-Joint-Veto scenario becomes

$$
\begin{aligned}
\langle T\rangle_{\Pi \Delta} & =\left\langle T_{\Pi}+T_{\Delta}\right\rangle_{\Pi \Delta} \\
& =\left\langle V_{\Pi} \theta\left(D-V_{\Delta}\right)\right\rangle_{\Pi \Delta}
\end{aligned}
$$

$$
\begin{aligned}
& +\left\langle V_{\Delta} \theta\left(V_{\Delta}-D\right) \theta\left(D-V_{\Pi}\right)\right\rangle_{\Pi \Delta} \\
+ & \left\langle V_{\Pi} \theta\left(V_{\Delta}-D\right) \theta\left(V_{\Pi}-D\right)\right\rangle_{\Pi \Delta} \\
= & \left\langle V_{\Pi}\right\rangle_{\Pi \Delta} \\
+ & \left\langle\left(V_{\Delta}-V_{\Pi}\right) \theta\left(V_{\Delta}-D\right) \theta\left(D-V_{\Pi}\right)\right\rangle_{\Pi \Delta},
\end{aligned}
$$

and the condition obeyed by the optimal damages becomes

$$
\begin{aligned}
\left\langle\left(V_{\Delta}-D\right) \theta\left(V_{\Delta}-D\right)\right\rangle_{\Delta}\left\langle\delta\left(V_{\Pi}-D\right)\right\rangle_{\Pi} \\
\quad=\left\langle\left(D-V_{\Pi}\right) \theta\left(D-V_{\Pi}\right)\right\rangle_{\Pi}\left\langle\delta\left(V_{\Delta}-D\right)\right\rangle_{\Delta} .
\end{aligned}
$$

The latter condition has the interpretation of causing the following quantities to balance: (i) the expectation value of $V_{\Delta}-D$ subject to the condition that $V_{\Delta}>D$, multiplied by the probabilities that $V_{\Delta}>D$ and $V_{\Pi}=D$; (ii) the expectation value of $D-V_{\Pi}$ subject to the condition that $V_{\Pi}<D$, multiplied by the probabilities that $V_{\Pi}<D$ and $V_{\Delta}-D$.

\section{Choosing between Single-Chooser and Dual-Chooser rules}

The tendency for the optimal choice among the four single and dual chooser allocations to be determined by the relative difference in the means and variances of the distributions can be seen by working through specific example. For uncorrelated asset valuations that are uniformly distributed on the intervals $\left[\mu_{\Pi}-\lambda_{\Pi}, \mu_{\Pi}+\lambda_{\Pi}\right]$ and $\left[\mu_{\Delta}-\lambda_{\Delta}, \mu_{\Delta}+\lambda_{\Delta}\right]$, it can be shown that:

(1) the defendant choice rule will produce higher expected joint payoffs than the plaintiff choice rule, if and only if $\lambda_{\Delta}>\lambda_{\Pi}$;

(2) the defendant joint veto rule will produce higher expected joint payoffs than the plaintiff joint veto rule, if and only if $\mu_{\Pi}>\mu_{\Delta}$; and

(3) the defendant choice rule will produce higher expected joint payoffs than the defendant joint veto rule, if and only if $\lambda_{\Delta}-\lambda_{\Pi}>\mu_{\Pi}-\mu_{\Delta}$.

For the uniform distribution, the last inequality shows that single chooser rules will dominate when the difference in variance is larger than the difference in means.

\section{HIGHER-ORDER RULES}

\section{A. Basic structure}

We now consider an example of a higher-order rule, specifically a scenario which may be indicated schematically by

$$
\begin{aligned}
& \Pi: \mathcal{A}-\mathcal{C}_{1}+\tilde{\mathcal{C}}_{1}-\mathcal{C}_{2}+\tilde{\mathcal{C}}_{2}-\cdots+\tilde{\mathcal{C}}_{N-1} \\
& \Delta: \quad+\mathcal{C}_{1}-\tilde{\mathcal{C}}_{1}+\mathcal{C}_{2}-\tilde{\mathcal{C}}_{2}+\cdots-\tilde{\mathcal{C}}_{N-1}
\end{aligned}
$$

In this scenario, $\Pi$ begins with the asset $\mathcal{A}, \Delta$ has a call option $\mathcal{C}_{1}$ with damages $D_{1}$ which she exercises whenever her valuation $V_{\Pi}$ exceeds the pivot value $Q_{1}$. If $\Delta$ does 
exercise her option then she is subject to П's call-back option $\tilde{\mathcal{C}}_{1}$ with damages $\tilde{D}_{1}$, which she exercises whenever her valuation $V_{\Delta}$ exceeds the pivot value $\tilde{Q}_{1}$. If $\Pi$ does exercise her option then she is subject $\Delta$ 's call-back option $\mathcal{C}_{2}$ with damages $D_{2}$ which she exercises whenever her valuation $V_{\Pi}$ exceeds the pivot value $Q_{2}$. This exercising of options can continue as far as two final options, $\mathcal{C}_{N-1}$ and $\tilde{\mathcal{C}}_{N-1}$ (with $N=2,3,4, \ldots$ ) for which the damages and pivot values are $D_{N-1}$ and $\tilde{D}_{N-1}$ and $Q_{N-1}$ and $\tilde{Q}_{N-1}$. Thus the scenario is characterized by a set of pivot values $\left\{Q_{n}, \tilde{Q}_{n}\right\}_{n=1}^{N-1}$ and a set of damages values $\left\{D_{n}, \tilde{D}_{n}\right\}_{n=1}^{N-1}$. For the sake of notational convenience we introduce the additional "pivot values" $Q_{0}$ and $\tilde{Q}_{0}$, which we respectively take to be smaller than any possible value of $V_{\Delta}$ and $V_{\Pi}$, and $Q_{N}$ and $\tilde{Q}_{N}$, which we respectively take to be larger than any possible value of $V_{\Delta}$ and $V_{\Pi}$. We also introduce an additional "damages value" $\tilde{D}_{0} \equiv 0$.

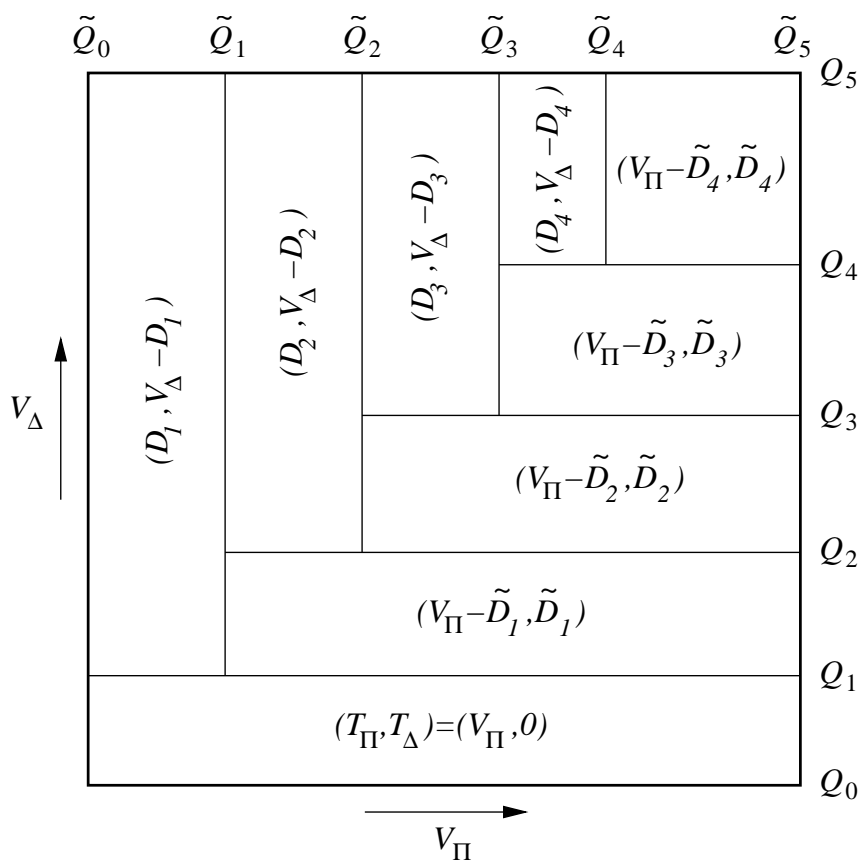

FIG. 1. Defendant and plaintiff profits $T_{\Pi}$ and $T_{\Delta}$, as determined by their valuations $V_{\Pi}$ and $V_{\Delta}$, for the $N=5$ case of the higher-order rule discussed in the text.

For any possible instance of $\Pi$ 's and $\Delta$ 's asset valuations $\left(V_{\Pi}, V_{\Delta}\right)$ their respective profits $\left(T_{\Pi}, T_{\Delta}\right)$ are specified by the entries in Fig. 1, which can readily be generalized from the depicted case of $N=5$ to arbitrary $N$. For example, when $Q_{2}<V_{\Delta}<Q_{3}$ and $\tilde{Q}_{2}<V_{\Pi}$ then $\left(T_{\Pi}, T_{\Delta}\right)=\left(V_{\Pi}-\tilde{D}_{2}, \tilde{D}_{2}\right)$; and when $\tilde{Q}_{2}<V_{\Pi}<\tilde{Q}_{3}$ and $Q_{3}<V_{\Delta}$ then $\left(T_{\Pi}, T_{\Delta}\right)=\left(D_{3}, V_{\Delta}-D_{3}\right)$. More generally: for $0 \leq n \leq(N-1)$ when $Q_{n}<V_{\Delta}<Q_{n+1}$ and $\tilde{Q}_{n}<V_{\Pi}$ then $\left(\bar{T}_{\Pi}, T_{\Delta}\right)=\left(V_{\Pi}-\tilde{D}_{n}, \tilde{D}_{n}\right)$; and for $0 \leq n \leq(N-2)$ when $\tilde{Q}_{n}<V_{\Pi}<\tilde{Q}_{n+1}$ and $Q_{n+1}<V_{\Delta}$ then $\left(\bar{T}_{\Pi}, T_{\Delta}\right)=\left(D_{n+1}, V_{\Delta}-D_{n+1}\right)$.

Within this scenario the expectation value of the total profit is given by

$$
\begin{aligned}
& \langle T\rangle_{\Pi \Delta}=\left\langle T_{\Pi}+T_{\Delta}\right\rangle_{\Pi \Delta}= \\
& \sum_{n=0}^{N-1}\left\langle V_{\Pi} \theta\left(Q_{n+1}-V_{\Delta}\right) \theta\left(V_{\Delta}-Q_{n}\right) \theta\left(V_{\Pi}-\tilde{Q}_{n}\right)\right\rangle_{\Pi \Delta} \\
& +\sum_{n=0}^{N-2}\left\langle V_{\Delta} \theta\left(\tilde{Q}_{n+1}-V_{\Pi}\right) \theta\left(V_{\Pi}-\tilde{Q}_{n}\right) \theta\left(V_{\Delta}-Q_{n+1}\right)\right\rangle_{\Pi \Delta},
\end{aligned}
$$

which depends on the damages implicitly, via the pivot values (which themselves are determined by the damages, as discussed below). This formula for $\langle T\rangle_{\Pi \Delta}$ encodes for general $N$ precisely the profit structure indicated from $N=5$ in Fig. 1.

In the absence of correlations between $V_{\Pi}$ and $V_{\Delta}$ the formula for the total expected profit reduces to

$$
\begin{aligned}
&\langle T\rangle_{\Pi \Delta}=\left\langle T_{\Pi}+T_{\Delta}\right\rangle_{\Pi \Delta}= \\
& \sum_{n=0}^{N-1}\left\langle V_{\Pi} \theta\left(V_{\Pi}-\tilde{Q}_{n}\right)\right\rangle_{\Pi}\left\langle\theta\left(Q_{n+1}-V_{\Delta}\right) \theta\left(V_{\Delta}-Q_{n}\right)\right\rangle_{\Delta} \\
& \quad+\sum_{n=0}^{N-2}\left\langle\theta\left(\tilde{Q}_{n+1}-V_{\Pi}\right) \theta\left(V_{\Pi}-\tilde{Q}_{n}\right)\right\rangle_{\Pi} \\
& \quad \times\left\langle V_{\Delta} \theta\left(V_{\Delta}-Q_{n+1}\right)\right\rangle_{\Delta} .
\end{aligned}
$$

We now set about the task of determining the conditions obeyed by the values of the damages that render $\langle T\rangle_{\Pi \Delta}$ stationary in the general case of correlated valuations.

\section{B. Optimal pivot values}

Selecting the damages that maximize total expected profit can be accomplished by first determining the pivot values that optimize the total expected profit and then using these pivot values to determine the damages that elicit the litigants to exercise their options at the desired pivot values.

Thus we first consider the consequences of demanding that the total mean profit be stationary with respect to variations of the pivot values:

$\frac{\partial\langle T\rangle_{\Pi \Delta}}{\partial Q_{n}}=0, \frac{\partial\langle T\rangle_{\Pi \Delta}}{\partial \tilde{Q}_{n}}=0($ for $n=1, \ldots, N-1)$.

Computing these derivatives leads to the conditions

$$
\begin{aligned}
0= & \left\langle V_{\Pi} \delta\left(V_{\Delta}-Q_{n}\right) \theta\left(V_{\Pi}-\tilde{Q}_{n-1}\right)\right\rangle_{\Pi \Delta} \\
& -\left\langle V_{\Pi} \delta\left(V_{\Delta}-Q_{n}\right) \theta\left(V_{\Pi}-\tilde{Q}_{n}\right)\right\rangle_{\Pi \Delta} \\
& -Q_{n}\left\langle\theta\left(\tilde{Q}_{n}-V_{\Pi}\right) \theta\left(V_{\Pi}-\tilde{Q}_{n-1}\right) \delta\left(V_{\Delta}-Q_{n}\right)\right\rangle_{\Pi \Delta}, \\
0= & -\tilde{Q}_{n}\left\langle\theta\left(Q_{n+1}-V_{\Delta}\right) \theta\left(V_{\Delta}-Q_{n}\right) \delta\left(V_{\Pi}-\tilde{Q}_{n}\right)\right\rangle_{\Pi \Delta} \\
& +\left\langle V_{\Delta} \delta\left(V_{\Pi}-\tilde{Q}_{n}\right) \theta\left(V_{\Delta}-Q_{n}\right)\right\rangle_{\Pi \Delta} \\
& -\left\langle V_{\Delta} \delta\left(V_{\Pi}-\tilde{Q}_{n}\right) \theta\left(V_{\Delta}-Q_{n+1}\right)\right\rangle_{\Pi \Delta},
\end{aligned}
$$

for $n=1, \ldots, N-1$, in which the last term on each of the preceeding two right-hand sides should be omitted 
when $n=N-1$. In arriving at these conditions we have removed trivial factors such as $\theta\left(Q_{n}-Q_{n-1}\right)$, which are unity because $Q_{n} \geq Q_{n-1}$. These stationarity conditions may be straightforwardly reorganized to yield the more elegant forms

$$
\begin{aligned}
0=\left\langle\left( V_{\Pi}-\right.\right. & \left.Q_{n}\right) \theta\left(\tilde{Q}_{n}-V_{\Pi}\right) \\
& \left.\times \theta\left(V_{\Pi}-\tilde{Q}_{n-1}\right) \delta\left(V_{\Delta}-Q_{n}\right)\right\rangle_{\Pi \Delta}, \\
0=\left\langle\left( V_{\Delta}-\right.\right. & \left.\tilde{Q}_{n}\right) \theta\left(Q_{n+1}-V_{\Delta}\right) \\
& \left.\times \theta\left(V_{\Delta}-Q_{n}\right) \delta\left(V_{\Pi}-\tilde{Q}_{n}\right)\right\rangle_{\Pi \Delta},
\end{aligned}
$$

for $n=1, \ldots, N-2$, along with

$$
\begin{aligned}
& 0=\left\langle V_{\Pi} \theta\left(\tilde{Q}_{N-1}-V_{\Pi}\right) \theta\left(V_{\Pi}-\tilde{Q}_{N-1}\right) \delta\left(V_{\Delta}-Q_{N-1}\right)\right\rangle_{\Pi \Delta}, \\
& 0=\left\langle\left(V_{\Delta}-\tilde{Q}_{N-1}\right) \theta\left(V_{\Delta}-Q_{N-1}\right) \delta\left(V_{\Pi}-\tilde{Q}_{N-1}\right)\right\rangle_{\Pi \Delta} .
\end{aligned}
$$

In the case of uncorrelated valuations these stationarity conditions become

$$
\begin{aligned}
& 0=\left\langle\left(V_{\Pi}-Q_{n}\right) \theta\left(\tilde{Q}_{n}-V_{\Pi}\right) \theta\left(V_{\Pi}-\tilde{Q}_{n-1}\right)\right\rangle_{\Pi}, \\
& 0=\left\langle\left(V_{\Delta}-\tilde{Q}_{n}\right) \theta\left(Q_{n+1}-V_{\Delta}\right) \theta\left(V_{\Delta}-Q_{n}\right)\right\rangle_{\Delta},
\end{aligned}
$$

for $n=1, \ldots, N-2$, along with

$$
\begin{aligned}
& 0=\left\langle V_{\Pi} \theta\left(\tilde{Q}_{N-1}-V_{\Pi}\right) \theta\left(V_{\Pi}-\tilde{Q}_{N-1}\right)\right\rangle_{\Pi}, \\
& 0=\left\langle\left(V_{\Delta}-\tilde{Q}_{N-1}\right) \theta\left(V_{\Delta}-Q_{N-1}\right)\right\rangle_{\Delta} .
\end{aligned}
$$

Equations (3.7a- $(3.7 \mathrm{~d})$ are the formal embodiment of the "dispositive takings principal' Optimal pivot values are set equal to the mean of non-choosers who will be dispositively affected by the particular taking.

\section{Optimal damages}

Let us imagine that we have succeeded in determining pivot values $\left\{Q_{n}, \tilde{Q}_{n}\right\}_{n=1}^{N-1}$ that optimize the total mean profit, i.e., that given a joint probability distribution $P_{\Pi \Delta}$ we have solved Eqs. (3.5a,3.5b) for a set of pivot values. We now address the task of determining the damages values $\left\{D_{n}, \tilde{D}_{n}\right\}_{n=1}^{N-1}$ that elicit these pivot values.

To do this, observe that the pivot value $Q_{1}$ is the answer to the question: For of given set of damages values, beyond what value of $V_{\Delta}$ is it, on average, profitable for $\Delta$ to exercise option $\mathcal{C}_{1}$ ? The averaging here accounts for $\Delta$ 's ignorance of $\Pi$ 's valuation of the asset. Thus, to determine $Q_{1}$ we seek the value of $V_{\Delta}$ such that $\Delta$ 's expected profit takes the same value, whether or not she exercises the option. This value obeys

$$
\begin{aligned}
0=\tilde{D}_{1} & \left\langle\delta\left(V_{\Delta}-Q_{1}\right) \theta\left(V_{\Pi}-\tilde{Q}_{1}\right)\right\rangle_{\Pi \Delta} \\
& +\left(Q_{1}-D_{1}\right)\left\langle\delta\left(V_{\Delta}-Q_{1}\right) \theta\left(\tilde{Q}_{1}-V_{\Pi}\right)\right\rangle_{\Pi \Delta} .
\end{aligned}
$$

The left hand side is $\Delta$ 's expected profit if she were not to exercise her option; the right hand side is her expected profit if she were to. Notice that the latter comprises two contributions, the former accounting for valuations $V_{\Pi}$ in which $\Pi$ does not exercise her call-back option $\tilde{\mathcal{C}}_{1}$, the latter accounting for valuations in which she does. Thus we see that, in addition to depending on the joint probability distribution $P_{\Pi \Delta}$ and the damages $D_{1}$ and $\tilde{D}_{1}$, this formula links $\tilde{Q}_{1}$ and $Q_{1}$.

Now let us consider determining $\tilde{Q}_{1}$, which answers the question: For of given set of damages values, beyond what value of $V_{\Pi}$ is it, on average, profitable for $\Pi$ to exercise option $\tilde{\mathcal{C}}_{1}$ ? Again we seek the pivot value at which the option holder's profits coincide, regardless of whether or not the option is exercised, thus arriving at the pivot condition

$$
\begin{aligned}
& D_{1}\left\langle\delta\left(V_{\Pi}-\tilde{Q}_{1}\right) \theta\left(V_{\Delta}-Q_{1}\right)\right\rangle_{\Pi \Delta} \\
& =D_{2}\left\langle\delta\left(V_{\Pi}-\tilde{Q}_{1}\right) \theta\left(V_{\Delta}-Q_{2}\right)\right\rangle_{\Pi \Delta} \\
& \quad+\left(\tilde{Q}_{1}-\tilde{D}_{1}\right)\left\langle\delta\left(V_{\Pi}-\tilde{Q}_{1}\right) \theta\left(Q_{2}-V_{\Delta}\right) \theta\left(V_{\Delta}-Q_{1}\right)\right\rangle_{\Pi \Delta} .
\end{aligned}
$$

In addition to depending on the joint probability distribution $P_{\Pi \Delta}$ and the pivot values $Q_{2}, \tilde{Q}_{1}$ and $Q_{1}$, this formula links damages $D_{1}, \tilde{D}_{1}$ and $D_{2}$. Extending these arguments to the general case, we find that in seeking $Q_{n}$ and $\tilde{Q}_{n}$ the decisions of whether or not to exercise options $\mathcal{C}_{n}$ and $\tilde{\mathcal{C}_{n}}$ respectively lead to the following conditions:

$$
\begin{array}{lr}
\tilde{D}_{n-1}\left\langle\delta\left(V_{\Delta}-Q_{n}\right) \theta\left(V_{\Pi}-\tilde{Q}_{n-1}\right)\right\rangle_{\Pi \Delta} & (3.10 \mathrm{a}) \\
=\tilde{D}_{n}\left\langle\delta\left(V_{\Delta}-Q_{n}\right) \theta\left(V_{\Pi}-\tilde{Q}_{n}\right)\right\rangle_{\Pi \Delta} & \\
+\left(Q_{n}-D_{n}\right)\left\langle\delta\left(V_{\Delta}-Q_{n}\right) \theta\left(\tilde{Q}_{n}-V_{\Pi}\right) \theta\left(V_{\Pi}-\tilde{Q}_{n-1}\right)\right\rangle_{\Pi \Delta}, & (3.10 \mathrm{~b}) \\
D_{n}\left\langle\delta\left(V_{\Pi}-\tilde{Q}_{n}\right) \theta\left(V_{\Delta}-Q_{n}\right)\right\rangle_{\Pi \Delta} & \\
=D_{n+1}\left\langle\delta\left(V_{\Pi}-\tilde{Q}_{n}\right) \theta\left(V_{\Delta}-Q_{n+1}\right)\right\rangle_{\Pi \Delta} & \\
+\left(\tilde{Q}_{n}-\tilde{D}_{n}\right)\left\langle\delta\left(V_{\Pi}-\tilde{Q}_{n}\right) \theta\left(Q_{n+1}-V_{\Delta}\right) \theta\left(V_{\Delta}-Q_{n}\right)\right\rangle_{\Pi \Delta},
\end{array}
$$

both holding for $n=1,2, \ldots, N-1$.

We mention that for the case of uncorrelated valuations these pivot conditions become

$$
\begin{aligned}
& \tilde{D}_{n-1}\left\langle\theta\left(V_{\Pi}-\tilde{Q}_{n-1}\right)\right\rangle_{\Pi} \\
& =\tilde{D}_{n}\left\langle\theta\left(V_{\Pi}-\tilde{Q}_{n}\right)\right\rangle_{\Pi} \\
& \quad+\left(Q_{n}-D_{n}\right)\left\langle\theta\left(\tilde{Q}_{n}-V_{\Pi}\right) \theta\left(V_{\Pi}-\tilde{Q}_{n-1}\right)\right\rangle_{\Pi}, \\
& D_{n}\left\langle\theta\left(V_{\Delta}-Q_{n}\right)\right\rangle_{\Delta} \\
& =D_{n+1}\left\langle\theta\left(V_{\Delta}-Q_{n+1}\right)\right\rangle_{\Delta} \\
& \quad+\left(\tilde{Q}_{n}-\tilde{D}_{n}\right)\left\langle\theta\left(Q_{n+1}-V_{\Delta}\right) \theta\left(V_{\Delta}-Q_{n}\right)\right\rangle_{\Delta},
\end{aligned}
$$

both holding for $n=1,2, \ldots, N-1$, and where we have cancelled factors of probability densities $\left\langle\delta\left(V_{\Pi}-\tilde{Q}_{n}\right)\right\rangle_{\Pi}$. and $\left\langle\delta\left(V_{\Delta}-Q_{n}\right)\right\rangle_{\Delta}$.

Now, what is the character of the task of determining the damages, given the pivot values, in the generically correlated case? We address this question as follows. Observe that Eq. (3.10a) for the case $n=1$ (which addresses the decision by $\Delta$ whether or not to exercise option $\mathcal{C}_{1}$ ) amounts to a linear inhomogeneous relation (LIR) between the pair of damages $\left(D_{1}, \tilde{D}_{1}\right)$. Similarly, 
Eq. (3.10b) for the case $n=1$ (which addresses the decision by $\Pi$ whether or not to exercise option $\tilde{\mathcal{C}}_{1}$ ) amounts to a LIR between the triple of damages $\left(D_{1}, \tilde{D}_{1}, D_{2}\right)$. Eliminating $D_{1}$ between these two leads to a LIR between the pair $\left(\tilde{D}_{1}, D_{2}\right)$. Continuing with Eq. (3.10a) for $n=2$ yields a LIR between the triple $\left(\tilde{D}_{2}, D_{2}, \tilde{D}_{2}\right)$; and eliminating $\tilde{D}_{1}$ leads to a LIR between the pair $\left(D_{2}, \tilde{D}_{2}\right)$. In general, the pair of pivot conditions at each $n$ allow us to replace the LIR between the pair
$\left(\tilde{D}_{n-1}, D_{n}\right)$ by one between the pair $\left(\tilde{D}_{n}, D_{n+1}\right)$, and to continue this process of elimination until we have used condition (3.10a) for $n=N-1$, at which stage we arrive at a LIR between the pair $\left(D_{N-1}, \tilde{D}_{N-1}\right)$. However, condition (3.10b) for $n=N-1$ also provides a LIR between the pair $\left(D_{N-1}, \tilde{D}_{N-1}\right)$ so we are now in a position to solve for this pair and, hence, to complete the boundary value problem of determining all damages values in terms of the pivot values. 